Universidad de Lima

Facultad de Ingeniería Industrial

Carrera de Ingeniería Industrial

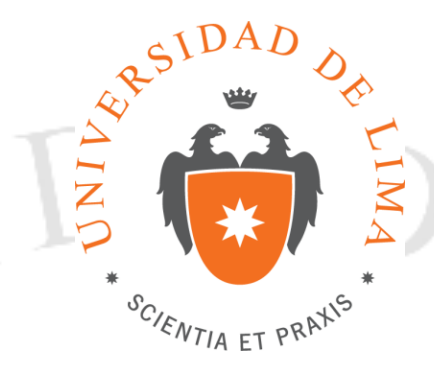

\title{
MEJORA DEL PROCESO DE COMPRAS Y VENTAS DE REPUESTOS EN LA EMPRESA LABORATORIO DIESEL SENATINOS S.A.
}

Trabajo de investigación para optar el Título Profesional de Ingeniero Industrial

\author{
María Elena Cárdenas Moza \\ Código 20041598
}
Jhon Norman Sánchez Suarez
Código 20052136

\author{
Asesor \\ Ing. Alex Vidal Paredes
}

Lima - Perú

Diciembre del 2015 


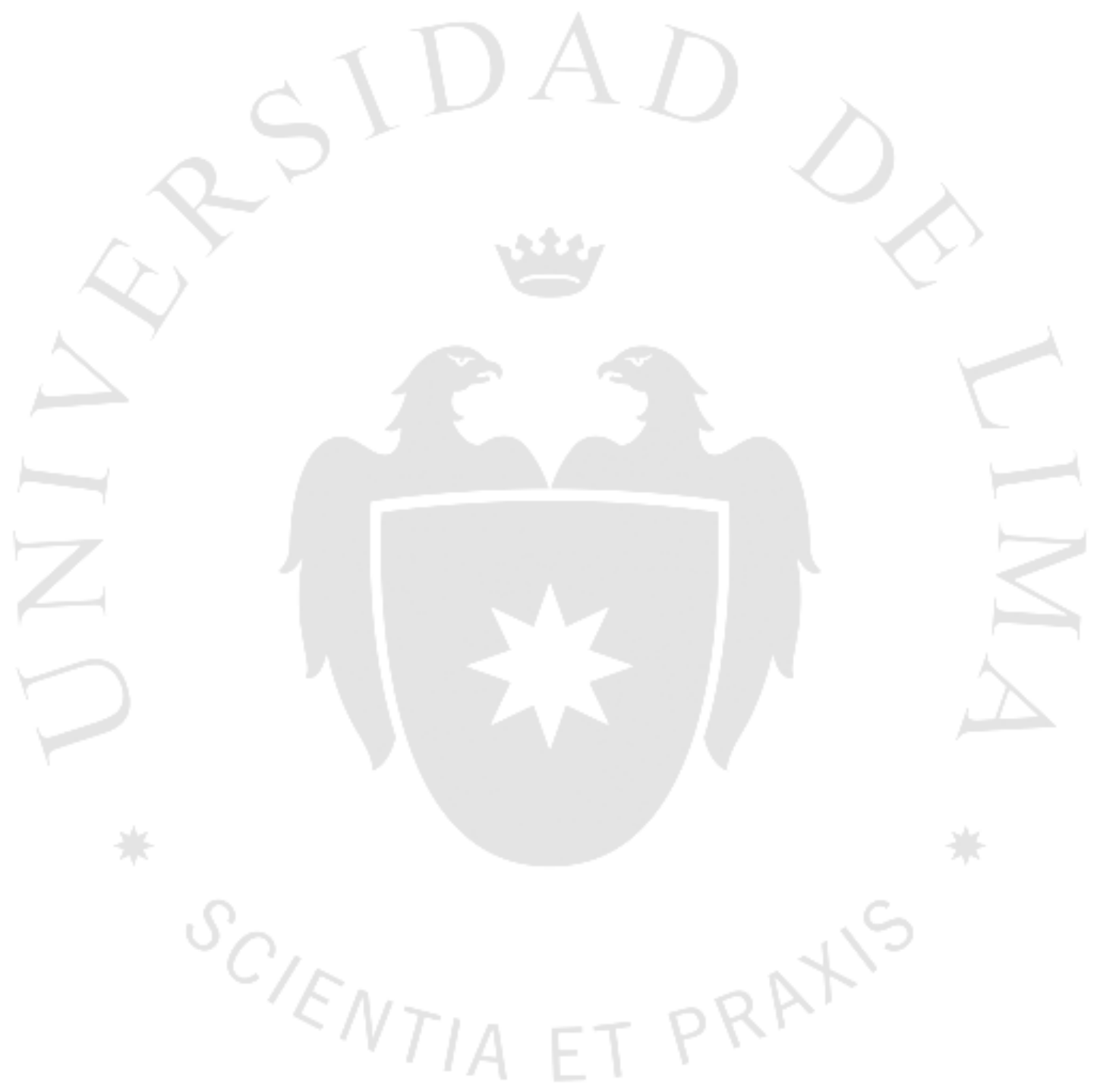




\section{MEJORA DEL PROCESO DE COMPRAS Y VENTAS DE REPUESTOS EN LA EMPRESA LABORATORIO DIESEL SENATINOS S.A.}




\section{TABLA DE CONTENIDO}

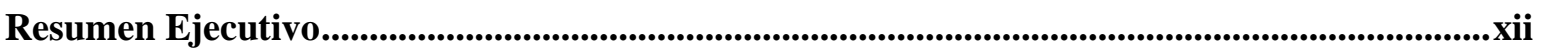

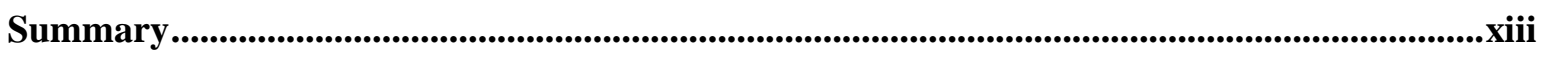

CAPÍTULO I: CONSIDERACIONES GENERALES DE LA INVESTIGACIÓN....................1

1.1 Antecedentes de la empresa .............................................

1.1.1 Breve descripción de la empresa y reseña histórica . ........................

1.1.2 Descripción de los productos o servicios ofrecidos ...........................

1.1.3 Descripción del mercado objetivo de la empresa . ............................5

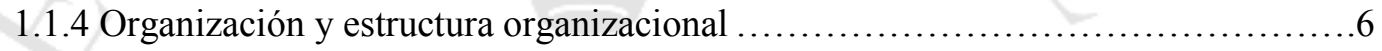

1.1.5 Visión, misión y objetivos organizacionales ............................... 8

1.2 Objetivos de la investigación (variables de investigación) ......................... 9

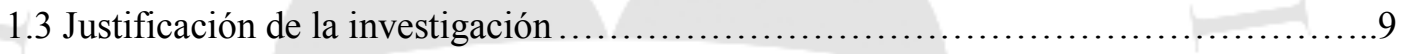

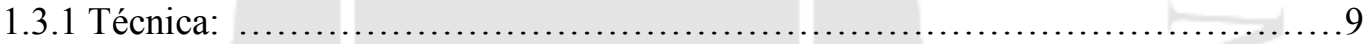

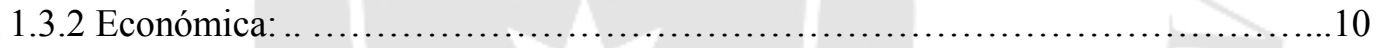

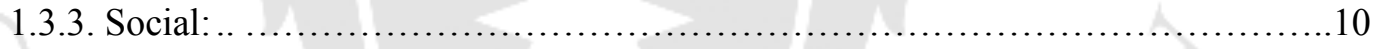

1.4 Hipótesis del trabajo: ................................................. 10

1.5 Marco referencial de la investigación... ........................................ 10

1.5.1 Marco referencial:. ..................................................10

1.5.2 Marco conceptual: . ...................................................11

CAPÍTULO II: ANÁlISIS SITUACIONAL DE LA EMPRESA: SELECCIÓN DEL

PROCESO A SER MEJORADO .................................................................................................... 15

2.1. Análisis del marco global. Entorno económico, social, demográfico, legal y

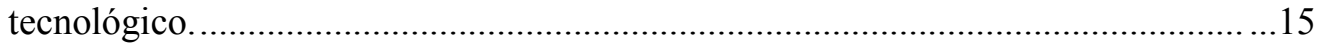

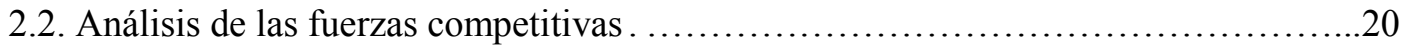

2.2.1 Poder de negociación de los compradores................................20

2.2.2 Poder de negociación de los proveedores..................................21 
2.2.3 Amenaza de entrada de nuevos competidores .............................21

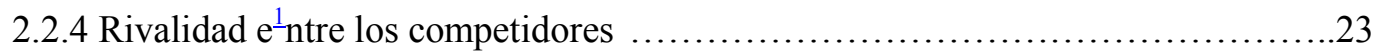

2.2.5 Amenaza de productos sustitutos... ......................................24

2.3. Breve descripción de los principales procesos . ...............................24

2.3.1 Identificación de los procesos más importantes .............................24

2.3.2. Selección del proceso a mejorar ......................................27

2.3.3 Determinación y descripción del proceso.................................32

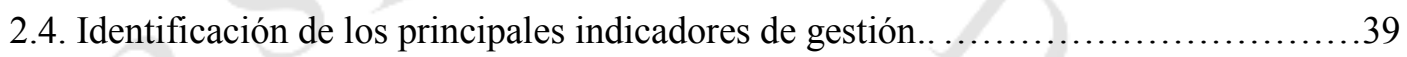

2.5 Identificación de los problemas principales...............................40

CAPÍTULO III: DIAGNÓSTICO DE LA EMPRESA ........................................................54

3.1. Determinación de las causas raíces de los problemas seleccionados ......................................54

3.2 Diagnóstico de los problemas principales . .................................60

3.2.1 Planificación del diagnóstico... .........................................60

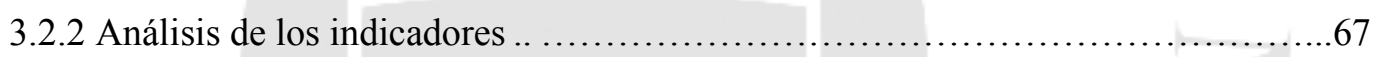

3.2.3 Aplicación de los métodos de diagnóstico................................69

CAPITULO IV: DETERMINACION DE LA SOLUCION PARA LOS PROBLEMAS

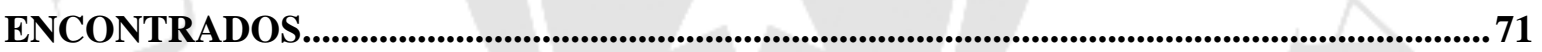

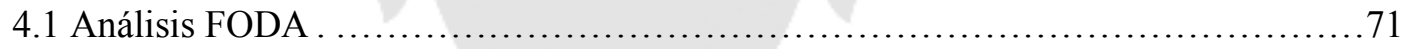

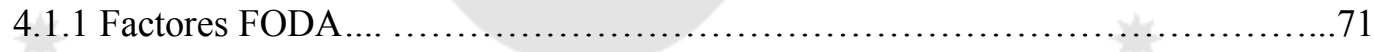

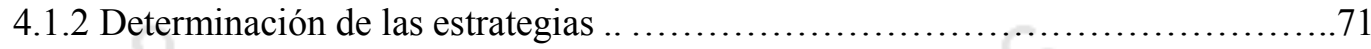

4.1.3 Definición de metas de la mejora ......................................74

4.2 Determinación de las alternativas de solución para cada problema encontrado.........74

4.3 Evaluación y selección de la mejor alternativa de mejora........................80

4.4 Evaluación del alcance y limitaciones de la solución propuesta .....................80

CAPITULO V: IMPLEMENTACIÓN DE LAS SOLUCIONES PROPUESTAS .....................82

5.1 Descripción detallada de cada una de las propuestas de solución . ..................82 
5.2 Identificación de las actividades necesarias para la implementación de la solución ...92

5.3 Presupuesto general para la implementación de la solución. ........................98

5.4 Cronograma de implementación. ............................................ 102

5.5 Propuesta de mecanismo y/o indicadores de gestión para garantizar la continuidad de la mejora................................................................106

\section{CAPITULO VI: EVALUACIÓN DE LA PROPUESTA Y BENEFICIOS ESPERADOS .... 108}

6.1 Evaluación cualitativa de la solución propuesta............................... 108

6.2 Determinación de escenarios para la solución propuesta .........................109

6.3 Estimación de los resultados de la implementación ..........................110

6.4 Análisis económico y financiero de la propuesta . .............................112

6.5 Impacto de la solución propuesta... ......................................... 119

6.5.1 Impacto Social....................................................119

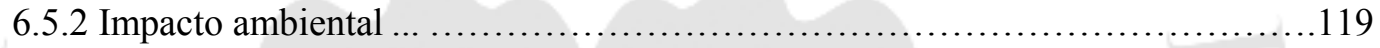

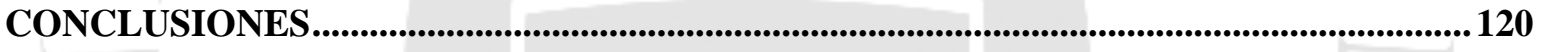

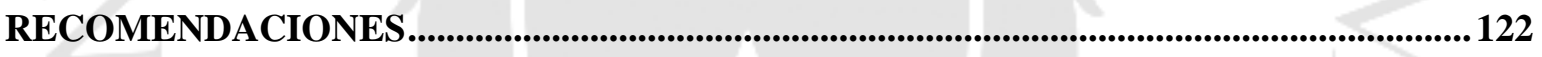

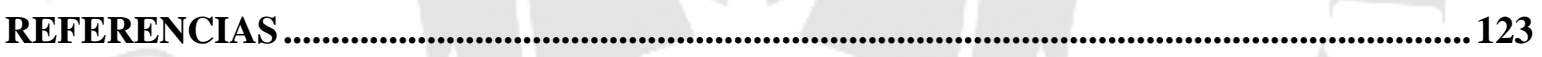

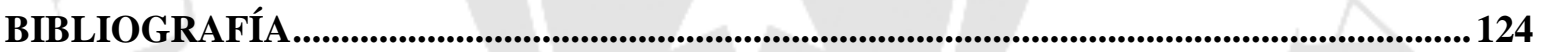

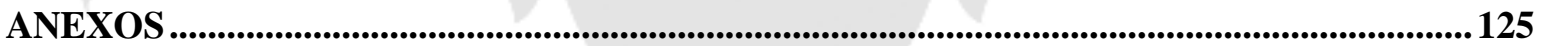




\section{ÍNDICE DE FIGURAS}

Figura 1.1 Crecimiento cronológico de laboratorio diesel senatinos s.a. ........................... 2

Figura 1.2 Organigrama de laboratorio diesel senatinos s.a........................................ 7

Figura 1.3 Crecimiento del parque automotor peruano .................................................. 12

Figura 1.4 Importación de autos entre el 2010 y 2012 ................................................ 13

Figura 1.5 Marcas de vehículos de mayor demanda....................................................... 13

Figura 2.1 Comparativo de ventas de vehículos.......................................................... 15

Figura 2. 2 Crecimiento de vehículo tipo "ligero" en el Perú......................................... 16

Figura 2. 3 Mapa de procesos de laboratorio diesel senatinos s.a. ................................. 27

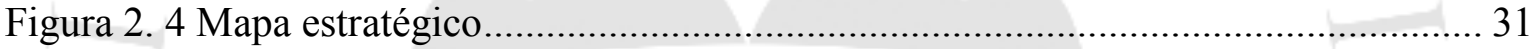

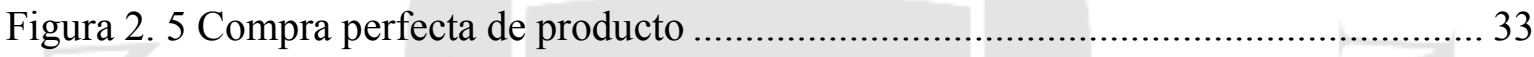

Figura 2.6: diagrama de flujo de proceso de compra de repuesto .................................. 37

Figura 2.7: diagrama de flujo del proceso de venta de repuesto..................................... 38

Figura 3.1: Diagrama de Ishikawa - Causa efecto......................................55

Figura 3.2: Diagrama de ishikawa - causa efecto ...................................................... 56

Figura 3.3: Diagrama de pareto de las causas raíces en la deficiencia de la evaluación de precios al seleccionar la compra de un repuesto........................................... 59

Figura 3.4: Diagrama de pareto de las causas raíces en la falta de estrategias en la venta de

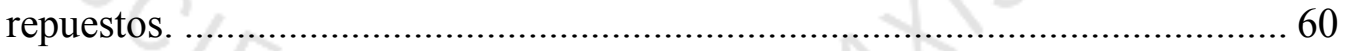

Figura 3.5: Participación de pedidos de compra - enero a diciembre $2014 \ldots \ldots \ldots \ldots \ldots \ldots \ldots . . . . . . .63$

Figura 3.6: Distribución de principales familias de repuestos ....................................... 64

Figura 3.7: Porcentaje de representación de compras por familias de repuestos ............... 65

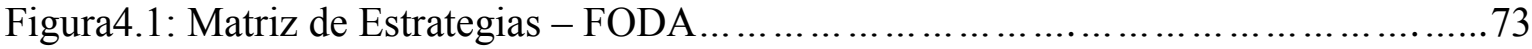

Figura 4. 2: Software winstock - información de proveedores - ladise s.a ..................... 75 


\section{ÍNDICE DE TABLAS}

Tabla 2.1 Plan de infraestructura vial hasta el 2020 ..................................................... 18

Tabla 2.2 Valores de efectividad - análisis klein ..................................................... 27

Tabla 2.3 Análisis del proceso gerencial y administrativo - klein................................... 28

Tabla 2.4 Análisis del proceso de compras - klein ...................................................... 29

Tabla 2. 5 Análisis del proceso de ventas - klein....................................................... 29

Tabla 2.6 Análisis del proceso de operaciones - klein.................................................. 30

Tabla 2.7 Análisis del proceso de laboratorio - klein ............................................... 30

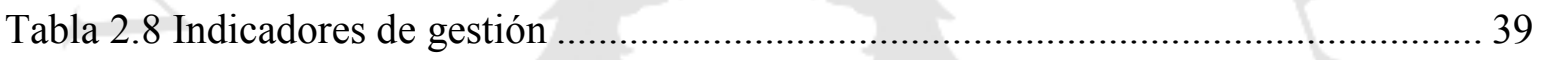

Tabla 2.9 Matriz para la validación del problema principal en el proceso de compras...... 47

Tabla 2.10 Matriz para la validación de problema principal en el proceso de ventas ........ 48

Tabla 2.11 Matriz enfrentamiento para la ponderación de criterios .................................. 50

Tabla 2.12 Tabla para la calificación de criterios ........................................................ 51

Tabla 2.13 Matriz de selección del problema principal del proceso de compras .............. 52

Tabla 2.14 Matriz de selección del problema principal del proceso de ventas .................. 53

Tabla 3.1 Evaluación de frecuencia e impacto de la causa raíz.........................57

Tabla 3.2 Tabla de frecuencias de pareto de las causas raíces de deficiencia en la evaluación de precios al seleccionar la compra de un repuesto ........................ 58

Tabla 3.3 Tabla de frecuencias de pareto - falta de estrategias en la venta de repuestos... 59

Tabla 3.4 Monto de compras durante los últimos doce meses del 2014(s/.) .................... 62

Tabla 3.5 Monto promedio mensual de pedidos de compras 2014 .................................. 63

Tabla 3.6 Monto promedio de compras por familia de repuestos 2014 ............................. 64

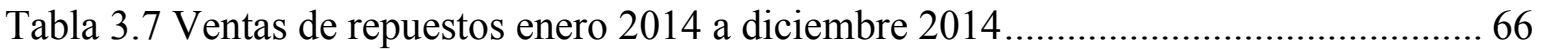

Tabla 3.8 Ventas de repuestos distribuidas por familia de sistema automotriz ................ 67

Tabla 3.9 Tabla de indicadores para la evaluación del proceso de compras ...................... 69

Tabla 3.10 Tabla de indicadores para la evaluación del proceso de ventas........................ 69 
Tabla 4.1 Alcances y limitaciones de las soluciones propuestas......................81

Tabla 5.1 Partidas arancelarias de repuestos de sistemas de inyección..................83

Tabla 5.2 Especificaciones técnicas del repuesto "tobera 105007-1120" ....................... 84

Tabla 5.3 Proveedores que importaron el repuesto "tobera 105007-1120" entre enero y

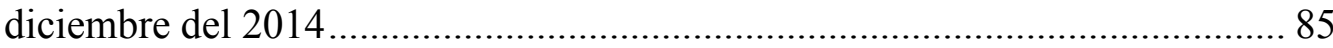

Tabla 5.4 Repuestos vendidos por marca de vehículo 2009 al 2014 .............................. 87

Tabla 5.5 Programa de capacitación para la venta de repuestos - sistema de inyección ..... 89

Tabla 5.6: Programa de capacitación para la venta de repuestos - sistema de

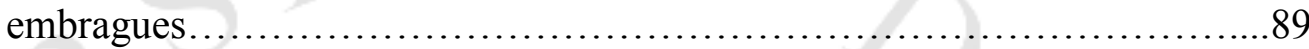

Tabla 5.7 Presupuesto para la implementación de solución - proceso de compras ............ 99

Tabla 5.8 Presupuesto para la implementación de solución - proceso de compras .......... 100

Tabla 5.9 Presupuesto para la implementación de solución - proceso de ventas............. 101

Tabla 5.10 Costo total de implementación de mejora .................................................. 101

Tabla 5.11 Cronograma de implementación para la solución de mejora en el proceso de compras 102

Tabla 5.12 Cronograma de implementación para la solución de mejora en el proceso de compras 103

Tabla 5.13 Cronograma de implementación para la solución de mejora en el proceso de ventas 104

Tabla 5.14 Cronograma de implementación para la solución de mejora en el proceso de ventas 105

Tabla 5.15 Indicadores de gestión para la evaluación de la mejora del proceso de compras 106

Tabla 5.16 Indicadores de gestión para la evaluación en la mejora del proceso de ventas....

Tabla6.1 Indicadores de gestión con la implementación del proyecto...................112

Tabla 6.2 Tiempo que tardan los compradores en encontrar al proveedor..................... 113

Tabla 6.3 Ahorro de costos por tiempo de búsqueda de proveedores ............................. 113

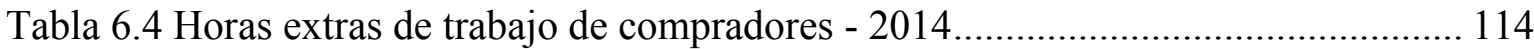

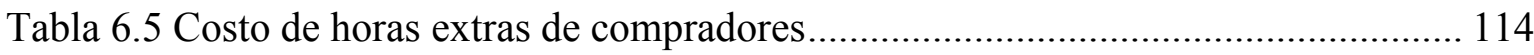

Tabla 6.6 Costo de compra errada y devolución de repuestos...................................... 115

Tabla 6.7 Costos logísticos de repuestos de mínima rotación ...................................... 116 
Tablas 6.8 Beneficios por implementación de mejora en el proceso de

Tabla 6.9 Beneficios por implementación de mejora en el proceso de ventas

Tabla 6.10 Beneficios totales de implementación de la mejora 118

Tabla 6.11 Flujo de caja.

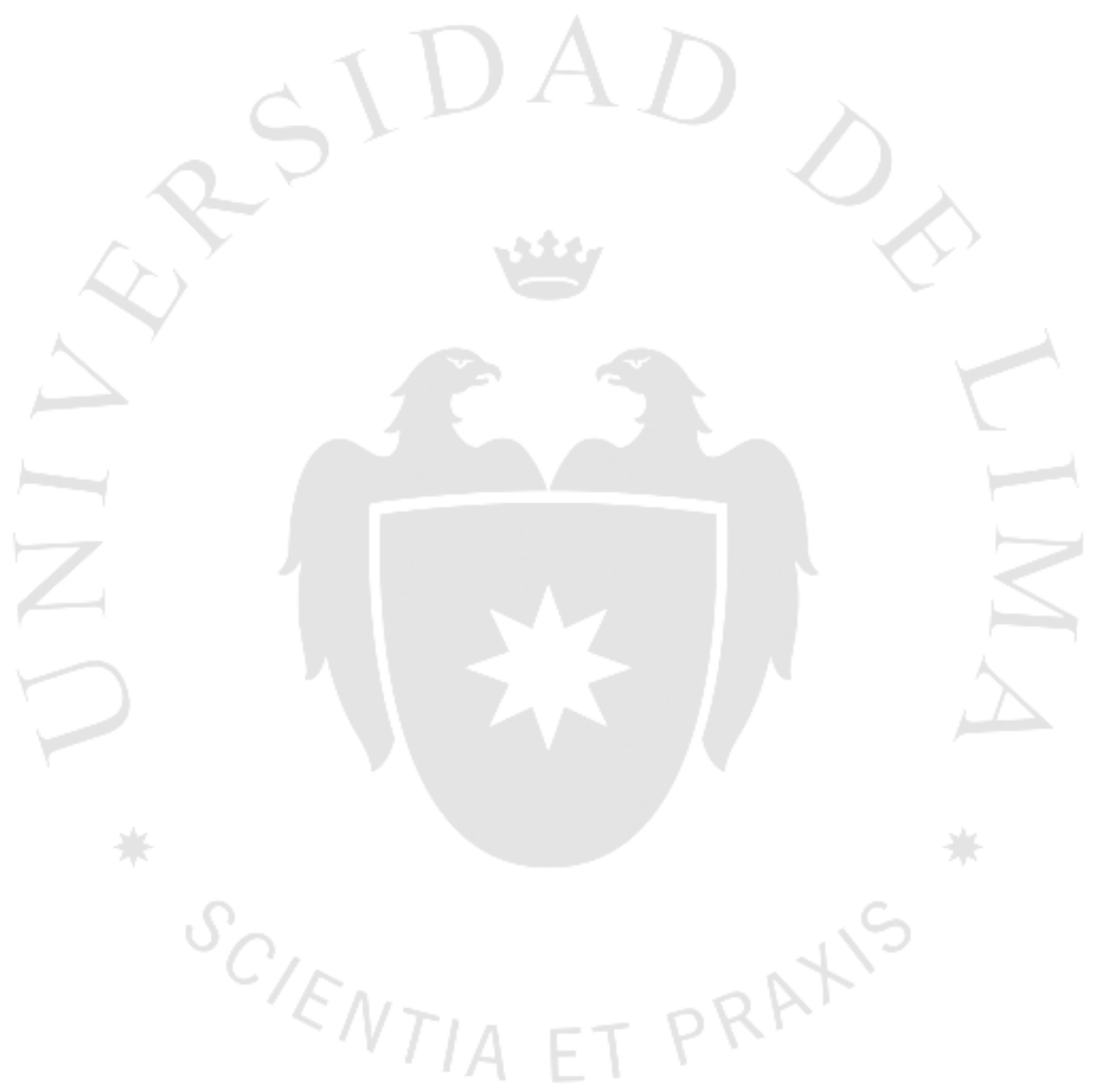




\section{ÍNDICE DE ANEXOS}

Anexo 1: Tabla de convenios firmados con países, que favorecen los montos de aranceles 126

Anexo 2: Base de datos aduanas - partida arancelaria nro. 8409993000/búsqueda de importador de repuesto "tobera1050071120" 128

Anexo 3: Costo para calcular el monto real del salario del trabajador 130

Anexo 4: Costo para capacitaciones en sistema de inyección diesel 131

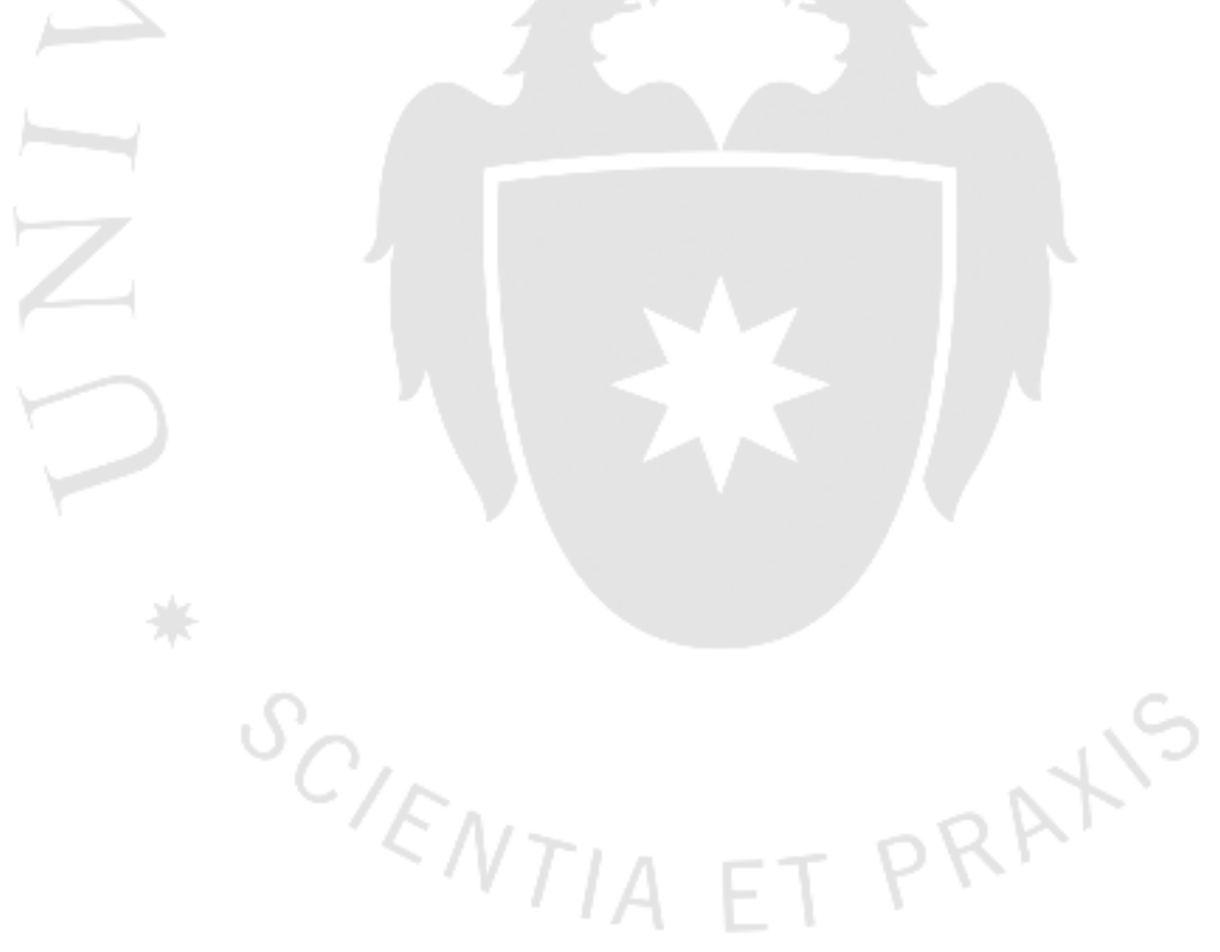




\section{Resumen Ejecutivo}

El objetivo del presente proyecto es identificar y mejorar los actuales procesos de compra y venta de la empresa Laboratorio Diesel Senatinos S.A., dedicada por tres décadas a brindar servicios y venta de repuestos del sector automotriz; Por tal motivo, el proyecto desarrolla y plantea la existencia de dos problemas principales localizados en los procesos de compras y ventas que se encuentran directamente relacionados con el desempeño en las actividades de los colaboradores de los procesos mencionados.

La investigación plantea dos posibles soluciones: (i) la sistematización de los procesos de compra y venta, y (ii) la capacitación del personal. Los resultados de la implementación de ambos mecanismos son el incremento de la rentabilidad de la empresa y el incremento de la satisfacción del cliente.

En respuesta a la actual coyuntura del mercado automotriz (disminución de aranceles e ingresos de nuevas marcas de vehículos), la evaluación de sus principales procesos determina que existe mayor incidencia y prioridad de atención en los procesos de compras y ventas de repuestos automotrices.

El análisis muestra que la falta de control y la falta de información de los colaboradores ocasionan que los procesos sean lentos dificultando el cumplimiento de los objetivos de la empresa. Por tal motivo, se propone la sistematización de los procesos de compra y venta de repuestos automotrices así como la capacitación al personal.

La primera solución reduce las horas de trabajo destinadas al proceso de compra y venta de productos y servicios, mientras que la segunda, genera un ahorro puesto que se adquieren productos a precios competitivos y de alta calidad. La ejecución del proyecto es viable con un beneficio monetario anual de S/. 120.344.87 nuevos soles que contribuyen a los objetivos organizacionales de la empresa. 


\section{Summary}

The purpose of this project is to identify and improve the present buy-and-sell processes of the Laboratorio Diesel Senatinos S.A. Company, so the project develops two possible solutions: (i) to systematize the buy-and-sell processes, and (ii) to train the staff. Once these two possible solutions have been executed, the results shown are satisfactory: (i) the rise of profit, and (ii) the rise of the clients' satisfaction.

Laboratorio Diesel Senatinos S.A. Company is a thirty-year-old company which has a long experience on the automotive market in Peru. It has a well-known knowledge on the diesel injections systems. In response to the current situation of the automotive market (the tariff reduction and the arrivals of new vehicles brands), the assessment of the company's most important processes shows that the most important project is the buy-and-sell processes of car parts.

The analysis shows that the lack of control and information of the workers make the processes very slow, so it is difficult to the company to achieve its goals. For this reason, the project proposes two possible solutions: (i) to systematize the buy-and-sell processes, and (ii) to train the staff.

The first solutions aims to reduce the work hours related to the buy-and-sell processes, on the other hand; the second solution aims to save money through the purchasing of cheaper products, nevertheless, these products will be high quality products. The project estimates that the execution of these two solutions would allow the company to save S/. 120.344,87. 


\section{CAPÍTULO I: CONSIDERACIONES GENERALES DE LA INVESTIGACIÓN}

\subsection{Antecedentes de la empresa}

\subsubsection{Breve descripción de la empresa y reseña histórica}

Laboratorio Diesel Senatinos S.A. inicia actividades en el año 1986, con su primer local alquilado en el distrito de San Luis en la ciudad de Lima. Se desempeñó desde sus inicios brindando servicios de diagnóstico, mantenimiento preventivo y reparación de los sistemas de inyección en vehículos diésel. Poco a poco fue ganando trayectoria y fidelidad de sus clientes lo que produjo que posteriormente, debido a la demanda y las necesidades de los clientes, se incorpore la atención de otros sistemas automotrices como sistema eléctrico, sistemas de inyección electrónica, reparación de motor, embragues y frenos.

En corto tiempo Senatinos S.A. añadió a sus actividades la venta de repuestos y componentes para los sistemas mencionados. En 1993 realiza sus primeras importaciones, siendo una de las primeras empresas que comercializó repuestos y equipos para el sistema de inyección Diesel.

La satisfacción de los clientes por los servicios recibidos permitió un crecimiento constante en la rentabilidad de la empresa, adquiriendo en 1997 un local propio con un área de 1.200 mts2, así como la renovación y compra de nuevos equipos de última tecnología.

La empresa fue avanzando significativamente abriendo diversos locales en diferentes distritos de la ciudad de Lima así como también en 
provincia, lo que permitió que la marca Senatinos se expandiera por todo el Perú.

Senatinos S.A. fue formando técnicos especialistas en diferentes sistemas automotrices como, motor, inyección, electrónica, electricidad e hidráulica. Todos ellos egresados de la institución SENATI (Servicio Nacional de Adiestramiento en Trabajo industrial) con amplia experiencia en el rubro, por lo que en el año 1997 fue galardonada como "Mejor empresa PYME" por la fabricación del primer Banco de Pruebas Diesel en El Perú.

En 1998 lanzan al mercado el Banco de pruebas Diesel consolidándose como la primera empresa en la fabricación de este producto en el Perú.

En su búsqueda constante de innovación y satisfacción del cliente, la empresa implementa un laboratorio hidráulico de última generación al ganar el concurso de Innovate Perú organizado por Fincyt Fidecom 2011 por la fabricación del "Primer banco de pruebas óleo - hidráulico automatizado y módulo portátil de diagnóstico" (Senatinos, s.f.). De esta forma la empresa se consolida como innovadora y tecnológica para el desarrollo de nuestro país.

Figura 1.1

Crecimiento cronológico de Laboratorio Diesel Senatinos S.A.

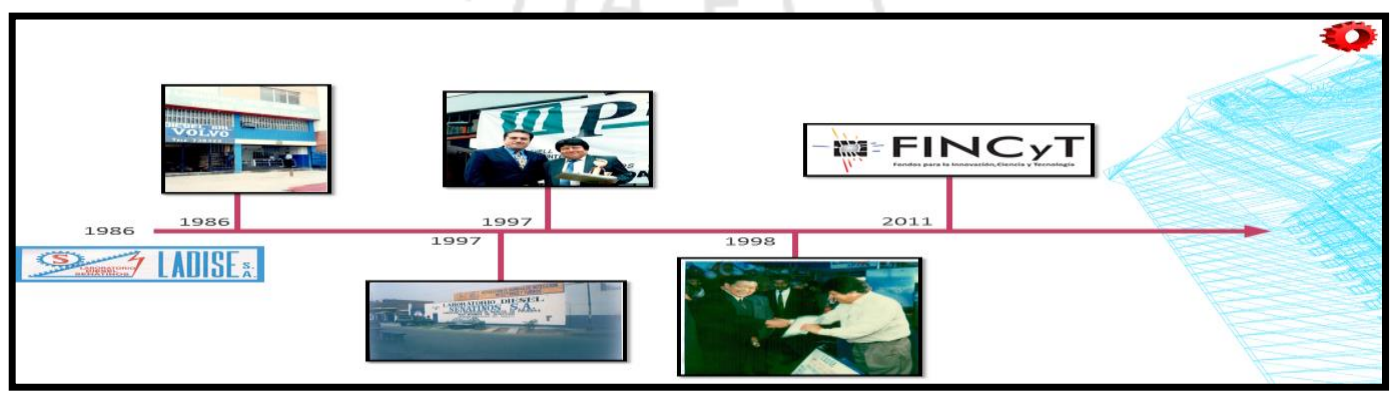

Fuente: Senatinos S.A. Elaboración: Propia 


\subsubsection{Descripción de los productos o servicios ofrecidos}

La empresa maneja una gama de productos y servicios que ofrece diariamente a sus clientes enfocándose en brindar soluciones en el mantenimiento y reparación a unidades multimarca diesel y gasolina. A continuación mencionamos los principales servicios y productos distribuidos por sistemas.

\section{Sistema de Inyección:}

- Mantenimiento y reparación de bombas de inyección rotativas, alta presión, lineales tipo A, P, en los sistemas mecánico y electrónico.

- Calibración de Bombas lineales y rotativas.

- Mantenimiento y reparación de inyectores diesel mecánico, common rail y electrónico.

- Mantenimiento y reparación de inyectores a gasolina, por limpieza en ultrasonido.

\section{Mantenimiento preventivo:}

- Afinamiento de 5.000, 10.000 y $40.000 \mathrm{~km}$.

- Cambio de aceite.

- Mantenimiento de inyectores mecánicos, electrónicos.

- $\quad$ Pruebas de diagnóstico de Opacidad y nivel de gases.

$>$ Motor:

- Afinamiento electrónico de motor.

- Medida de compresión.

- Cambio de anillos.

- Diagnostico con escáner,

- Cambio de empaque de culata.

- Cambio de componentes de distribución.

- Mantenimiento de radiador. 
$>$ Sistema de dirección:

- Cambio de amortiguadores.

- Alineamiento de ruedas.

Sistema de transmisión, embragues:

- Mantenimiento de cajas mecánicas y automáticas.

- Cambio de disco, plato y collarín de embrague.

- Rectificado de volante.

- Cambio de cremallera.

$>$ Frenos:

- Mantenimiento y regulación de frenos.

- Remplazo de pastillas, zapatas de las ruedas delanteras y posteriores.

- Rectificado de discos de freno.

Sistemas eléctricos y electrónicos:

- Reparación de tableros electrónicos.

- Mantenimiento de líneas eléctricas.

\section{Repuestos y componentes automotrices:}

- Familia de sistema de Inyección: toberas, elementos, válvulas, cabezales, Bombas de inyección, cebador, Bomba de alimentación, Eje de transferencia, deslizador, empaques, pines, rodajes, filtro de combustible.

- Familia de sistema de suspensión: amortiguador, crucetas.

- Familia de sistema de transmisión: plato, disco, collarín de embrague, rodajes, bomba de embrague, retenes, cremalleras de dirección. 
- Familia de frenos: pastillas, zapatas, disco, tambor, bomba de freno.

- Familia de sistema de lubricación: aceite de motor, SAE 25W40, 20W50, 15W40, 13W70, Aceite de transmisión Dexron I, II, III y IV, aceite de caja, aceite de corona, filtro de aceite.

- Familia repuestos de motor: válvulas de admisión, válvulas de escape, bocinas de biela, empaque de tapa de balancines, empaque de culata, empaque de motor, pistones, camisetas, guías de válvulas, retenes, rodajes, válvulas, termóstato, biela, cigüeñal, buzos, bomba de aceite y de agua, faja de distribución, poleas, fajas exteriores.

\subsubsection{Descripción del mercado objetivo de la empresa}

La empresa brinda servicios y venta de productos multimarca, es por ello que actualmente atiende a un grupo muy variable y cambiante de clientes que pertenecen a los segmentos A, B y C. Estas unidades son en mayor proporción vehículos livianos. Asimismo también realiza reparaciones de maquinaria pesada.

Senatinos S.A. no tiene claramente definido una mercado objetivo, ya que el producto y servicio que ofrece no va dirigido a un sector en particular, sino que espera alcanzar atender el mayor número de unidades vehiculares sin importar alguna variable cualitativa del mercado, esperando atender cualquier necesidad del cliente tanto en servicios como en la venta de repuestos (venta de mostrador).

Actualmente su principal enfoque y especialización está en la venta de servicios y repuestos para los sistemas de inyección, es por ello que cuenta con equipos y herramientas de última tecnología para solucionar cualquier requerimiento en este sistema. 


\subsubsection{Organización y estructura organizacional}

La empresa está conformada por 51 colaboradores distribuidos en 03 órganos principales: dirección, apoyo y línea, esta última contiene dos departamentos fundamentales, la gerencia de Administración y la gerencia de Operaciones, que a su vez se encuentran subdivididas por áreas, la primera conformada por: contabilidad, ventas, y logística, mientras la segunda contiene a las áreas de: mantenimiento y reparación así como laboratorio diesel.

La estructura orgánica de la empresa está dividida según:

\section{Órganos de dirección}

$>$ Gerencia General

\section{Órganos de apoyo}

$>$ Sistemas e Informática

\section{Órgano de línea}

$>$ Gerencia de administración

- Jefe contabilidad

- Jefe de ventas

- Jefe de logística

$>$ Gerencia de Operaciones

- Jefe de mantenimiento y reparación

- Jefe de laboratorio Diesel

En la figura 1.2 se muestra la estructura de la organización de la empresa. 


\section{Figura 1.2}

Organigrama de Laboratorio Diesel Senatinos S.A.

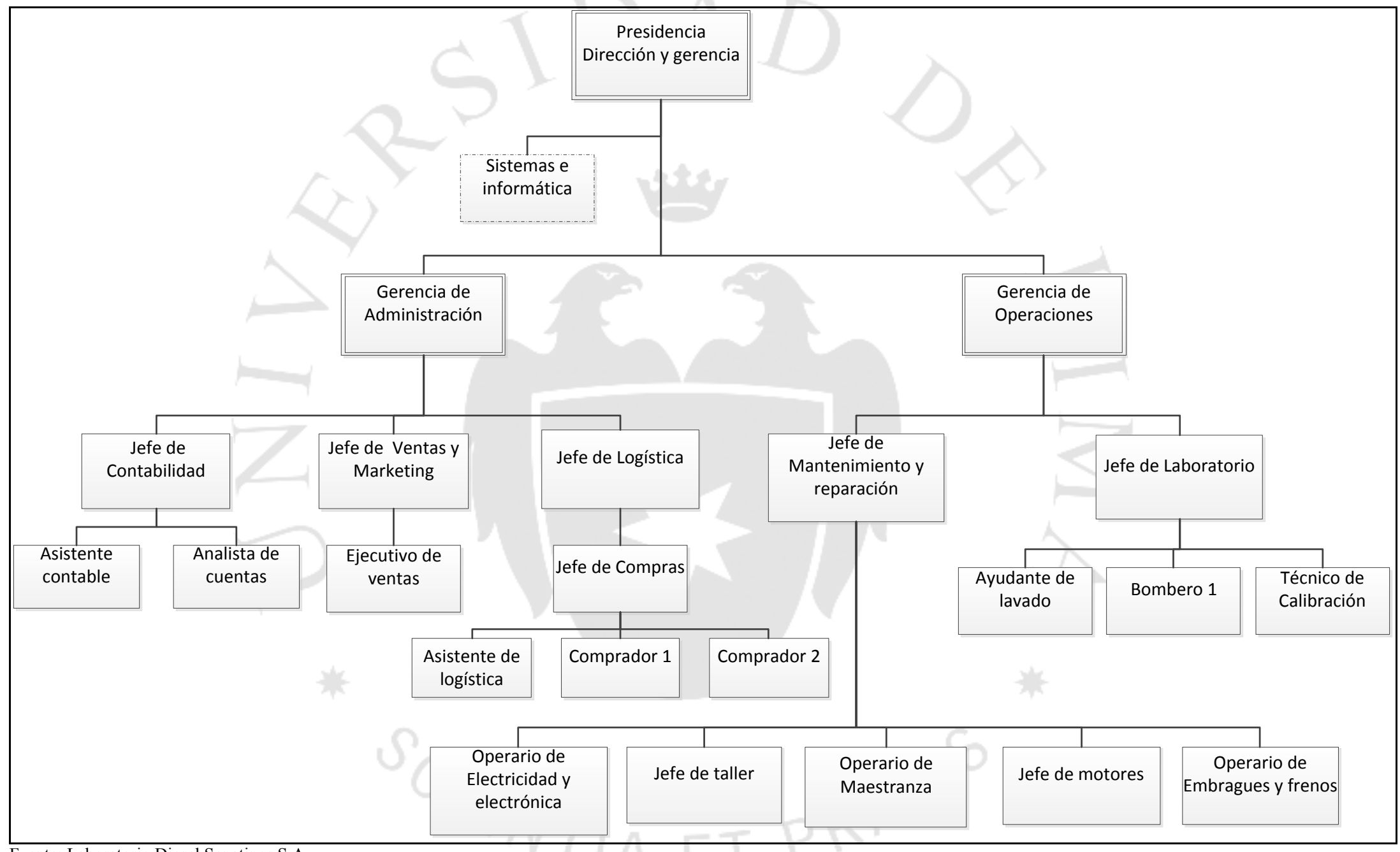

Fuente: Laboratorio Diesel Senatinos S.A.

Elaboración: Propia 


\subsubsection{Visión, misión y objetivos organizacionales}

Misión:

Encantar al cliente con un servicio de primera clase brindando un acertado diagnóstico en el mantenimiento y reparación de vehículos multimarca, así como en la venta de repuestos automotrices y maquinaria a nivel nacional, con el mejor personal técnico capacitado y con equipos tecnológicos.

\section{Visión:}

"Posicionar la marca SENATINOS a nivel nacional y ser reconocidos como los mejores especialistas en soluciones automotrices"

\section{Objetivos Organizacionales:}

- Lograr en corto plazo la rentabilidad y reconocimiento de SENATINOS como una empresa líder en el mercado peruano.

- Incrementar la satisfacción del cliente brindando productos y servicios de calidad, generando confianza y fidelización.

- Mejorar y optimizar los procesos internos logísticos, promoviendo la productividad de los recursos y minimizando los costos de no calidad.

- Lograr el desarrollo profesional de los colaboradores a través de continuas capacitaciones para el mejor desenvolvimiento y eficiencia en sus funciones como en la mejora de sus actividades.

- Lograr la representatividad de empresas internacionales de productos de calidad mundial del sector automotriz.

- Elaborar continuamente proyectos de innovación tecnológica, que permita el desarrollo de la industria peruana. 


\subsection{Objetivos de la investigación (variables de investigación)}

El objetivo principal del presente trabajo de investigación, es diseñar un plan para optimizar los procesos críticos en la empresa Laboratorio Diesel Senatinos S.A. que permita generar una eficiente gestión de sus recursos.

\section{Los objetivos específicos son:}

- Evaluar e identificar los procesos críticos de la empresa.

- Identificar las principales causas de los problemas en los procesos críticos.

- Diseñar y proponer alternativas de solución que faciliten la comunicación y coordinación entre los procesos operativos y los procesos de apoyo.

- Plantear indicadores de gestión que permitan evaluar los resultados de desempeño y económicos en los procesos internos de la empresa.

- Plantear los beneficios y costos asociados a la mejora.

- Evaluar la viabilidad económica del proyecto.

\subsection{Justificación de la investigación}

\subsubsection{Técnica:}

El presente proyecto es viable técnicamente debido a que se desarrollará, evaluará y analizará mediante las adecuadas herramientas de ingeniería industrial, enfatizando el diseño y planificación de los procesos de compra, venta y abastecimiento de repuestos automotrices. Asimismo se cuenta con el apoyo de la gerencia y la plana operativa para la obtención de datos y la recopilación de información actual e histórica. En conjunto, tanto la debida utilización de los conceptos de mejora así como la veraz información proporcionada por la empresa permitirá obtener resultados satisfactorios alcanzando cada uno de los objetivos de la investigación como los de la organización. 


\subsubsection{Económica:}

La factibilidad económica de la investigación es viable debido a la evaluación de los beneficios económicos y organizacionales que busca una inversión justa y necesaria para obtener resultados de incremento de rentabilidad y eficiencia en los procesos de compra y venta, así como también la reducción de costos de operación y costos logísticos.

\subsubsection{Social:}

Los resultados obtenidos por la ejecución del proyecto beneficiarán a los clientes internos a través de capacitaciones y utilización de herramientas tecnológicas. De esta forma, mejorarán sus competencias personales y laborales creando un ambiente de confianza y buen clima laboral. De esta manera los clientes externos podrán acceder con mayor facilidad a todos los productos que brinda la empresa, con la finalidad de lograr su plena satisfacción.

\subsection{Hipótesis del trabajo:}

La mejora de los procesos de compra y venta de repuestos automotrices en la empresa SENATINOS S.A. será factible y económicamente viable, porque existen las herramientas de ingeniería que proporcionan resultados consistentes y sostenibles para incrementar la rentabilidad de la empresa.

\subsection{Marco referencial de la investigación}

\subsubsection{Marco referencial:}

Según H. Fayol, las actividades comerciales donde refiere a las compras, ventas e intercambios, son fundamentales para la organización de una empresa, "tan importante es comprar como producir" (Thibaut, 1994, p.135). Debido a que existe varias causas que lo explican: 
"La función de las compras y el abastecimiento depende de la industria, por tanto, se trata de una demanda según la producción y el comercio. Por ese motivo, se le ha conferido un status subordinado, a menudo vinculado a la dirección técnica o administrativa y financiera" (Thibaut, 1994, p.136 ).

Como explica Jean Pierre Thibaut (1994), "una reducción de un 3\% sobre las compras cuando representa el $40 \%$ de la estructura de la cuenta de resultados y una disminución del $10 \%$ de stock que supone el $30 \%$ en necesidad en fondos de operación no puede ser consideradas como decisiones minoritarias" (p.136).

\subsubsection{Marco conceptual:}

El sector automovilístico se incrementa en forma constante año a año y las industrias en este campo han aumentado. Por lo tanto, la variedad y la tecnología de los vehículos han ido cambiando progresivamente, lo que ha generado una competencia global, es decir, los precios de los automóviles han disminuido considerablemente respecto de hace 10 años. De esta forma se ha creado mayores posibilidades a los consumidores para poder adquirir este producto. Asimismo, la flexibilidad y cambios que se han dado en el marco tributario también han contribuido a la expansión de este sector, ya que hace 4 años los aranceles por la importación de autos nuevos ascendía a 17\% de Advalorem, en cambio a la fecha sólo corresponde al $6 \%$ según la procedencia del vehículo. Todo ello, debido a los beneficios de los tratados internacionales con los principales países de producción automovilística a gran escala, lo que ha permitido que nuevas marcas de vehículos ingresen a competir al mercado peruano.

Si sumamos otros factores que han llevado al incremento de este sector (como los créditos vehiculares que facilitan a personas con bajos recursos el acceso a este beneficio y las reformas que se han dado con las 
múltiples restricciones en la importación de vehículos usados) todo ello genera, como resultado, el dinamismo efectivo del crecimiento en el parque automotor.

Hoy en día, la venta de automóviles nuevos en el Perú tiene un notorio crecimiento en 7 veces más respecto al año 2006 como se muestra en la figura 1.3. En consecuencia ha generado y seguirá generando una mayor demanda en la venta de repuestos y servicios automotrices. Asimismo aumentará progresivamente la competencia entre las empresas de servicio automotriz creando una rivalidad punzante para las mismas y logrando ventajas competitivas, diferenciación en los productos y mayor calidad en los servicios.

Figura 1.3

Crecimiento del parque automotor peruano

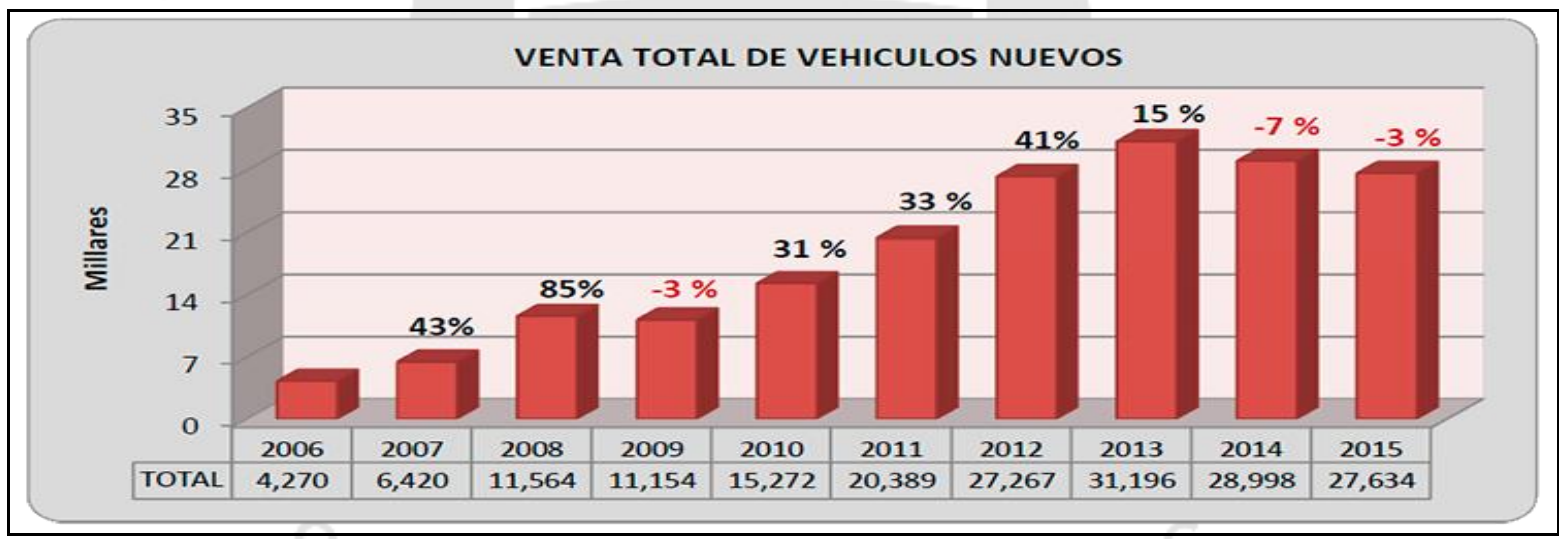

Fuente: ARAPER (Asociación de Representantes de Automotrices del Perú)

Las marcas de vehículos livianos y de carga con mayor presencia son provenientes del continente asiático, siendo los países más destacados, Corea del sur, Japón y China, debido a sus precios altamente competitivos y económicos. La mayor venta de unidades se registra en las marcas Hyundai, Kia y Toyota, como se muestra en las figuras 1.4 y 1.5. Las marcas en mención han invadido el parque automotor con diversos modelos y diseños de última tecnología. 
Figura 1.4

Importación de autos entre el 2010 y 2012

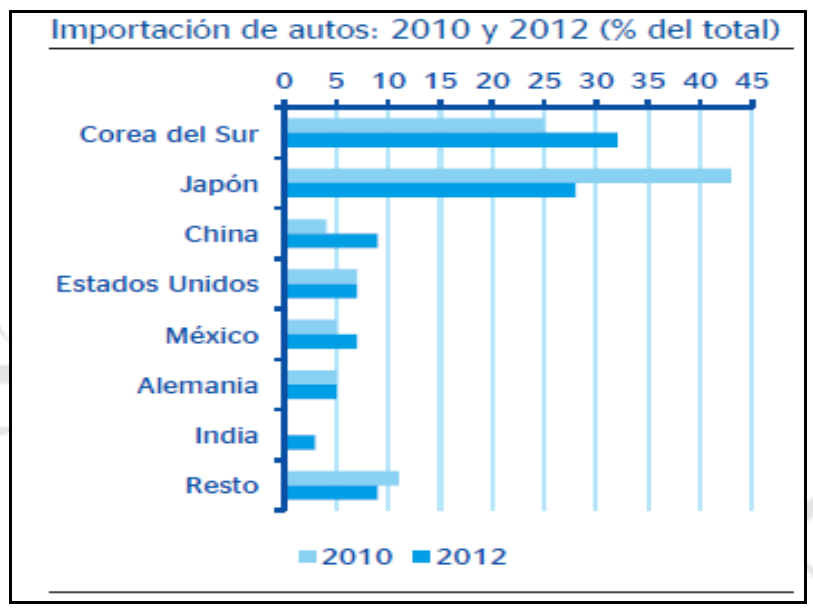

Fuente: BCRP y BBVA

El crecimiento del parque automotor ha permitido el ingreso de nuevas marcas de vehículos, llevando consigo a todos los subproductos generando una gran diversidad de opciones de compra para el cliente de acuerdo a sus necesidades.

Figura 1.5

Marcas de vehículos de mayor demanda

\begin{tabular}{lrr} 
Ventas acumuladas de autos nuevos en 2013 (hasta octubre)* & Participación (\%) \\
\hline Marca & Total General & 18,6 \\
\hline Toyota & 31.188 & 13,4 \\
Hyundai & 22.543 & 10,9 \\
Kia & 18.365 & 9,7 \\
Chevrolet & 16.373 & 6,2 \\
Nissan & 10.457 & 4,6 \\
Suzuki & 7.734 & 3,3 \\
Volkswagen & 5.466 & 2,2 \\
Mitsubishi & 3.755 & 2,0 \\
Renault & 3.437 & 1,7 \\
JAC & 2.888 & 27,3 \\
Otros & 45.916 & $100 \%$ \\
Totales & 168.122 & \\
* 15.5\% de las ventas totales corresponden a marcas de China e India. & \\
Fuente: Araper & &
\end{tabular}

Fuente: Araper 2013

El registro de crecimiento es aún mayor en las importaciones de 
repuestos originales y alternativos tanto para la línea liviana como pesada. El avance registrado hasta el primer semestre del 2012 fue de 10,9\%, liderando este grupo a los neumáticos y ruedas con un crecimiento del $54,3 \%$, seguido de embragues y frenos con $42,9 \%$, según la revista Maximixe y la información de Sunat.
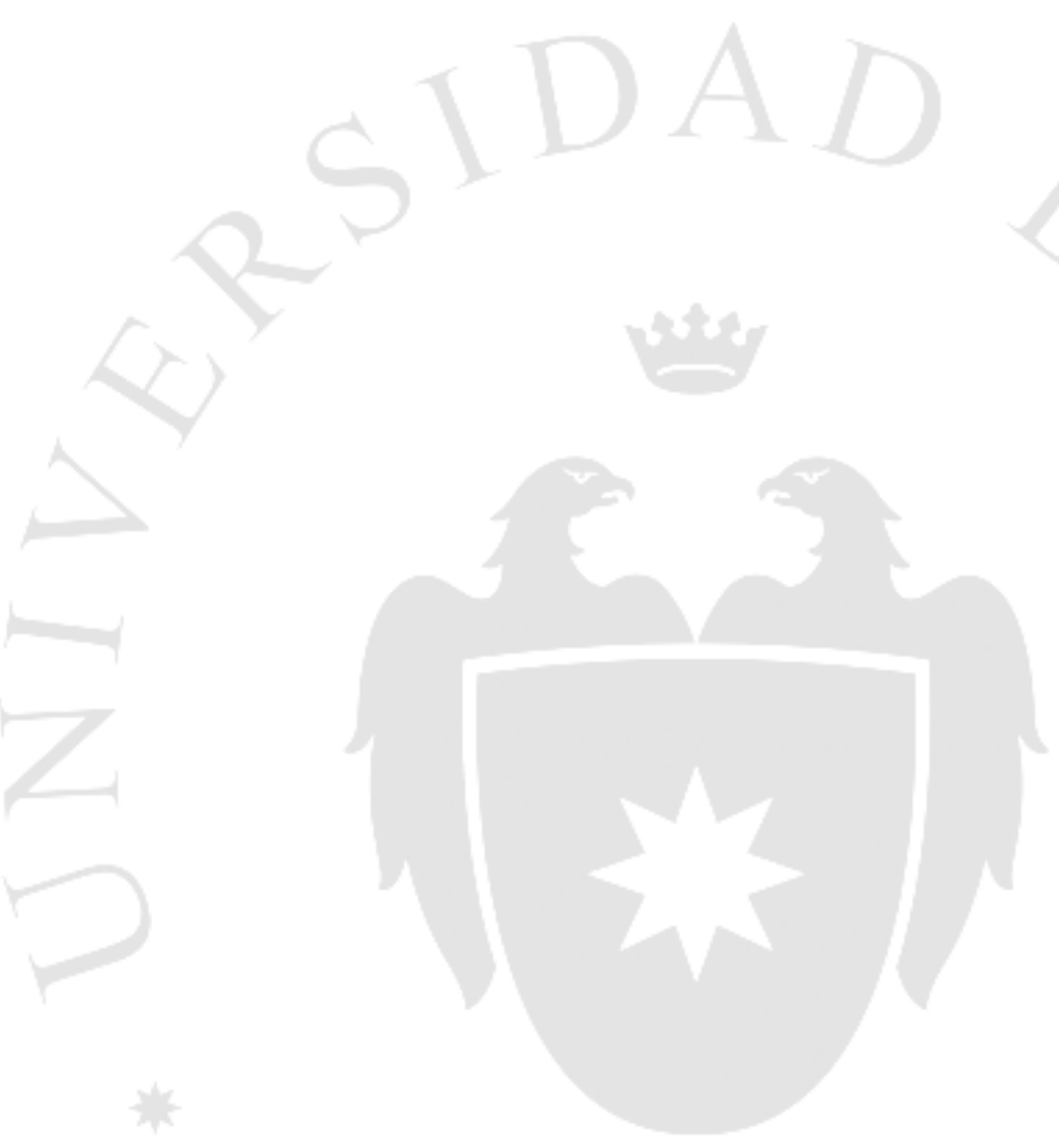


\section{CAPÍTULO II: ANÁLISIS SITUACIONAL DE LA EMPRESA: SELECCIÓN DEL PROCESO A SER MEJORADO}

\subsection{Análisis del marco global. Entorno económico, social, demográfico, legal y tecnológico. \\ $>$ Entorno económico.}

Al tomar como referencia el crecimiento de la economía de los últimos años en el Perú y según el marco económico multianual del MEF (Ministerio de Economía y finanzas) "La economía peruana crecerá 5,7\% en el 2014, iniciando un proceso de aceleración en torno a $6.4 \%$ en el periodo del 2015 - 2017 y con ello se posicionará como una de las economías de mayor crecimiento en el mundo"

Algunos de los países hermanos que están en igual o menor crecimiento económico que el Perú tienen un nivel de venta de vehículos 4 veces mayor que el nuestro como los muestra la figura 2.1. Es decir, a nivel local, existen 67 autos por cada mil habitantes, mientras que en países como Chile y Argentina existen 198 y 279 respectivamente según cifras del Banco Mundial.

Debido al contexto y al crecimiento de la economía se espera un aumento considerable de todo el sistema global automotriz.

\footnotetext{
2 Marco Macroeconómico Multianual 2015-2017. Ministerio de Economía y finanzas. Aprobado en sesión de Consejo de Ministros del 23 de Abril del 2014.
} 
Figura 2. 1

Comparativo de ventas de vehículos

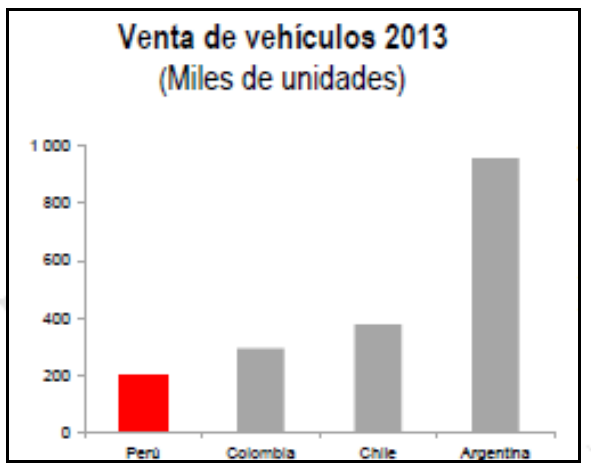

Fuente: ACCEP, Acecolombia, Ministerio de Comercio de países, SBS Elaboración: MEF (Ministerio de Economía y Finanzas)

El incremento de los ingresos económicos y la accesibilidad a mayores créditos en las familias han determinado que el vehículo tipo "ligero" sea el más vendido y tenga una mayor demanda en el mercado como se muestra en la figura 2.2.

Figura 2. 2

Crecimiento de vehículo tipo "Ligero" en el Perú

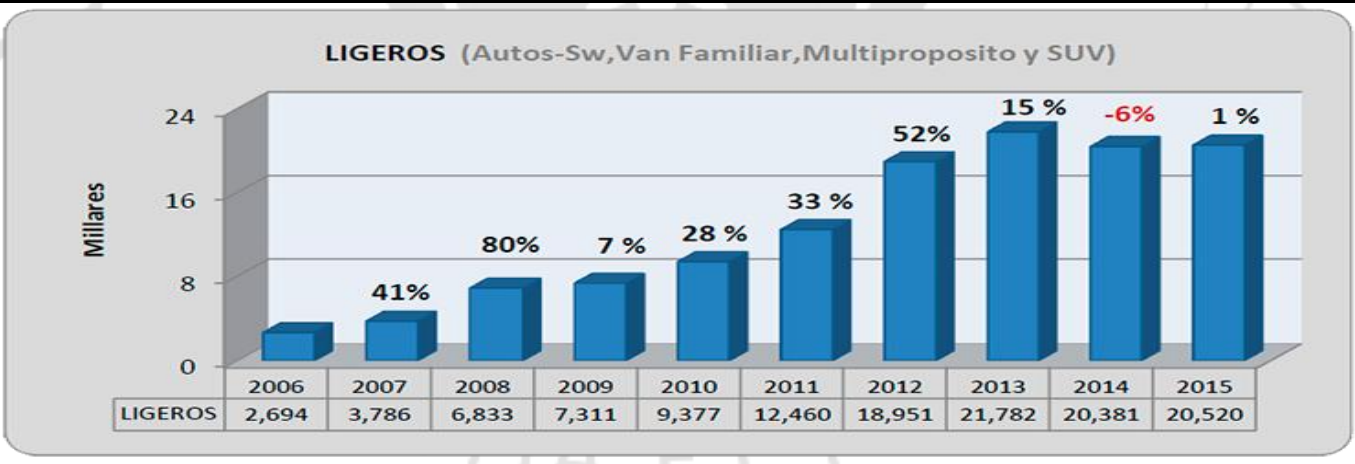

Fuente: ARAPER (Asociación de Representantes de Automotrices del Perú)

El crecimiento de la demanda en la adquisición de vehículos nuevos se verá reflejado directamente en el incremento de las empresas de venta de autopartes, insumos, venta de equipos y máquinas así como también la apertura de nuevos talleres mecánicos; de esta manera, el dinamismo de 
este sector ha impulsado la inversión de empresas nacionales e internacionales, así como de nuevos competidores a apostar en mejorar la tecnología, infraestructura y competencias para el desarrollo del mercado automotor.

A su vez la importación de repuestos en el Perú también ha crecido considerablemente para satisfacer las necesidades de los vehículos. Con base en el análisis del entorno global económico, la empresa Laboratorio Diesel Senatinos S.A. considera que es fundamental la inversión en recursos y tecnología ya que apoyará y mejorará el crecimiento sistemático de la organización.

\section{Entorno Social}

El crecimiento del parque automotor va de la mano con la mejora de la infraestructura vial, ya que fomenta y desarrolla la inversión de proyectos como ampliaciones de autopista, reconstrucciones, elaboración de túneles y nuevas vías que finalmente benefician a la población generando empleo e inversión.

La municipalidad de Lima junto con el gobierno regional viene impulsando una serie de proyectos de infraestructura, con la finalidad de aliviar las demandas de tráfico vehicular y transporte público como se observa en la tabla 2.1 . 
Tabla 2.1

Plan de infraestructura Vial hasta el 2020

\begin{tabular}{|c|c|c|c|c|}
\hline \multicolumn{5}{|l|}{ Lima: Proyectos de infraestructura vial } \\
\hline Proyecto & Trayecto & $\mathrm{Km}$ & $\begin{array}{c}\text { Inversión en } \\
\text { millones }\end{array}$ & $\begin{array}{c}\text { Fecha de } \\
\text { culminación }\end{array}$ \\
\hline Tramo 2, Línea 1 & Cercado-San Juan de Lurigancho & 12,4 & USD 901 & Abril 2014 \\
\hline Línea 2 Metro de Lima & Plaza Central Ate-Plaza Garibaldi Callao & 35,0 & USD 6,500 & 2019 \\
\hline Vía Expresa Sur & Barranco-Panmericana Sur & 4,5 & USD 230 & 2018 \\
\hline Conexión La Molina - Angamos & Vía Expresa-Cerro Centinela & 8,7 & USD 400 & 2018 \\
\hline Eje vial Javier Prado-La Molina- Faucett & Óvalo de Huarochirí- Av Faucett & 20,5 & USD 900 & 2021 \\
\hline Túneles Santa Rosa y San Martín & Cerro Santa Rosa & 2,0 & USD 50 & 2015 \\
\hline Vía Parque Rímac & Trébol de Javier Prado-Ovalo Habich & 9,0 & USD 700 & 2015 \\
\hline Vías Nuevas de Lima & Panamericana Norte-Puente Los Ángeles & 115 & USD 590 & 2016 \\
\hline
\end{tabular}

Fuente: Municipalidad de Lima

El dinamismo del mercado automotor ha causado que la circulación de autos nuevos sea considerablemente mayor y que poco a poco desaparezcan los vehículos antiguos que generan emisiones contaminantes que son contraproducentes para el medio ambiente.

La competitividad y el crecimiento de la demanda han hecho que la empresa Laboratorio Diesel Senatinos S.A. busque continuamente la mejora en todos los ámbitos organizacionales, asimismo genere más puestos de trabajo en las diferentes áreas y genere mayores competencias entre los colaboradores que se desarrollan en este sector.

\section{Entorno demográfico}

Laboratorio Diesel Senatinos S.A. se ubica en el departamento de Lima que aloja a la mayor cantidad de unidades de vehículos livianos y pesados en el Perú, generando mayor demanda y competencia para atender servicios de mantenimiento y venta de repuestos. Así mismo se encuentra muy cerca al puerto del Callao, principal puerto del país, lo que genera un mayor beneficio en los costos de transporte para recepción de productos de importación (autopartes y repuestos) a diferencia de las empresas de diferentes departamentos y provincias que también se encuentran en este sector. 
El distrito de San Luis, donde se localiza el local principal de Senatinos, es el tercer distrito de mayor venta de repuestos automotrices en el Perú con 350 establecimientos, antecedido por La Victoria e Independencia con 1.103 y 416 respectivamente, según las estadísticas de Ipsos Apoyo del 2012.

\section{Entorno Legal}

En el Perú se cuenta con varios beneficios legales y tributarios para la importación y comercialización de repuestos automotrices, debido a los tratados internacionales con países de gran producción como China, Corea y Estados unidos, que permiten que disminuyan los costos de las importaciones para brindar mejores precios a los consumidores, permitiéndoles la elección de diversas alternativas de productos para la accesibilidad del cliente, mostrando repuestos de calidad y a un menor precio.

En el Anexo Nro. 1. se puede observar la relación de tratados internacionales con beneficios arancelarios que se ha firmado a la fecha, que en su mayoría son a partir del 2010 hasta el 2014.

\section{Entorno Tecnológico}

La creciente demanda de vehículos nuevos y la variedad de nuevas marcas que han ingresado al Perú para competir han logrado que el mercado de repuestos automotrices sea muy atractivo para abastecer a la fuerte demanda.

La globalización y modernización han hecho que podamos tener una diversidad de modelos y diseños de vehículos, pero no solo ha sido cambiante la parte externa del mismo, sino también todo el sistema interno ha sido modificado por piezas y componentes de mayor performance, en su gran mayoría el sistema mecánico ha sido 
desplazado por el sistema eléctrico y electrónico. Por esta razón la necesidad de nuevos repuestos de alta tecnología han tenido una fuerte demanda en el Perú.

La tecnología que ahora poseen los sistemas internos de los vehículos nuevos han desencadenado una serie de factores para el sector automotor, debido a que se requiere mayor inversión para los equipos de última tecnología, la implementación de laboratorios de diagnóstico, capacitación constante de técnicos y personal de ventas, implementación de software para información técnica, despiece de repuestos así también como para el control de inventarios.

\subsection{Análisis de las fuerzas competitivas}

\subsubsection{Poder de negociación de los compradores}

El poder de negociación de los compradores es alto debido a que muchos de los ellos están concientizados que es más seguro y de mayor garantía optar por comprar servicios o productos en la compañías que son representantes de las grandes marcas de vehículos automotrices, lo cual en muchos casos no es cierto. Lamentablemente, es un poco más complicado hacer cambiar de parecer en costumbres y mentalidades a compradores que vienen siguiendo el mismo ritmo de negociación desde varios años atrás.

Debido al crecimiento del sector automotriz hay un gran porcentaje de demanda insatisfecha que muy por el contrario de los compradores antes mencionados optan por elegir un buen producto o servicio (considerando los alternativos) al mejor precio. Actualmente existe una gran diversidad de repuestos alternativos a precios muy competitivos según la calidad que elija el consumidor.

Si bien es cierto que el comprador tiene opciones para elegir entre 
productos sustitutos, también es importante mencionar que carece de información para optar por la mejor elección debido al desconocimiento técnico de cada uno de los productos o servicios a comprar.

\subsubsection{Poder de negociación de los proveedores.}

El poder de negociación con los proveedores es bajo debido a que según la tendencia de crecimiento de la demanda de compra de repuestos automotrices se puede contar con productos alternativos de iguales características técnicas pero de diferente precio debido a la procedencia y la producción del producto.

Los principales proveedores son compañías del exterior que realizan producción a escala de determinados productos automotrices, así como las grandes distribuidoras que poseen alianzas estratégicas con concesionarias o marcas reconocidas internacionalmente.

Los precios de producto son los que definen la compra del producto, ya que en el mercado se encuentra diversidad de proveedores con el mismo producto de igual características y marca. La diferenciación está en el precio y el valor agregado al producto, es por ello que se puede optar por el proveedor que pueda brindar mayores beneficios.

\subsubsection{Amenaza de entrada de nuevos competidores}

El riesgo de ingreso de nuevos competidores potenciales es bajo, debido a que corresponden a las grandes tiendas de repuestos así como a los talleres que poseen laboratorio Diesel y equipos de medición de tecnología, para la calibración y reparación de los vehículos Diesel y gasolina.

\section{Descripción de las barreras de entrada:}

- Inversión elevada: Actualmente se requiere de una alta inversión 
para la apertura de un taller automotriz, debido a que desde hace 8 años las nuevas unidades que ingresan al mercado presentan sistemas electrónicos por lo cual se requiere de varios equipos de medición costosos para brindar al cliente un efectivo diagnóstico. Sin embrago aún existe un alto porcentaje de talleres informales que poco a poco se va reduciendo a causa de falta de equipos y tecnología y que por ello se dedican a atender las vehículos de antaño.

Asimismo, para el caso de los repuestos, se requiere de un importante capital para las importaciones donde los costos son muy variables debido al tipo de cambio, regulaciones internacionales y otros factores que pueden alterar los precios de los productos más competitivos. Además se necesita límites de stocks de gran proporción teniendo en cuenta que existe una larga familia y subfamilias para cada tipo de motor de vehículo, sumando a eso que es fundamental contar con software de despiece por marca de producto o marca de vehículo que brinden información exacta de códigos y datos técnicos.

- Curva de experiencia: La empresa es reconocida en el parque automotor por ser especialista en sistemas de inyección diesel que es un servicio que requiere mucho conocimiento y precisión, que en la mayor parte se gana a través de los años mediante la experiencia directa, por lo que entonces, un nuevo ingresante incurrirá en costos elevados de profesionales o en investigaciones y capacitaciones para poder brindar un servicio eficiente con un producto de calidad.

- Información técnica: para la venta de repuestos y la venta de servicios, es necesario contar con la información técnica oportuna. Laboratorio Diesel Senatinos S.A. cuenta con softwares como Autodata, Tecdoc, Esitronic, Kts6000, Denso, programas que 
brindan información necesaria para la eficiente atención de sus clientes.

\subsubsection{Rivalidad entre los competidores}

La rivalidad entre los competidores es bajo, y los factores determinantes de la rivalidad entre los competidores son a causa de:

- Precios: El 90\% de los productos automotrices son manufacturados en las grandes industrias de las principales potencias mundiales, es decir, en el Perú el mayor porcentaje de los repuestos automotrices provienen de importaciones y proporcionan una variedad de características, calidad, precio y aplicación. Por tal motivo, la principal razón de competencia es a través de guerra de precios.

- Diferenciación: La empresa posee una gran trayectoria en brindar calidad en los productos y servicios por la especialización en diversos sistemas, y sus 29 años de experiencia han posicionado a la marca SENATINOS como una de las mejores del sector. Por tal razón se considera que se debe explotar dicha marca para obtener la diferenciación del producto y servicio. Sin embargo, también existe competencia a causa de la informalidad que aún hay en el mercado llevando consigo una serie de problemas con los resultados de servicios por no contar con los equipos adecuados, haciendo que se genere desconfianza por parte de los clientes y que finalmente lleven sus unidades a las empresas concesionarias de cada marca de vehículos.

- Demanda: Debido al alto crecimiento del parque automotor, existe elevada demanda insatisfecha por atender.

- Representaciones de marcas: Es importante obtener la 
representación de marcas de calidad de repuestos que aseguren un óptimo resultado del servicio. Debido a que este sector es altamente competitivo, se requiere llevar buenas relaciones y alianzas con los proveedores, esto facilitará la adquisición de sus productos e inclusive una reducción de costos lo que permitiría ofrecer mejores precios a los clientes.

\subsubsection{Amenaza de productos sustitutos}

La amenaza de productos sustitutos es alta debido a que los clientes potenciales son muy sensibles al cambio cuando encuentran varias opciones de compra de producto sustituto. Si bien es cierto, existe una gran competencia en la venta de repuestos alternativos por el factor precio, es decir, son mucho más económicos que los repuestos originales y crean varias posibilidad de compra para el cliente, se puede mencionar que la competencia es reñida sólo para los productos más comerciales, como de modelos de marcas más representativas.

\subsection{Breve descripción de los principales procesos}

\subsubsection{Identificación de los procesos más importantes}

Se describirá los procesos principales en base a tres procesos generales que se interrelacionan. Cada uno de ellos posee sus propios objetivos específicos a fin de lograr la satisfacción del cliente:

\section{$>$ Procesos estratégicos}

Es aquel proceso que se basa en la toma de decisiones y la planificación estratégica para el desarrollo de la empresa.

La gerencia analiza el comportamiento de los indicadores del sistema de gestión como ratios financieros, cartera de clientes, 
ventas y costos para determinar la evolución en los avances y mejoras, con el fin de encaminar y cumplir con los objetivos trazados y lograr el crecimiento de la empresa.

\section{$>$ Procesos Operativos}

Son los procesos motores que se aplican directamente en los servicios y giro de la empresa.

- Ventas: se encarga directamente de satisfacer las necesidades del cliente, brindar información respecto a los productos y servicios que ofrece la empresa, así como realizar las negociaciones y gestionar las cotizaciones. Finalmente elabora el seguimiento de post venta.

- Inspección y evaluación: Proceso encargado de la evaluación inicial del vehículo, donde se detecta y diagnostica que posibles fallas o problemas se deben resolver y que servicios se van a realizar.

- Producción: Es el proceso que se encarga de resolver y dar solución a los requerimientos de los servicios solicitados por los clientes, los cuales se dividen en dos procesos principales, mantenimiento preventivo y correctivo.

En el proceso de producción el recurso más importante es el humano, ya que se requiere de conocimiento y experiencia para obtener el resultado final del servicio, el que se basa principalmente en datos e información técnica.

- Despacho de productos y servicios: proceso que se encarga de la preparación final para la entrega de los productos y servicios terminados. 
Procesos de apoyo:

Son aquellos procesos que dan soporte a los procesos operativos, aportándoles los recursos necesarios e indispensables para la finalización del entregable. En esta etapa el cliente es interno.

- Recursos humanos: proceso que se encarga del reclutamiento, evaluación, selección y capacitación del personal. Con base en las necesidades y perfiles definidos del recurso humano son atendidos los requerimientos de las áreas de la empresa.

- Compras: proceso que atiende las necesidades de insumos, materiales y repuestos en caso de una ruptura de stock o el requerimiento específico de un repuesto no comercial. Selecciona, evalúa, negocia y coordina con los proveedores nacionales e internacionales para el cumplimiento de entregas de los bienes solicitados en base a especificaciones técnicas.

- Almacén: Proceso que se encarga de distribuir, organizar, controlar y custodiar los inventarios de la empresa.

- Mantenimiento y seguridad: proceso que se encarga de velar por el buen funcionamiento y la operatividad de cada una de las máquinas y equipos de la empresa. Se añaden a este rubro los procesos de seguridad y limpieza que se interesan primordialmente en el bienestar físico de todo el personal y para que puedan desempeñarse cómodamente en cada una de las operaciones.

A continuación, la figura 2.3 detalla el mapa de procesos de la empresa. 
Figura 2. 3

Mapa de procesos de Laboratorio Diesel Senatinos S.A.

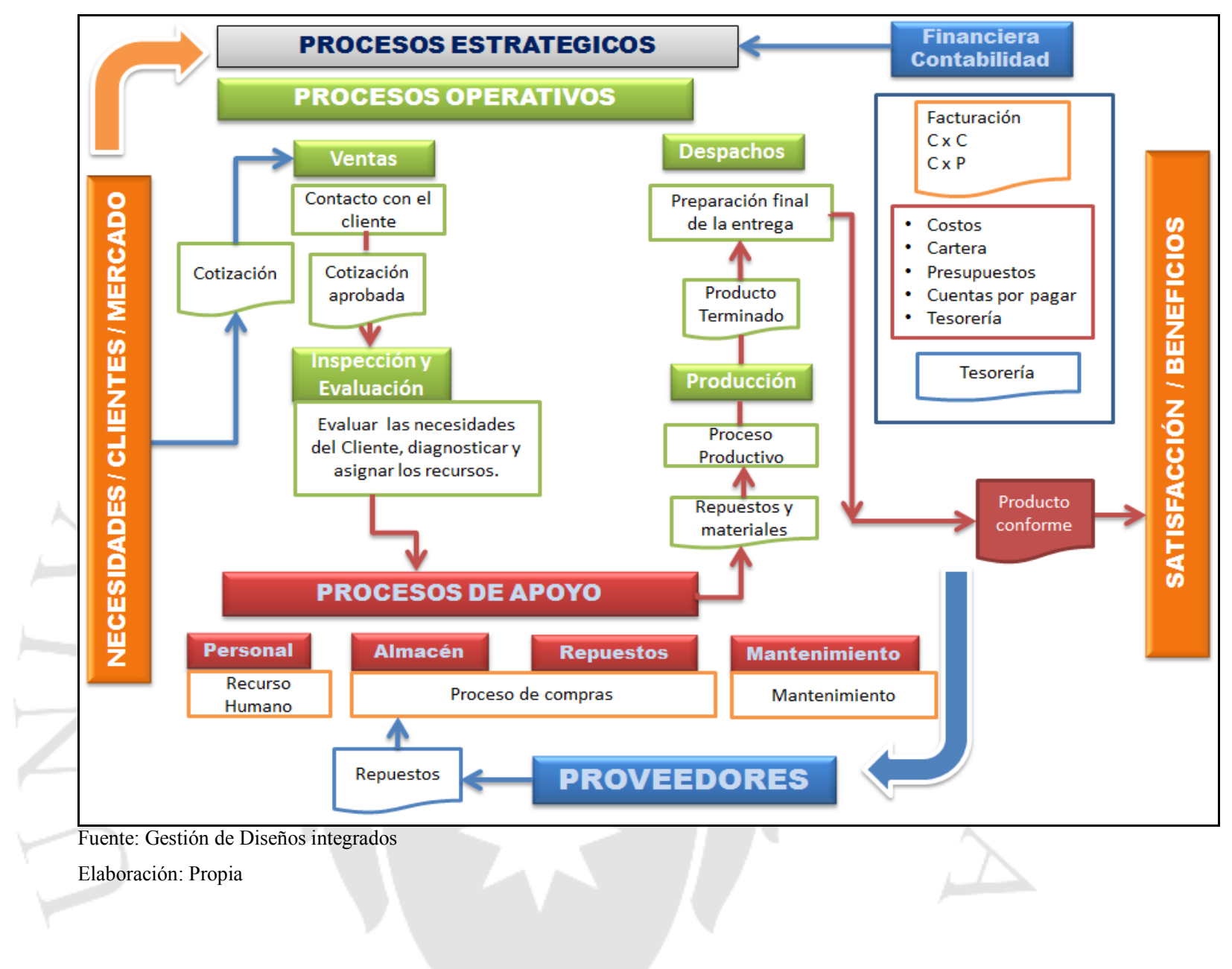

2.3.2. Selección del proceso a mejorar

Para seleccionar el proceso principal a evaluar se realizará un análisis de todas las áreas de la empresa mediante el análisis factorial de Klein. De esta manera se podrá determinar de manera cualitativa la efectividad de la empresa y extraer las principales áreas y procesos en estado crítico.

El cálculo de la efectividad de las áreas de la empresa se realiza hallando el factor (E) con base en los valores que muestran la tabla 2.2. 
Tabla 2.2

Valores de efectividad - Análisis Klein

\begin{tabular}{|c|c|c|}
\hline \multicolumn{3}{|c|}{ Tabla de valores de efectividad } \\
\hline A & 1 & Muy adecuado \\
\hline B & 0.5 & Adecuado \\
\hline C & 0.25 & Poco adecuado \\
\hline N & \multicolumn{2}{|c|}{$\begin{array}{c}\text { Números de } \\
\text { elementos evaluados }\end{array}$} \\
\hline
\end{tabular}

$\mathbf{E}=\frac{\mathbf{N}^{\circ} \mathbf{A} * \mathbf{f A}+\mathbf{N}^{\circ} \mathbf{B} * \mathbf{f B}+\mathbf{N}^{\circ} \mathbf{C} * \mathbf{f C}}{\mathbf{N}} \times 100 \%$
$E=$ efectividad del factor

Elaboración propia

La evaluación de la efectividad y el desempeño se realizó mediante una encuesta a los 4 principales responsables en cada área (jefe de área, dos colaboradores del área y el gerente general) acerca de las principales funciones y procesos. De esta manera cada uno realizó la evaluación en función a la tabla de valores de efectividad, los resultados se muestran en las tablas $2.3,2.4,2.5,2.6$ y 2.7

Tabla 2.3

Análisis del proceso Gerencial y Administrativo - Klein

\begin{tabular}{|c|c|c|c|c|}
\hline Nro. & Gerencial y Administrativo/ Área Contable & $\mathbf{A}$ & B & $\mathbf{C}$ \\
\hline 1 & $\begin{array}{l}\text { ¿Es aceptable cada uno de los sistemas } \\
\text { administrativos que lleva la empresa en sus registros } \\
\text { contables? }\end{array}$ & $\mathrm{xxxx}$ & & \\
\hline 2 & $\begin{array}{l}\text { ¿Se elabora adecuadamente los informes de } \\
\text { contabilidad requeridos internamente y por } \\
\text { organismos externos? }\end{array}$ & $\mathrm{xxx}$ & $\mathrm{x}$ & \\
\hline 3 & $\begin{array}{l}\text { ¿Se informa satisfactoriamente la situación de la } \\
\text { empresa, tanto en su aspecto económico-cuantitativo } \\
\text { como en su aspecto económico-financiero? }\end{array}$ & $\mathrm{xxx}$ & $\mathrm{x}$ & \\
\hline 4 & $\begin{array}{l}\text { ¿Se supervisa de forma adecuada la contabilidad } \\
\text { general y auxiliar de la empresa? }\end{array}$ & $x$ & $\mathrm{xxx}$ & \\
\hline 5 & $\begin{array}{l}\text { ¿Se realiza de forma satisfactoria la comunicación del } \\
\text { área contable con las áreas de la empresa que crea } \\
\text { conveniente? }\end{array}$ & $\mathrm{xx}$ & $\mathrm{xx}$ & \\
\hline & Resultado & $13 x$ & $7 x$ & $\mathbf{8 3 \%}$ \\
\hline \multicolumn{5}{|c|}{ Elaboración propia } \\
\hline & $\frac{13 * 1+7 * 0,5+0 * 0.25}{20}$ & $83 \%$ & & \\
\hline
\end{tabular}


Tabla 2. 4

Análisis del proceso de compras - Klein

\begin{tabular}{|c|c|c|c|c|c|}
\hline Nro. & Área Compras & $\mathbf{A}$ & $\mathbf{B}$ & $\mathbf{C}$ & \\
\hline 1 & ¿La recepción de los productos es el adecuado? & & $\mathrm{xxx}$ & $\mathrm{x}$ & \\
\hline 2 & $\begin{array}{l}\text { ¿Se realiza de forma satisfactoria el } \\
\text { aprovisionamiento de los productos? }\end{array}$ & & $\mathrm{xx}$ & $\mathrm{xx}$ & \\
\hline 3 & $\begin{array}{l}\text { ¿Es adecuado el despacho de los productos hacia las } \\
\text { áreas respectivas de la empresa? }\end{array}$ & & $\mathrm{x}$ & $\mathrm{XXX}$ & \\
\hline 4 & $\begin{array}{l}\text { ¿Se evalúan de forma adecuada los precios de } \\
\text { compras que se realizan a los proveedores? }\end{array}$ & & $\mathrm{x}$ & $\mathrm{xxx}$ & \\
\hline 5 & $\begin{array}{l}\text { ¿Se elaboran de forma adecuada registros de los } \\
\text { niveles de inventarios? }\end{array}$ & & $\mathrm{xx}$ & $\mathrm{xx}$ & \\
\hline 6 & $\begin{array}{l}\text { ¿Se realiza de forma satisfactoria la comunicación del } \\
\text { área de compras con las áreas de la empresa que crea } \\
\text { conveniente? }\end{array}$ & $\mathrm{x}$ & $\mathrm{xx}$ & $\mathrm{x}$ & \\
\hline \multirow{3}{*}{ boración: } & Resultado & $1 \mathbf{x}$ & $11 x$ & $12 \mathrm{x}$ & $40 \%$ \\
\hline & $2 \sqrt{20}$ & & 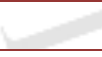 & & \\
\hline & $\frac{1 * 1+11 * 0,5+11 * 0,25}{24}$ & $=$ & $40 \%$ & & \\
\hline
\end{tabular}

Tabla 2. 5

Análisis del proceso de ventas - Klein

\begin{tabular}{|c|c|c|c|c|c|}
\hline Nro. & Área Ventas & $\mathbf{A}$ & $\mathbf{B}$ & $\mathrm{C}$ & \\
\hline 1 & $\begin{array}{l}\text { ¿Se establece adecuadamente los precios para los } \\
\text { clientes? }\end{array}$ & & $\mathrm{X}$ & $\mathrm{xxx}$ & \\
\hline 2 & $\begin{array}{l}\text { ¿Se lleva un adecuado seguimiento, control y análisis } \\
\text { de venta? }\end{array}$ & & XXXX & & \\
\hline 3 & $\begin{array}{l}\text { ¿Se lleva una adecuada capacitación técnica a los } \\
\text { vendedores? }\end{array}$ & & $\mathrm{x}$ & $\mathrm{xxx}$ & \\
\hline 4 & $\begin{array}{l}\text { ¿Existe un procedimiento específico para cada tipo de } \\
\text { venta? }\end{array}$ & $\mathrm{xx}$ & $\mathrm{XX}$ & & \\
\hline 5 & $\begin{array}{l}\text { ¿Se realiza un adecuado perfil para el puesto de } \\
\text { vendedores? }\end{array}$ & & & Xxxx & \\
\hline 6 & $\begin{array}{l}\text { ¿Se realiza de forma satisfactoria la comunicación del } \\
\text { área de ventas con las áreas de la empresa que crea } \\
\text { conveniente? }\end{array}$ & & $x x$ & $\mathrm{Xx}$ & \\
\hline \multicolumn{2}{|c|}{ - } & $2 x$ & $10 x$ & $12 x$ & $42 \%$ \\
\hline \\
\hline & $\frac{2 * 1+10 * 0,5+12 * 0,25}{24}$ & $=$ & $42 \%$ & & \\
\hline
\end{tabular}


Tabla 2.6

\section{Análisis del proceso de Operaciones - Klein}

\begin{tabular}{|c|c|c|c|c|c|}
\hline Nro. & $\begin{array}{c}\text { Área de Operaciones / Mantenimiento y } \\
\text { Reparación }\end{array}$ & $\mathbf{A}$ & B & $\mathbf{C}$ & \\
\hline 1 & $\begin{array}{l}\text { ¿La disposición de planta, facilita la eficiencia de las } \\
\text { operaciones que se realizan en dicha área? }\end{array}$ & $\mathrm{xxx}$ & $\mathrm{X}$ & & \\
\hline 2 & $\begin{array}{l}\text { ¿Es adecuado el tiempo de los servicios y/o } \\
\text { operaciones? }\end{array}$ & & $\mathrm{XX}$ & $\mathrm{XX}$ & \\
\hline 3 & $\begin{array}{l}\text { ¿Se lleva una adecuada capacitación técnica a los } \\
\text { operarios en dicha área? }\end{array}$ & $\mathrm{XX}$ & $\mathrm{XX}$ & & \\
\hline 4 & ¿El servicio brindado en esta área es eficiente? & $\mathrm{xx}$ & $\mathrm{xx}$ & & \\
\hline 5 & $\begin{array}{l}\text { ¿Se realiza un adecuado perfil para el puesto de los } \\
\text { operarios del área mencionada? }\end{array}$ & $\mathrm{XX}$ & $\mathrm{xx}$ & & \\
\hline 6 & $\begin{array}{l}\text { ¿Se realiza de forma satisfactoria la comunicación del } \\
\text { área de mantenimiento y reparación con las áreas de la } \\
\text { empresa que crea conveniente? }\end{array}$ & & $\mathrm{xxx}$ & $\mathrm{x}$ & \\
\hline & Resultado & $9 X$ & $12 x$ & $3 \mathbf{x}$ & $66 \%$ \\
\hline
\end{tabular}

$$
\mathrm{E}=\frac{9 * 1+12 * 0,5+3 * 0,25}{24} \quad \times 100 \%=66 \%
$$

Tabla 2.7

Análisis del proceso de Laboratorio - Klein

\begin{tabular}{|c|c|c|c|c|}
\hline Nro. & Área de Laboratorio & $\mathbf{A}$ & B & $\mathbf{C}$ \\
\hline 1 & $\begin{array}{l}\text { ¿La disposición de planta, facilita la eficiencia de las } \\
\text { operaciones que se realizan en dicha área? }\end{array}$ & $\mathrm{XXXX}$ & & \\
\hline 2 & $\begin{array}{l}\text { ¿Es adecuado el tiempo de los servicios y/o } \\
\text { operaciones? }\end{array}$ & & $\mathrm{xxx}$ & $x$ \\
\hline 3 & $\begin{array}{l}\text { ¿Se lleva una adecuada capacitación técnica a los } \\
\text { operarios en el área de laboratorio? }\end{array}$ & $\operatorname{xxxx}$ & & \\
\hline 4 & ¿El servicio brindado en esta área es eficiente? & $\mathrm{xx}$ & $\mathrm{xx}$ & \\
\hline 5 & $\begin{array}{l}\text { ¿Se realiza un adecuado perfil para el puesto de los } \\
\text { operarios del área mencionada? }\end{array}$ & & $\mathrm{xxx}$ & $x$ \\
\hline 6 & $\begin{array}{l}\text { ¿Se realiza de forma satisfactoria la comunicación del } \\
\text { área de mantenimiento y reparación con las áreas de la } \\
\text { empresa que crea conveniente? }\end{array}$ & $\mathrm{x}$ & $\mathrm{xxx}$ & \\
\hline & Resultado & $11 X$ & $11 x$ & $2 \mathbf{x}$ \\
\hline
\end{tabular}

Elaboración: propia

$$
\mathrm{E}=\frac{11 * 1+11 * 0,5+2 * 0,25}{24} \quad \times 100 \%=71 \%
$$


Con los resultados que se obtienen del análisis factorial de Klein se determina que las áreas con mayor criticidad y problemática en sus procesos son las áreas de compras y ventas con valores de 40\% y $42 \%$ respectivamente.

De igual forma, como muestra la figura 2.4, donde se detalla la estrategia de excelencia operativa, se puede observar que la perspectiva de los procesos internos junto con el aprendizaje y crecimiento son las bases fundamentales para lograr incrementar la satisfacción del cliente y a su vez obtener el incremento de las utilidades de la empresa.

Por lo tanto, los procesos a evaluar, analizar y determinar las soluciones de los principales problemas en la empresa Laboratorio Diesel Senatinos S.A. serán compras y ventas.

Figura 2. 4

\section{Mapa estratégico}

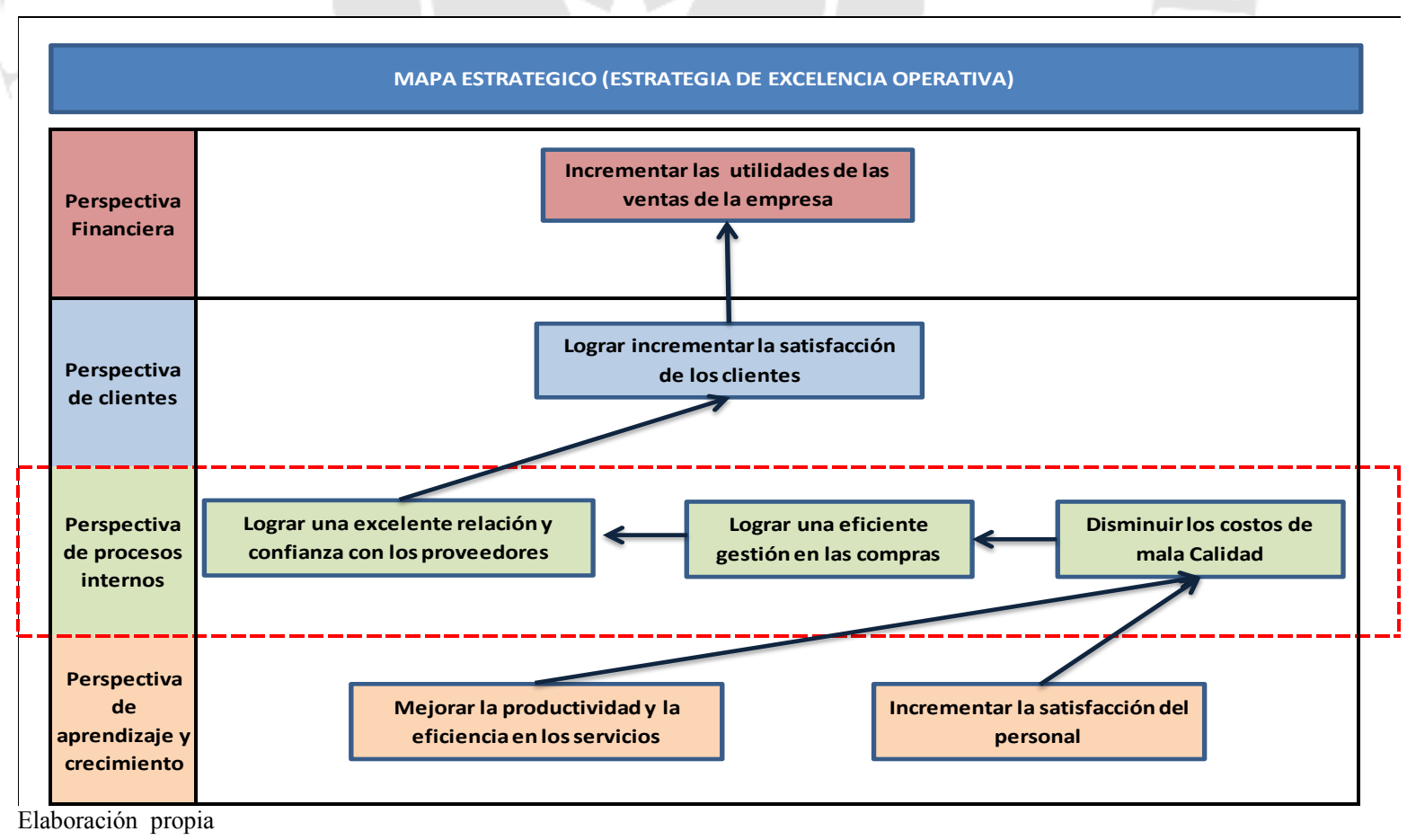




\subsubsection{Determinación y descripción del proceso}

En una organización generalmente no se toma en consideración la rentabilidad que puede generar la buena gestión de compras ya que su beneficio es intrínseco en comparación con otras funciones de producción, sin embrago, la óptima gestión de compras disminuye los costos (absolutos y relativos) de consumo, reduce el nivel de existencias, contrae los gastos en función del abastecimiento y reduce los tiempos de entrega.

En función de realizar una eficiente gestión de compras se determina que "No existe peor compra que la compra urgente o de emergencia" que finalmente genera altos costos para la empresa. Se busca por tanto, reducir al máximo los procesos logísticos haciéndolos más rápidos, sencillos, cómodos y económicos empleando los mínimos recursos posibles.

El proceso de compras es una de las bases fundamentales a nivel de la cadena de valor de la empresa, porque interviene directamente en los procesos operativos como mantenimiento y reparación de los vehículos. Todos los repuestos, suministros, y materiales deben llegar en el momento oportuno para realizar eficientemente cualquier orden de servicio, brindando un producto de calidad, a un bajo costo y con las especificaciones técnicas solicitadas por el especialista, todo esto en conjunto, para lograr obtener un óptimo resultado y alcanzar la satisfacción del cliente.

$\mathrm{Si}$ se obtiene un producto con las características antes mencionadas a un bajo costo y de alta calidad, se lo podrá ofrecer a un precio competitivo o mucho mejor que el del mercado, por consiguiente se obtiene la satisfacción del cliente y se lo fideliza. 
Al mejorar el proceso de compras se podrá reducir los costos de mala calidad y excesivos costos logísticos, minimizando los stocks, tanto en volumen como en espacio. Se espera lograr una mejora en el proceso, con el objetivo de conseguir una compra perfecta con los alcances que se detallan en la figura 2.5 .

Figura 2. 5

Compra perfecta de producto

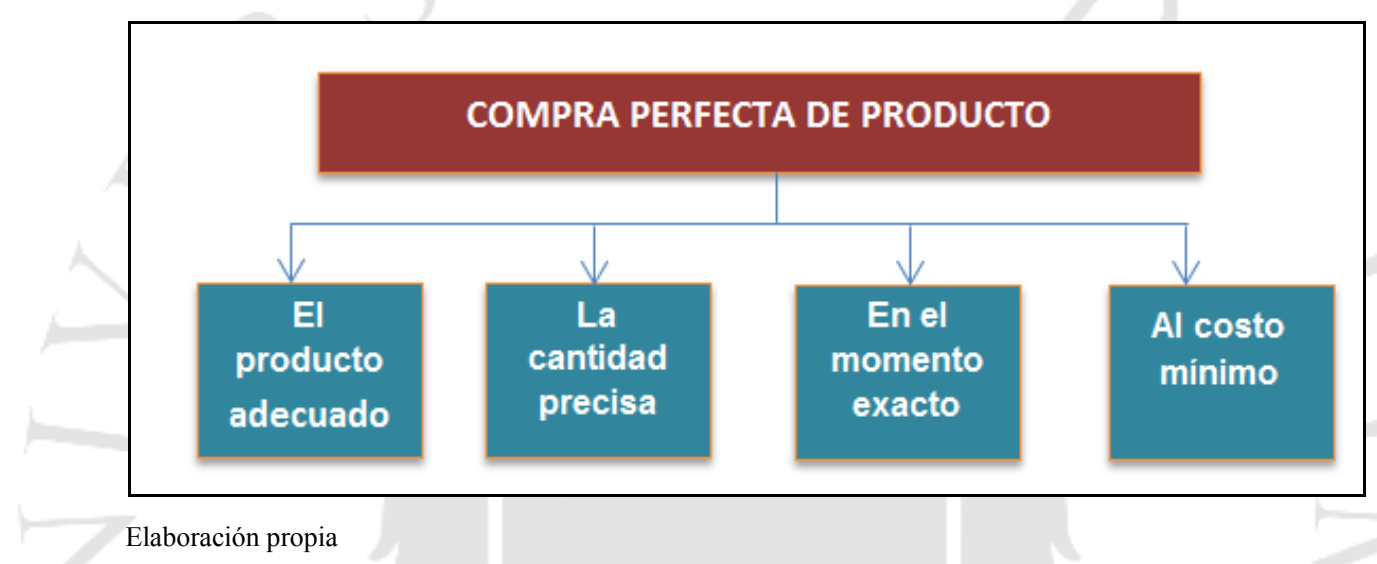

\section{Descripción del proceso de compras de repuestos:}

Las compras de los repuestos se inician con la solicitud de pedido, que puede ser emitida por el área de Ventas, Taller y Logística, de acuerdo a las necesidades de los clientes y de la empresa, las cuales son descritas en un formato específico según requerimiento del pedido.

La empresa distingue dos tipos de compras: de stock y de emergencia; La primera puede ser adquirida en el mercado local o compra internacional que en su mayoría es de gran volumen y con una lista promedio de 10 ítems como mínimo.

Las compras de repuesto de emergencia son aquellas que se requieren con urgencia para algún servicio que la empresa esté 
brindando, para este caso el área solicitante emite una solicitud de compra prioritaria dependiendo el tipo de servicio que esté brindado la empresa, reparación o mantenimiento, ya que el factor tiempo de entrega es lo más importante.

El jefe de compras revisa la solicitud de pedido, verifica los stocks, información técnica y determina cuáles son los pedidos prioritarios según el requerimiento, asignándole los códigos para compra de producto.

Para los dos casos, compra para stock o de emergencia el jefe deriva la lista de requerimiento y entrega el listado al asistente, que es el encargado de realizar la solicitud de compra y enviarla a los proveedores para su respectiva cotización; Asimismo, realiza una selección previa de proveedores, consultando como mínimo a tres. La información de los proveedores se toma de los datos históricos de compras de la empresa que han sido registrados en el sistema Winstock (sistema de control de inventarios de la empresa Laboratorio Diesel Senatinos S.A)

El comprador se contacta con los proveedores y recibe las cotizaciones según la orden de pedido, envía dicha información al jefe de compras, quien se encarga de evaluar, analizar y seleccionar al proveedor según considere la oferta la más adecuada en base a los factores, tiempo, calidad, precio y especificaciones técnicas del producto.

El comprador prepara y envía las órdenes de compra y hace el seguimiento respectivo hasta la entrega de los productos solicitados.

Sólo para las compras de emergencia, que poseen solicitud de 
prioridad, el comprador solicitará a la cajera dinero para efectuar la compra en el menor tiempo posible, ya que este tipo de compras se realizan directamente por mostrador.

Los productos solicitados llegan al área de almacén y son atendidos por el asistente de logística, quien se encarga de la inspección de los mismos según la orden de compra, factura y guía de remisión del proveedor. Asimismo, e inmediatamente después procede a registrar, inventariar y distribuir en los diferentes niveles del almacén central.

\section{Proceso de venta de repuestos}

Las ventas de repuestos se inician con el requerimiento de alguna necesidad del cliente con respecto a la falta o cambio de algún componente dañado o inoperativo que afecten directamente a su vehículo.

El proceso empieza con la solicitud de cotización, donde el cliente manifiesta que repuesto necesita, para ello la vendedora le pide algunos datos importantes del vehículo como: marca, modelo, año, modelo de motor y cilindrada, de esta forma puede determinar el código de repuesto solicitado.

Si la vendedora tiene la información necesaria para poder realizar la cotización, en cuanto al código exacto del repuesto, verifica el stock y realiza la cotización.

En el caso de que la vendedora no tenga la información necesaria del código correcto del producto solicita el apoyo al asistente de logística quien se encarga revisar el pedido y realizar la búsqueda. Esta función la realiza al ingresar a sistemas especializados (Esitronic, Datatenic, Autodata, Tecdoc, KTS600) que 
posee la empresa para determinar que código de producto requiere el cliente. El asistente de logística envía, los códigos de producto para que la vendedora realice la cotización y la entregue al cliente.

El cliente analiza la cotización y decide aceptar o rechazar la oferta. Si el cliente rechaza la oferta se concluye con la finalización del proceso, sin embargo, si el cliente aprueba la cotización, la vendedora procede a solicitar datos del cliente, generar y enviar la orden de pedido que será revisado por el asistente de logística quien inmediatamente hará la búsqueda de los repuestos según la orden de pedido.

El asistente de logística realiza la descarga del repuesto solicitado y entrega a la vendedora quien se encarga de preparar la factura o boleta según lo determine el cliente.

El cliente procede a efectuar el pago en la caja, donde la cajera realiza el cobro y sella guía de remisión y factura. Seguidamente la vendedora verifica los documentos y entrega el repuesto previamente embalado.

\subsubsection{Diagrama de procesos}

Se puede observar gráficamente a través del diagrama de flujo, los procesos de compras y ventas de repuestos como se muestra en las figuras 2.6 y 2.7 


\section{Figura 2.6}

Diagrama de flujo de proceso de compra de repuesto

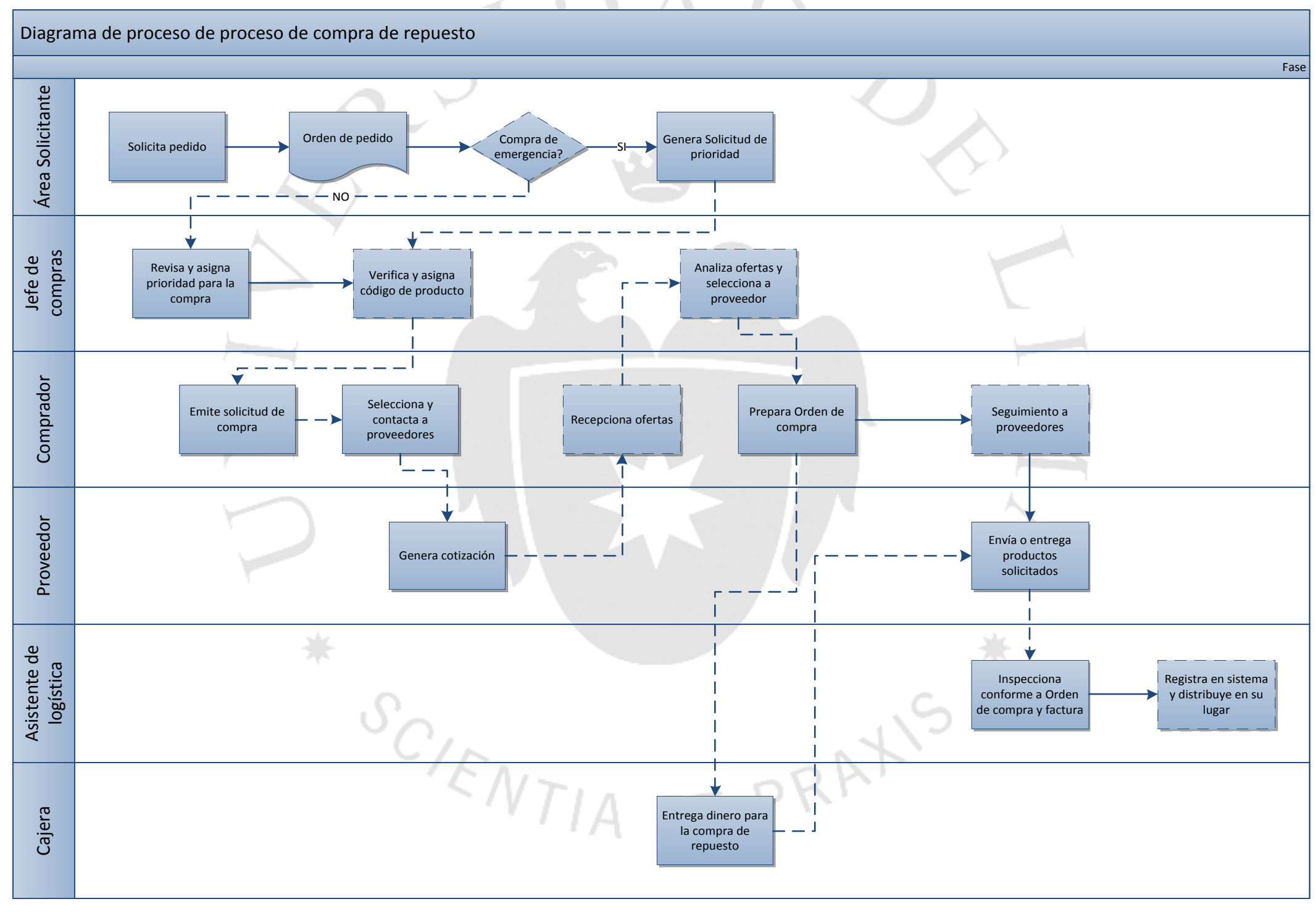


Figura 2.7

Diagrama de flujo del proceso de venta de repuesto

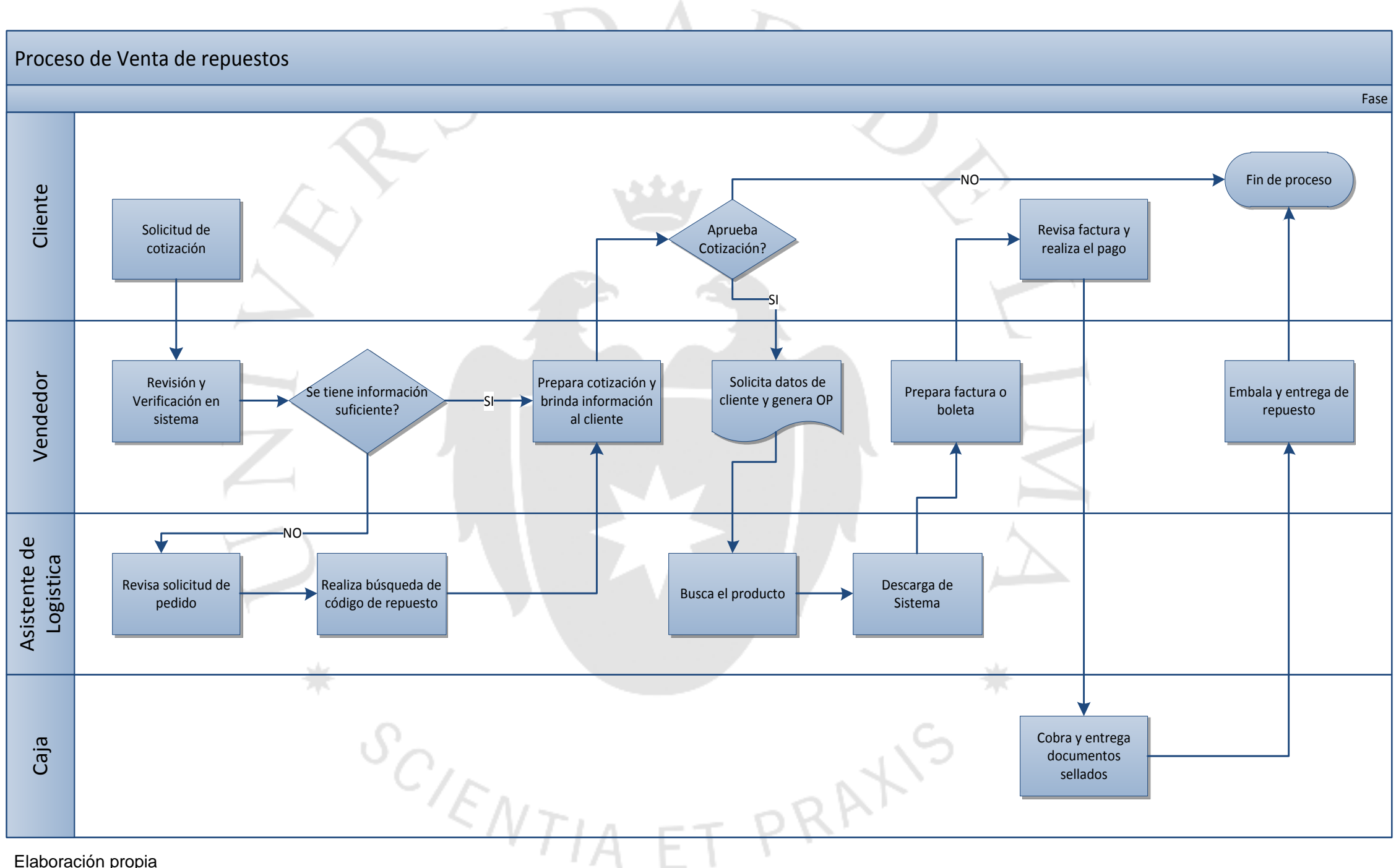




\subsection{Identificación de los principales indicadores de gestión}

Al mejorar los procesos de compras y ventas se pretende incrementar la rentabilidad global de la empresa, reduciendo costos innecesarios o por mala calidad, así como también ampliar y mejorar la estructura en las ventas. En la tabla 2.8 se puede observar los indicadores que detallan la situación actual de la empresa tomando como información un histórico del último año de trabajo de la empresa, de Enero a Diciembre 2014.

Tabla 2.8

Indicadores de gestión

\begin{tabular}{|c|c|c|c|}
\hline \multicolumn{4}{|c|}{ CUADRO DE INDICADORES } \\
\hline Objetivos & Indicadores & Unidades & $\begin{array}{l}\text { Indicador } \\
\text { Actual }\end{array}$ \\
\hline \multirow{3}{*}{$\begin{array}{l}\text { Incrementar la } \\
\text { satisfacción del } \\
\text { cliente }\end{array}$} & $\begin{array}{l}\text { Nivel de satisfacción } \\
\text { del cliente }\end{array}$ & $\%$ de satisfacción & $75,4 \%$ \\
\hline & Nivel de servicio & $\begin{array}{c}\text { (Total de entregas cumplidas al } \\
\text { cliente en los plazos pactados/ } \\
\text { total de entregas al cliente en el } \\
\text { año)*100\% }\end{array}$ & $85,4 \%$ \\
\hline & $\begin{array}{l}\% \text { de reclamos por venta } \\
\text { de repuesto }\end{array}$ & $\frac{\text { Nro. De Reclamo x rpto vendido }}{\text { Total de Repuestos vendidos }}$ & $6,82 \%$ \\
\hline \multirow{3}{*}{$\begin{array}{l}\text { Lograr un } \\
\text { eficiente sistema } \\
\text { de gestión en las } \\
\text { compras }\end{array}$} & Productividad Total & $\frac{\text { Ventas de repuestos }}{\text { Costo de ventas de repuestos }}$ & 1,247 \\
\hline & $\begin{array}{c}\text { Productividad de la mano } \\
\text { de obra }\end{array}$ & costo de la mano de obra & 9,256 \\
\hline & $\begin{array}{c}\text { Ahorro por buena gestión } \\
\text { de compras }\end{array}$ & $\frac{\text { Ahorro en costos de compras }}{\text { Total de costos de compra }}$ & $2,51 \%$ \\
\hline \multirow{2}{*}{$\begin{array}{l}\text { Lograr una } \\
\text { excelente } \\
\text { relación y } \\
\text { confianza con los } \\
\text { proveedores }\end{array}$} & $\begin{array}{l}\% \text { de cumplimiento de los } \\
\text { proveedores en la entrega } \\
\text { de las fechas establecidas }\end{array}$ & $\frac{\text { Entregas cumplidas }}{\text { Total de entregas }}$ & $79,2 \%$ \\
\hline & $\begin{array}{c}\% \text { de productos } \\
\text { defectuosos entregados } \\
\text { por los proveedores }\end{array}$ & $\stackrel{\text { Productos defectuosos }}{\text { Total de repuestos adquiridos }}$ & $2,30 \%$ \\
\hline
\end{tabular}




\subsection{Identificación de los problemas principales}

$\mathrm{La}$ identificación de los problemas principales de los procesos a mejorar, compras y ventas, se realizará utilizando la técnica "lluvia de ideas". De esta forma se logrará encontrar los problemas que limitan el óptimo resultado de los objetivos de la empresa lo que permitirá detectar oportunidades de mejora. Al utilizar la técnica lluvia de ideas lo que se podrá plantear y resolver los problemas existentes (Bonilla, E., Diaz, B., Kleeberg, F., Noriega, M. T. 2010).

Con la participación de la gerencia general, los responsables de las áreas que se interrelacionan con este proceso y el equipo de trabajo del área de compras, se realizan juntas y reuniones que facilitan el surgimiento de nuevas ideas que ayudarán a encontrar e identificar los principales problemas que intervienen en el proceso aprovechando la experiencia y capacidad creativa de los participantes.

En la primera etapa se convoca a reunión donde se tuvieron en cuenta los siguientes pasos:

1. Se define el tema en discusión: Principales problemas del proceso de compras.

2. Se fijan y mencionan los objetivos de la reunión: Reducir los costos por mala calidad e incrementar las ventas.

3. Se nombra al conductor del ejercicio: Jefe del área de logística y compras.

4. Antes de iniciar el ejercicio se explican las reglas.

- Todas las ideas de los participantes son válidas, sin críticas, no existe idea buena o mala.

- Las ideas no se deben repetir. 
- Se emiten ideas libremente sin extraer conclusiones en esta primera etapa, mientras más ideas existan, se podrá obtener un mejor resultado.

- Todas las ideas deben listarse.

- Las ideas deben ser motivadas e interrelacionarse con otras.

Para lograr el óptimo resultado de la técnica, fue necesario motivar a cada uno de los participantes generando clima de confianza, para intercambiar informaciones, tomar decisiones en común, equilibrar el grado de participación entre los miembros del grupo y obtener una idea clara entre los mismos.

\section{Principales problemas en el proceso de compras:}

- Deficiencia en la evaluación de precios al seleccionar la compra de un repuesto, la empresa sólo toma como referencia los precios históricos de la base de datos del sistema interno para realizar las comparaciones de precios. Muchos de ellos se encuentran desactualizados y provienen de proveedores que no han sido homologados.

- Excesivo tiempo en la compra de repuesto de emergencia, esto sucede cuando el servicio de una orden de trabajo depende directamente del repuesto y no es posible avanzar con el servicio en global por la falta de repuestos, materiales o insumos. De esta forma no se cumple con el tiempo de entrega establecido con el cliente, obteniendo un grado de insatisfacción.

- Compra de repuesto equivocado, se da generalmente cuando el comprador no brinda la información correcta de las especificaciones del producto, también cuando no realiza las equivalencias adecuadas 
de repuestos alternativos y solicita la compra de un producto "parecido".

- Incumplimiento de entrega de repuestos por parte del proveedor, sucede cuando el proveedor no cumple con las especificaciones de la orden compra incumpliendo en los tiempos de entrega de los repuestos.

- Demora en la selección de proveedores para la adquisición de nuevos productos, debido a que sólo se efectúa la búsqueda en la base de datos histórica de la empresa, donde sólo detalla mínima información de los proveedores muchos de los cuales no son importadores directos y realizan reventas, los precios que ofrecen son elevados. Asimismo se genera retraso en la búsqueda de nuevos proveedores lo que retrasa la compra.

- Incumplimiento de las especificaciones técnicas de productos por parte del proveedor, cuando se realiza una entrega errada de producto (dimensiones, voltaje, mecanismo, marca, código)

- Rechazo de incrementos en línea de crédito de los proveedores, a falta de constantes volúmenes de compra y retrasos en los pagos programados, los proveedores no brindan facilidades para los accesos de compra.

- Falta de información en el despiece de los sistemas en cada vehículo, la empresa realiza servicios y vende repuestos multimarca. Es necesario contar con sistemas de cada marca de vehículo en específico para encontrar el código de repuesto requerido. 
- Falta de capacitación técnica al personal de compras para la elaborar la solicitud de pedido, continuamente los compradores desconocen el producto que están solicitando en forma, tamaño, volumen y función; lo que genera equivocaciones al solicitar cotizaciones a los proveedores si el personal no está correctamente capacitado.

- Inadecuada comunicación entre las áreas de compras, ventas y almacén; reiteradas veces existen dificultades con la información de las ventas programadas, requiriéndose más tiempo para la búsqueda, cotización y negociación con proveedores y asimismo para manejar la disponibilidad de los productos.

- Falta de procedimientos y políticas de compras, no existen procedimientos específicos de los diversos tipos de compra: compra directa, por concurso, licitaciones y contrato marco.

- Capacitación limitada en negociaciones con proveedores, los compradores desconocen técnicas de negociación para discutir con los proveedores en cuanto a precios, líneas de crédito, promociones, tabla de comparaciones de precios y beneficios para la toma de decisiones de compra y adquirir una compra efectiva.

- Autoridad limitada para la decisión de compra, No existe una persona encargada (comprador) con autoridad para realizar una compra de un repuesto menor, dependiendo siempre de la respuesta de jefe de compras o de la gerencia, ocasionando siempre retrasos en la adquisición de repuestos.

\section{Principales problemas en el área de ventas:}


- Falta de estrategias de venta de repuestos, los vendedores no brindan información detallada de los productos a los clientes, sus bondades, beneficios y opciones de marcas de producto.

- Inestabilidad de los precios en las ventas de repuestos de emergencia, los precios que se brindan a los clientes son inestables, debido a que se están en función a un porcentaje para determinar el margen respecto al costo de compra del producto.

- Falta de seguimiento de ventas realizadas, no hay un control del servicio post venta, no existe una recopilación de información de la satisfacción del cliente después que este adquirió el producto.

- Los objetivos y las metas de ventas no están claras, no existe un plan con metas de ventas. Todas las ventas se realizan en mostrador y sólo se espera que el cliente llegue a solicitar un producto. El vendedor no tiene objetivos de ventas mensuales, ni comisiones por venta.

- Venta de repuesto equivocado, por lo general se vende un producto equivocado cuando un cliente interno o externo, no brinda la información correcta de lo que requiere. También, cuando el cliente desea un repuesto que sea muy similar a las especificaciones técnicas de lo que realmente busca.

- Excesivo tiempo en la venta de un repuesto de emergencia, por lo general sucede con los productos que no se tienen en stock, para atender un servicio específico de un vehículo.

- Falta de planificación en presupuestos de costos de venta, no se realiza un plan para determinar cuáles serán los gastos en 
promociones, publicidad y otros que refieren al área, así como tampoco se define cuáles son las metas de ganancias esperadas.

- Inadecuada comunicación entre las áreas de ventas, compras y almacén, no existe una comunicación efectiva entre el área de ventas y compras dificultando la finalización del proceso de venta de un producto al no contar/con los stocks y precios actualizados, y la información de las aplicaciones de marca de vehículo de cada producto.

- Falta de políticas de venta, los procesos no están bien definidos, no existen rangos claros de cuáles son los límites y máximos precios que se les puede brindar a un cliente en la venta de un repuesto.

En base a la lista de problemas de los procesos compras y ventas se utilizará la metodología de mejora continua (KAIZEN) para determinar cuáles son los principales problemas y que oportunidades de mejora se aplicarían mejor para llegar a la solución.

Para la evaluación de los problemas planteados e ir filtrando poco a poco los problemas principales fue necesario establecer criterios de evaluación, que fueron minuciosamente analizados por la gerencia y la jefatura del área de los procesos de compras y ventas. De esta forma se pretende determinar si la implementación de mejora y solución del problema es viable con la utilización de los recursos que posee la empresa, buscando además que pueda ser medible para su comparación en el tiempo y que implique un ahorro o disminución de costos buscando que puedan intervenir todos los integrantes del proceso para que sean parte de la implementación piloto.

Por ello se determinaron los semáforos de validación de problemas en 
función de:

1. El problema puede ser cuantificado.

2. El análisis y la solución del problema dependen mayormente del área de compras.

3. La solución es sencilla o medianamente compleja.

4. La inversión a realizar es mínima o el ratio beneficio costo es aceptable.

Con el resultado de la evaluación de problemas del proceso de compras, se determinó que de los 13 encontrados sólo 10 problemas son viables para hacer el diagnóstico de implementación de mejora, como se aprecia en la tabla 2.9.

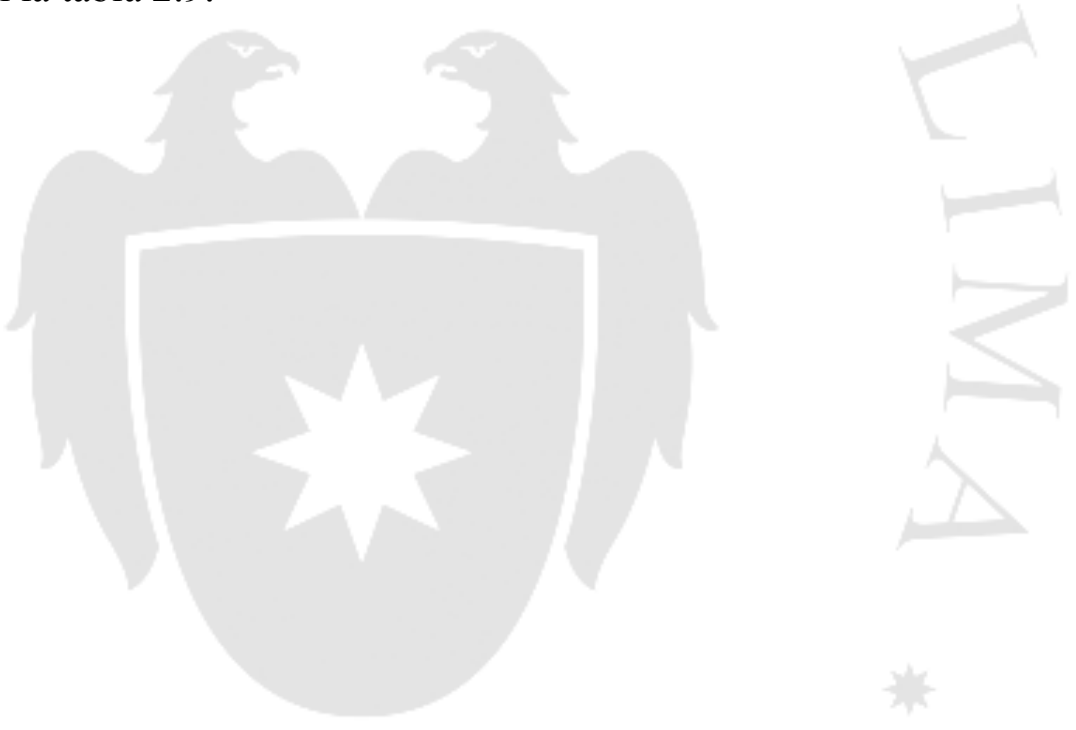




\section{Tabla 2.9}

Matriz para la validación del problema principal en el proceso de compras

\begin{tabular}{|c|c|c|c|c|c|c|}
\hline Nro. & Lista de problemas u oportunidades de mejora & $\begin{array}{c}\text { El problema } \\
\text { puede } \\
\text { ser cuantificado }\end{array}$ & $\begin{array}{l}\text { El análisis y la } \\
\text { solución del } \\
\text { problema } \\
\text { dependen } \\
\text { mayormente del } \\
\text { área de Compras }\end{array}$ & $\begin{array}{c}\text { La solución } \\
\text { es } \\
\text { sencilla o } \\
\text { mediamente } \\
\text { compleja }\end{array}$ & $\begin{array}{l}\text { La inversión a } \\
\text { realizar es } \\
\text { mínima o el } \\
\text { ratio beneficio/ } \\
\text { costo es } \\
\text { aceptable }\end{array}$ & $\begin{array}{l}\text { Semáforo de } \\
\text { validación } \\
\text { (Problema) }\end{array}$ \\
\hline 1 & $\begin{array}{l}\text { Deficiencia en la evaluación de precios, al seleccionar la } \\
\text { compra de un repuesto. }\end{array}$ & SI & SI & SI & SI & SI \\
\hline 3 & Compra de repuesto equivocado & SI & SI & SI & SI & SI \\
\hline 4 & Incumplimiento de entrega de repuestos por parte del proveedor & SI & SI & SI & SI & SI \\
\hline 5 & $\begin{array}{l}\text { Demora en la selección de proveedores para la adquisición de } \\
\text { nuevos productos }\end{array}$ & SI & SI & SI & SI & SI \\
\hline 6 & $\begin{array}{l}\text { Se recepciona productos que no cumple requerimientos } \\
\text { técnicos. }\end{array}$ & SI & SI & SI & SI & SI \\
\hline 9 & $\begin{array}{l}\text { Falta de capacitación técnica al personal de compras para la } \\
\text { elaborar la solicitud de pedido. }\end{array}$ & SI & SI & SI & SI & SI \\
\hline 10 & $\begin{array}{l}\text { Inadecuada comunicación entre las áreas de compras, ventas y } \\
\text { almacén }\end{array}$ & SI & NO & SI & SI & NO \\
\hline 11 & Falta de procedimientos y políticas de compras & SI & SI $\mathrm{C}_{\text {- }}$ & SI & SI & SI \\
\hline 12 & Capacitación Limitada en negociaciones con proveedores & SI & SI & SI & SI & SI \\
\hline 13 & Autoridad limitada para la decisión de compra $/ / T / A$ & SI & NO & SI & SI & NO \\
\hline
\end{tabular}


De manera similar al proceso de compras se realizó la validación de la lista de problemas del proceso de ventas. En base a los semáforos de validación, clasificaron 7 de los 9 problemas encontrados, como se muestra en la tabla 2.10.

Tabla 2. 10

Matriz para la validación de problema principal en el proceso de ventas

\begin{tabular}{|c|c|c|c|c|c|c|}
\hline \multicolumn{7}{|c|}{ MATRIZ PARA LA VALIDACIÓN DE PROBLEMAS DEL PROCESO DE VENTAS } \\
\hline Nro. & $\begin{array}{l}\text { Lista de problemas u oportunidades } \\
\text { de mejora }\end{array}$ & $\begin{array}{l}\text { El problema } \\
\text { puede } \\
\text { ser } \\
\text { cuantificado }\end{array}$ & $\begin{array}{l}\text { El análisis y la } \\
\text { solución del } \\
\text { problema } \\
\text { dependen } \\
\text { mayormente del } \\
\text { área de Ventas }\end{array}$ & $\begin{array}{l}\text { La solución es } \\
\text { sencilla o } \\
\text { mediamente } \\
\text { compleja }\end{array}$ & $\begin{array}{l}\text { La inversión a } \\
\text { realizar es } \\
\text { mínima o el } \\
\text { ratio } \\
\text { beneficio/ } \\
\text { costo es } \\
\text { aceptable }\end{array}$ & $\begin{array}{c}\text { Semáforo de } \\
\text { validación } \\
\text { (Problema) }\end{array}$ \\
\hline 1 & Falta de estrategias de venta de repuestos & SI & SI & SI & SI & SI \\
\hline 2 & $\begin{array}{l}\text { Inestabilidad de los precios en las ventas de repuestos de } \\
\text { emergencia }\end{array}$ & SI & NO & SI & SI & NO \\
\hline 3 & Falta de seguimiento ventas realizadas & SI & SI & SI & SI & SI \\
\hline 4 & Los objetivos y las metas de ventas no están claras & SI & SI & SI & SI & SI \\
\hline 5 & Venta de repuesto equivocado & SI & SI & SI & SI & SI \\
\hline 6 & Excesivo tiempo en la venta de un repuesto de emergencia & SI & NO & NO & SI & NO \\
\hline 7 & Falta de planificación en presupuestos de costos de venta & SI & SI & SI & SI & SI \\
\hline 8 & $\begin{array}{l}\text { Inadecuada comunicación entre las áreas de ventas, compras } \\
\text { y almacén }\end{array}$ & SI & SI & SI & SI & SI \\
\hline 9 & Falta de políticas de venta & SI & SI & SI & SI & SI \\
\hline
\end{tabular}


Una vez preparada la matriz de validación de los problemas, el siguiente paso es detectar cuáles son los criterios prioritarios, los que una vez resueltos o mejorados puedan lograr algunos de los objetivos de la organización. De esta forma los criterios primordiales son:

- Impacto en la satisfacción de los clientes, con la finalidad que al resolver el problema el cliente sea directamente beneficiado y se compruebe el cambio, obteniendo la satisfacción del mismo.

- Ahorro en costos, se pretende disminuir los costos por mala calidad y detallar la magnitud de la implicancia en los resultados de la empresa.

- Complejidad de la solución, deben existir métodos y formas sencillas de operar para llegar al resultado de una manera rápida y eficaz.

- Alineamiento con los objetivos de la organización, la implementación de la solución tiene que reflejarse en los indicadores de gestión y estar alineada con los objetivos de la empresa.

- Tiempo estimado de la implementación de la solución mínimo, con el compromiso de la gerencia y los participantes del proceso se debe tomar conciencia que el resultado debe ser ejecutado en el menor tiempo posible.

Para determinar la ponderación de cada factor es necesario utilizar la matriz de ponderación de criterios. Aplicando valores subjetivos pero obtenidos de manera colectiva, se verificará que criterio es el que más influye de manera sistémica sobre el conjunto. Se tomarán las siguientes consideraciones para el análisis de cada factor:

$\checkmark \quad$ La lectura se lee en forma horizontal, "influye sobre" 
El total más alto es de mayor influencia o importancia

Ninguna relación: 0

Poca relación: 1

Bastante relación: 2

Mucha relación: 3

Con la elaboración de la matriz de enfrentamiento para la ponderación de criterios (ver tabla 2.11) podemos concluir que los criterios más importantes son el impacto en la satisfacción del cliente y el ahorro en costo con un porcentaje de $33 \%$ y $30 \%$ respectivamente.

Tabla 2.11

Matriz enfrentamiento para la ponderación de criterios

\begin{tabular}{|c|c|c|c|c|c|c|c|c|}
\hline CRITERIOS & 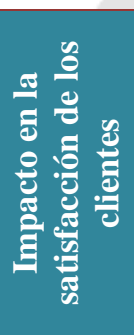 & 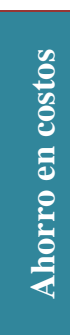 & 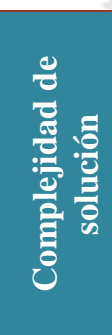 & 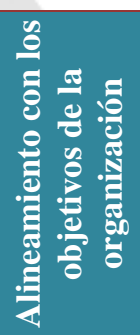 & 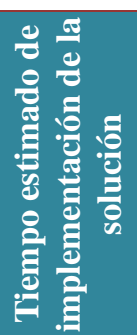 & हैं & 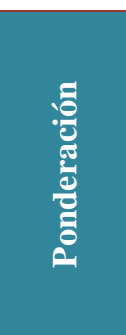 & 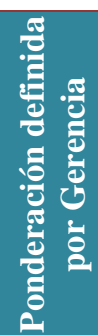 \\
\hline $\begin{array}{l}\text { Impacto en la satisfacción } \\
\text { de los clientes }\end{array}$ & & 2 & 3 & 3 & 2 & 10 & $33,33 \%$ & $33 \%$ \\
\hline Ahorro en costos & 2 & & 2 & 3 & 2 & 9 & $30,00 \%$ & $30 \%$ \\
\hline Complejidad de solución & 0 & 1 & & 2 & 2 & 5 & $16,67 \%$ & $17 \%$ \\
\hline $\begin{array}{l}\text { Alineamiento con los } \\
\text { objetivos de la organización }\end{array}$ & 0 & 1 & 1 & & 2 & 4 & $13,33 \%$ & $13 \%$ \\
\hline $\begin{array}{l}\text { Tiempo estimado de } \\
\text { implementación de la } \\
\text { solución }\end{array}$ & 0 & 0 & 1 & & & 2 & $6,67 \%$ & $7 \%$ \\
\hline Totales & 7 & $\angle$ & $=$ & & & 30 & $100 \%$ & $100 \%$ \\
\hline
\end{tabular}

Elaboración propia

Finalmente para obtener el problema principal del proceso de compras de repuestos es necesario elaborar la tabla para la calificación de criterios, que está diseñada en función al impacto que causa la solución del problema con respecto al criterio. 
La escala de cada impacto fue determinada por la gerencia general que va de 0 a 90 en base a cuanto puede repercutir la solución del problema en función al criterio determinado, como se muestra en la tabla 2.12 .

Mientras mayor calificación se le otorgue a un problema, la solución será más favorable para el criterio.

Tabla 2.12

Tabla para la calificación de criterios

\begin{tabular}{|c|c|}
\hline \multicolumn{2}{|c|}{ Tabla de calificación de criterios } \\
\hline Impacto & Escala \\
\hline Nada & 0 \\
\hline Poco & 10 \\
\hline Regular & 40 \\
\hline Mucho & 90 \\
\hline
\end{tabular}

Elaboración propia

Por último lugar se elabora una nueva tabla de selección de problema a principal, con los resultados de la matriz de validación de problemas y la matriz de enfrentamiento para la ponderación de criterios, de esta forma se realiza un análisis minucioso y se otorga una calificación a cada problema en base al impacto de solución a los criterios.

De esta forma como lo indica la tabla 2.13. El principal problema para el proceso de compras de repuestos, es la deficiencia en la evaluación de precios al seleccionar la compra de un repuesto con un puntaje de 62 , seguido del problema, excesivo tiempo en la compra de repuesto de emergencia con un puntaje de 57. 
Tabla 2.13

Matriz de selección del problema principal del proceso de compras

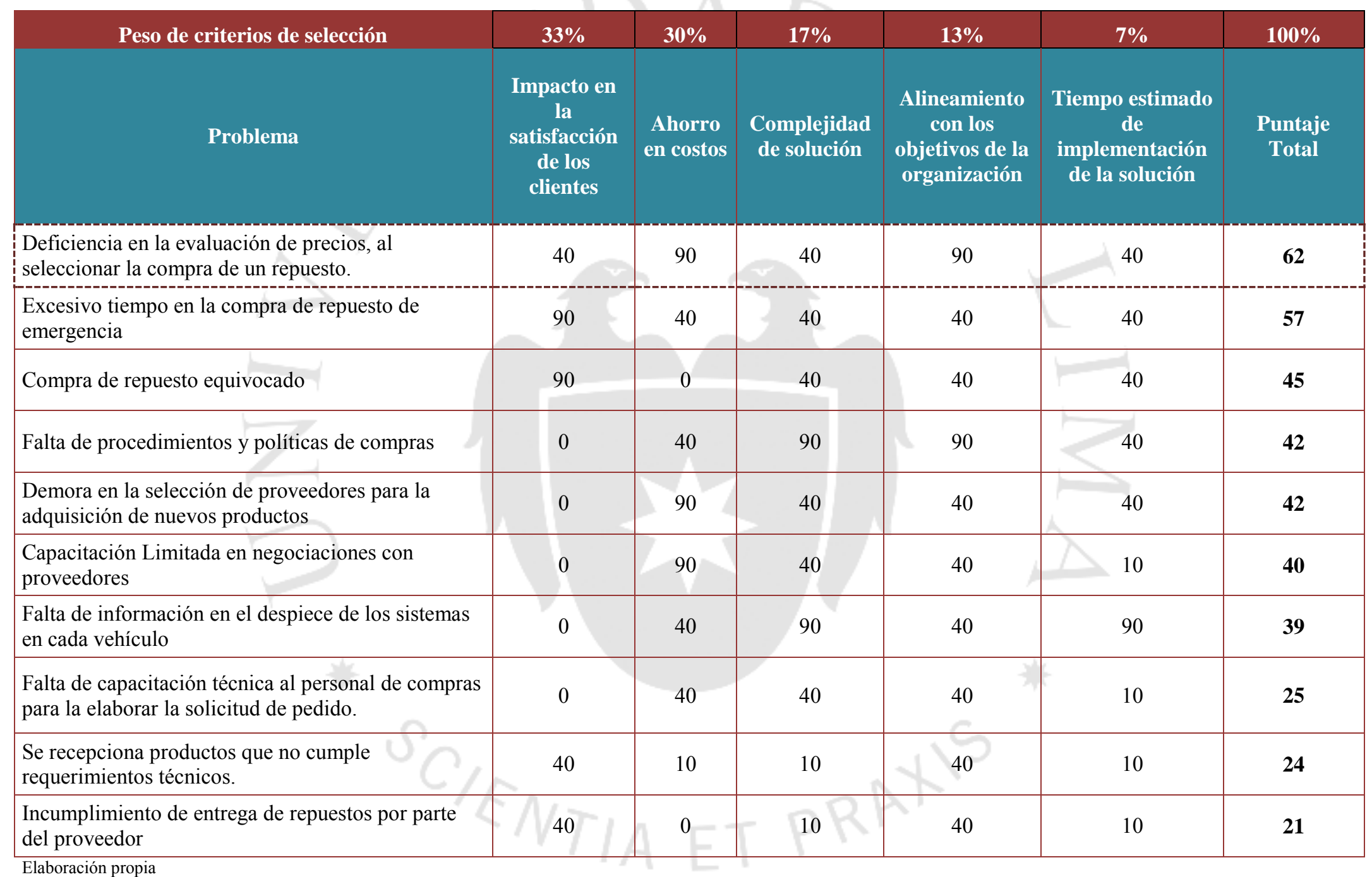

Elaboración propia 
Aplicando los mismos criterios para la determinación del problema principal del proceso compras, se muestra en la tabla 2.14 para la selección del problema principal del proceso de ventas, siendo la falta de estrategias de venta de repuestos con un puntaje de 63 , seguido por la falta de seguimiento de ventas realizadas con 52 puntos.

Tabla 2.14

Matriz de selección del problema principal del proceso de ventas

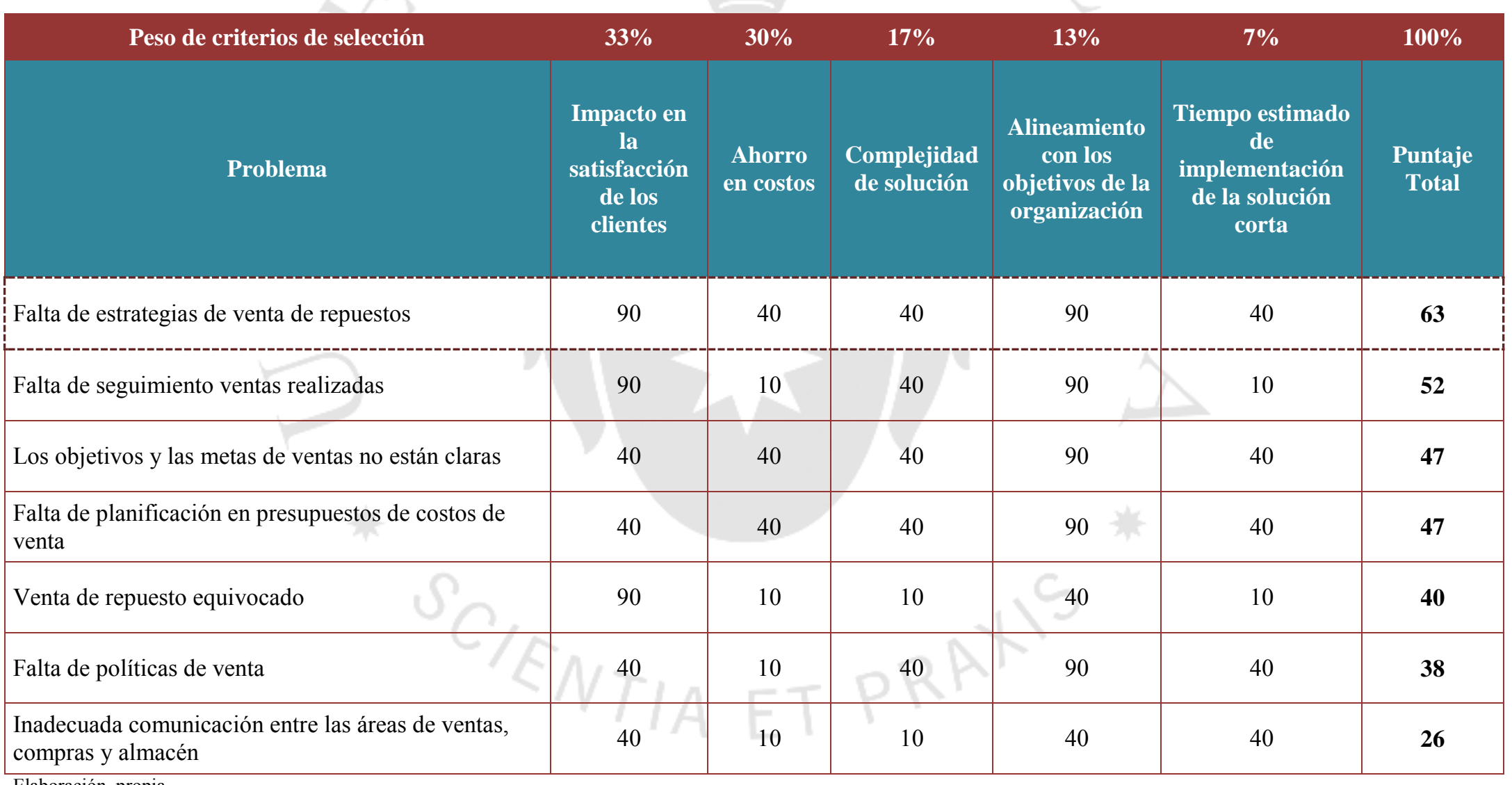




\section{CAPÍTULO III: DIAGNÓSTICO DE LA EMPRESA}

\subsection{Determinación de las causas raíces de los problemas seleccionados}

Una vez hallado el principal problema, el siguiente paso es comprenderlo en su totalidad, determinar cuáles son los objetivos que se espera lograr al solucionarlo, el impacto que genera en todo el proceso y las limitaciones que acarrea para la buena gestión de la empresa.

Para la evaluación de todas las cusas raíces de los problemas seleccionados, tanto para el proceso de compras como para el proceso de ventas, se utilizó la herramienta "Diagrama de Ishikawa análisis Causa Efecto" como se muestra en las figuras 3.1 "Deficiencia en la evaluación de precios al seleccionar la compra del repuesto" y 3.2 "Falta de estrategias en la venta de repuestos" respectivamente. 


\section{Figura 3.1}

Diagrama de Ishikawa - Causa efecto

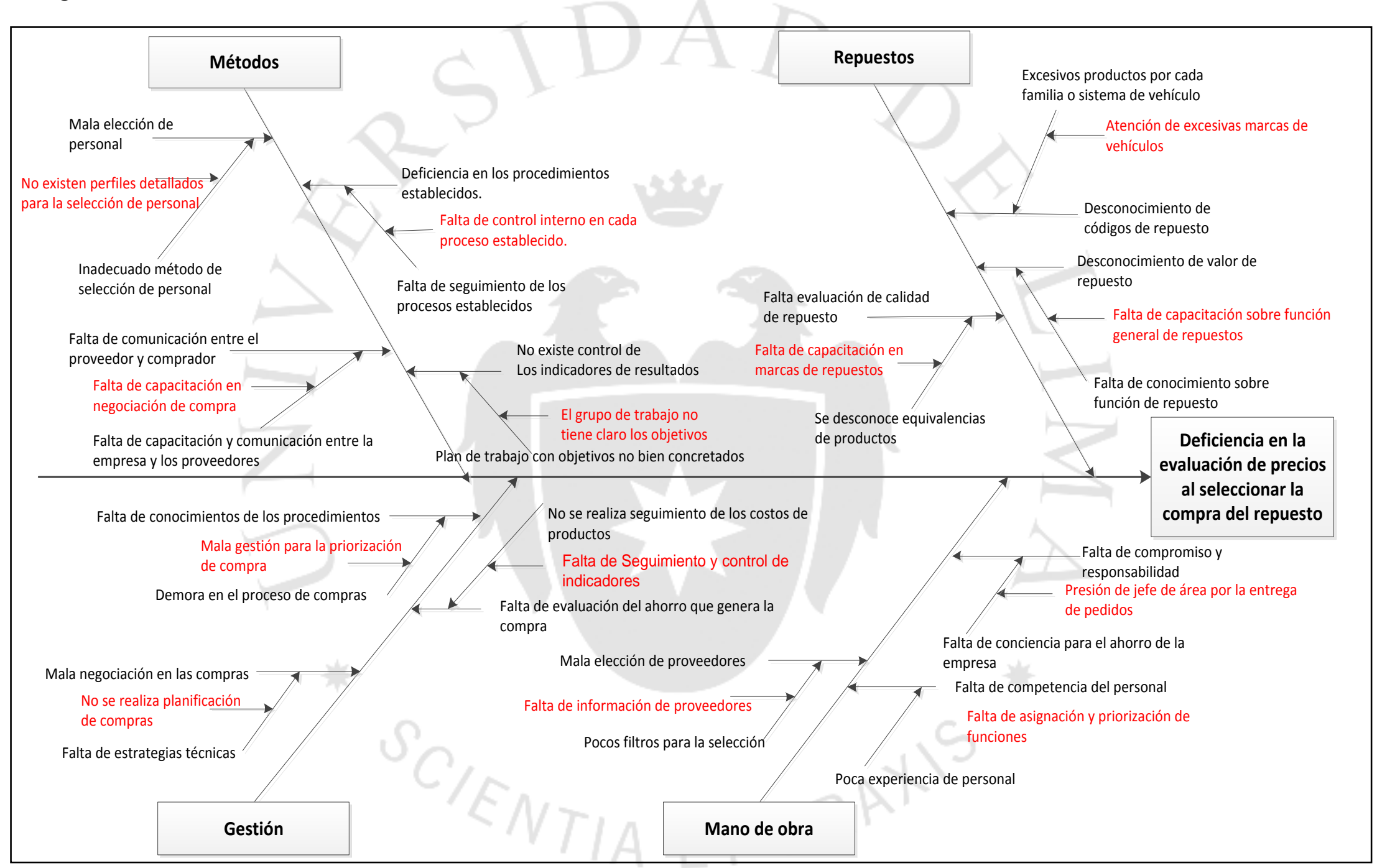

Elaboración propia 
Figura 3.2

Diagrama de Ishikawa - Causa Efecto

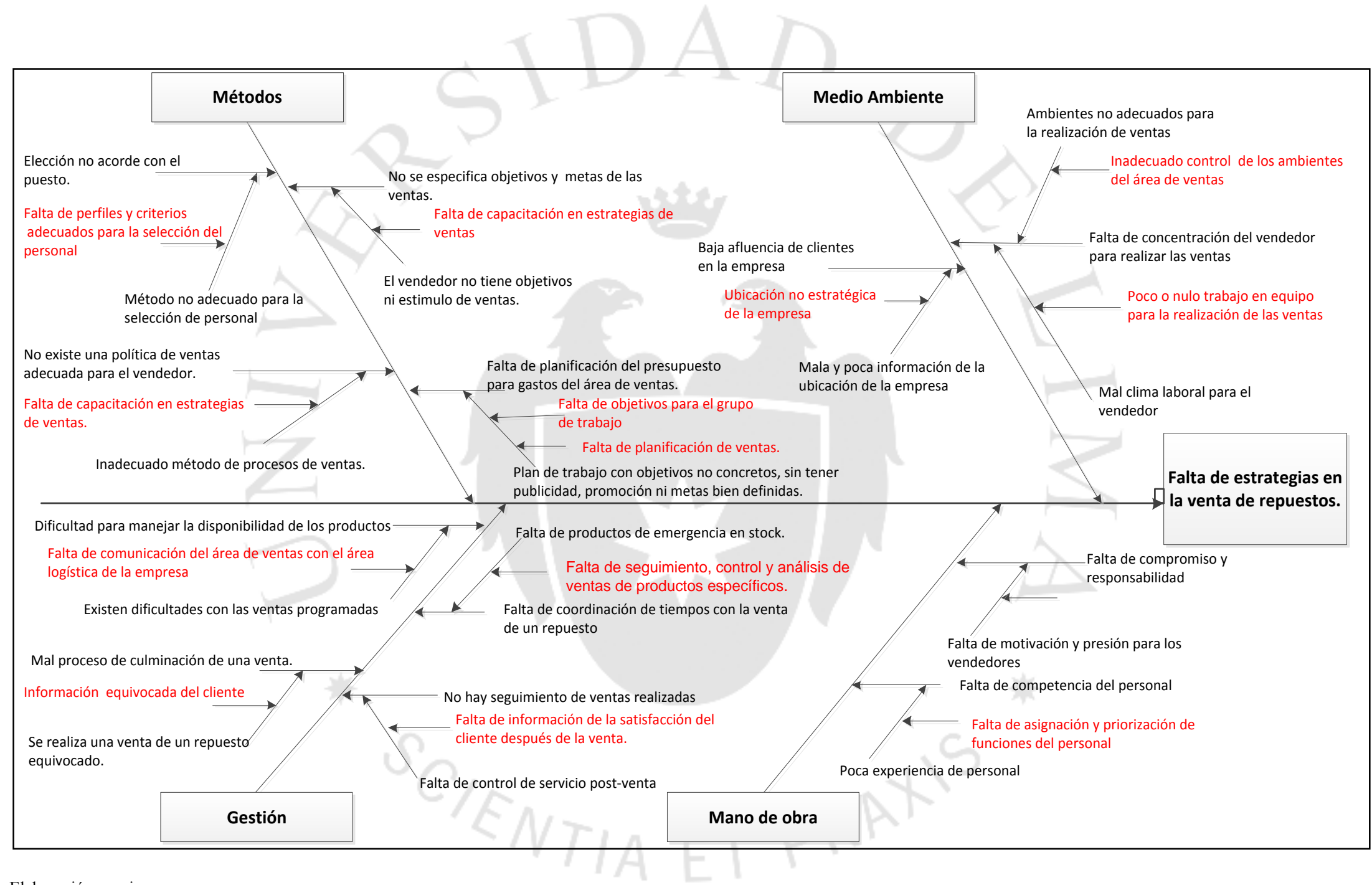

Elaboración propia 
Con la elaboración del diagrama de Ishikawa se observó cuáles son las causas raíz de los problemas principales de los procesos del área de compras y de ventas. Asimismo, es necesario clasificar y determinar cuáles son las principales causas que generan mayor impacto al problema encontrado, para ello es necesario realizar un análisis de criticidad de todas estas causas raíz.

Para hacer el análisis de criticidad se reunió a los principales responsables del área que se encargaron de evaluar cada una de las causas según la frecuencia e impacto que generan (Ver tabla 3.1).

De esta manera se utiliza la herramienta de Pareto, con la clasificación de los valores ponderados de mayor a menor y sus respectivos acumulados como se observa en la tabla 3.2.

Tabla 3. 1: Evaluación de frecuencia e impacto de la causa raíz

\begin{tabular}{|l|c||c|c|}
\hline \multicolumn{2}{|c|}{ Tabla de evaluación de frecuencia } & \multicolumn{2}{c|}{ Tabla de evaluación de impacto } \\
\hline \multicolumn{1}{|c|}{ Frecuencia } & Puntaje & \multicolumn{1}{c|}{ Impacto } & Puntaje \\
\hline Muy Frecuente & 10 & Muy alto impacto & 12 \\
\hline Frecuente & 5 & Alto Impacto & 9 \\
\hline Poco frecuente & 1 & Impacto Medio & 3 \\
\hline \multicolumn{2}{|l}{} \\
& Bajo Impacto & 1 \\
\hline
\end{tabular}




\section{Tabla 3.2}

Tabla de frecuencias de Pareto de las causas raíces de Deficiencia en la evaluación de precios al seleccionar la compra de un repuesto.

\begin{tabular}{|c|l|c|c|c|c|c|}
\hline Nro. & Principales Causas & Frec. & Impacto & $\begin{array}{c}\text { Efecto } \\
\text { de }\left(F^{*} \text { i) }\right.\end{array}$ & $\begin{array}{c}\text { Frec. } \\
\%\end{array}$ & $\begin{array}{c}\% \\
\text { acumulado }\end{array}$ \\
\hline 1 & $\begin{array}{l}\text { Falta de información para la búsqueda de } \\
\text { proveedores }\end{array}$ & 10 & 12 & 120 & $29,7 \%$ & $29,70 \%$ \\
\hline 2 & Atención de excesivas marcas de vehículos & 10 & 12 & 120 & $29,7 \%$ & $59,41 \%$ \\
\hline 3 & $\begin{array}{l}\text { El grupo de trabajo no tiene claro los objetivos } \\
\text { y metas }\end{array}$ & 10 & 9 & 90 & $22,3 \%$ & $81,68 \%$ \\
\hline 4 & Falta de seguimiento y control de indicadores & 5 & 3 & 15 & $3,7 \%$ & $85,40 \%$ \\
\hline 5 & $\begin{array}{l}\text { Falta de capacitación en la negociación de } \\
\text { compras }\end{array}$ & 5 & 3 & 15 & $3,7 \%$ & $89,11 \%$ \\
\hline 6 & Falta de asignación y priorización de funciones & 5 & 3 & 15 & $3,7 \%$ & $92,82 \%$ \\
\hline 7 & $\begin{array}{l}\text { No existen perfiles detallados para la selección } \\
\text { del personal }\end{array}$ & 1 & 9 & 9 & $2,2 \%$ & $95,05 \%$ \\
\hline 8 & $\begin{array}{l}\text { Falta de control interno de cada proceso } \\
\text { establecido }\end{array}$ & 5 & 1 & 5 & $1,2 \%$ & $96,29 \%$ \\
\hline 9 & $\begin{array}{l}\text { Falta de capacitación en función general de } \\
\text { repuestos. }\end{array}$ & 5 & 1 & 5 & $1,2 \%$ & $97,52 \%$ \\
\hline 10 & Falta de capacitación en marcas de repuestos & 5 & 1 & 5 & $1,2 \%$ & $98,76 \%$ \\
\hline 11 & Mala gestión en la priorización de compras & 1 & 3 & 3 & $0,7 \%$ & $99,50 \%$ \\
\hline 12 & No se realiza planificación de compras & 1 & 1 & 1 & $0,2 \%$ & $99,75 \%$ \\
\hline 13 & $\begin{array}{l}\text { Presión de jefe de área por la entrega de } \\
\text { pedidos }\end{array}$ & 1 & 1 & 1 & $0,2 \%$ & $100,00 \%$ \\
\hline & & 64 & & 404 & $100 \%$ & \\
\hline
\end{tabular}

Con el resultado del análisis de criticidad de las causas raíces, se puede determinar que existen dos principales causas que son determinantes para la solución del problema principal hallado, siendo las causas ( $\left.\begin{array}{lll}1 & \text { y } & 2\end{array}\right)$ responsables de 59,41\% del problema del proceso de compras "Deficiencia en la evaluación de precios, al seleccionar la compra de un repuesto" y “Atención de excesivas marcas de vehículos" (ver Figura 3.3)

De la misma forma al realizar el diagrama de Pareto (ver Figura 3.4) se puede determinar que las principales causas raíces del problema del proceso de ventas son, "Falta de capacitación en estrategias de ventas" e "Inexistencia de funciones para los vendedores", con un porcentaje acumulado de $69,57 \%$ respectivamente. 
Figura 3.3

Diagrama de Pareto de las causas raíces en la deficiencia de la evaluación de precios al seleccionar la compra de un repuesto.

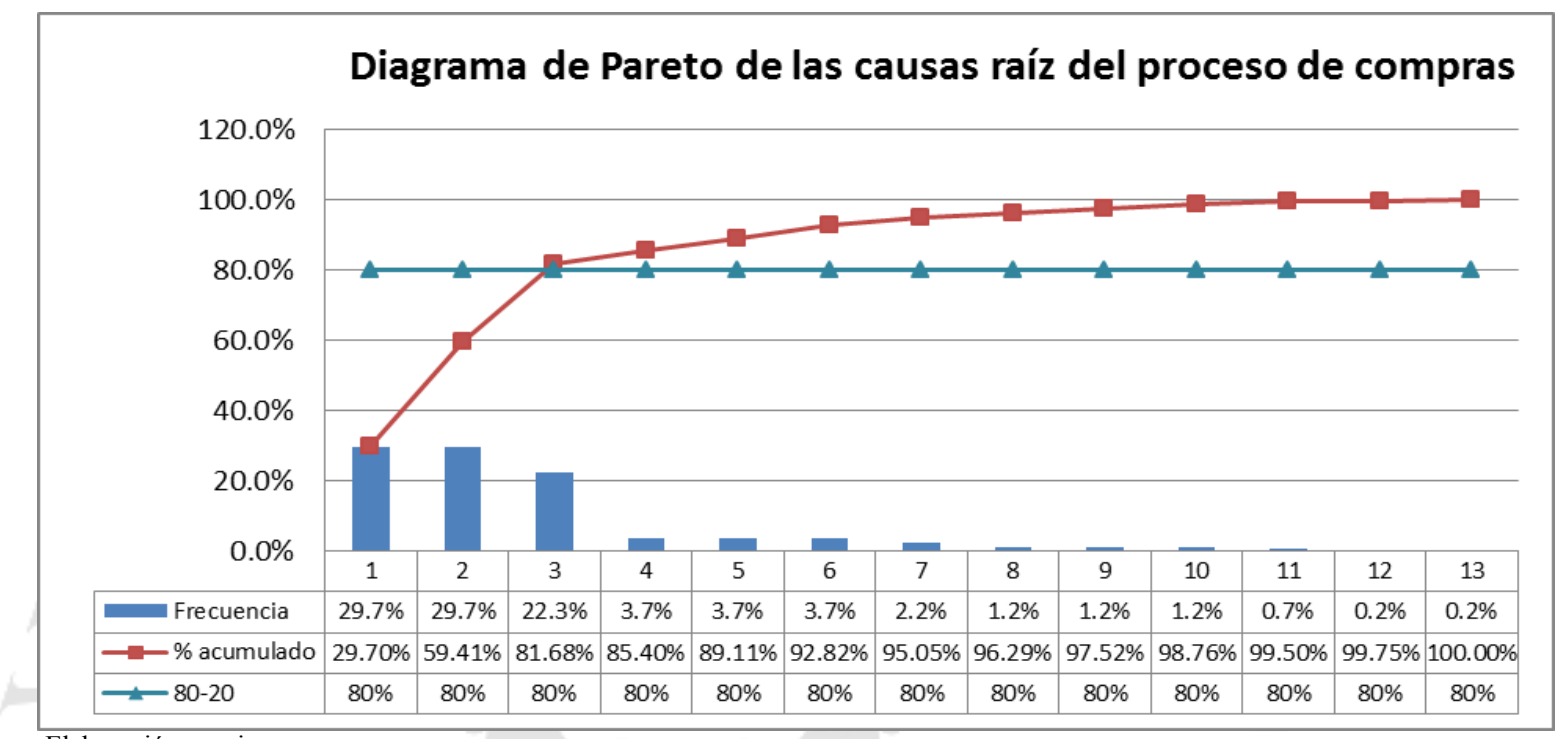

Elaboración propia

Tabla 3.3

Tabla de frecuencias de Pareto - Falta de estrategias en la venta de repuestos

\begin{tabular}{|c|l|c|c|c|c|c|}
\hline Nro. & \multicolumn{1}{|c|}{ Principales Causas } & $\begin{array}{c}\text { Frec } \\
\text { Impacto }\end{array}$ & $\begin{array}{c}\text { Efecto } \\
\text { de }\left(F^{*} \text { ) }\right.\end{array}$ & Frec. \% & $\begin{array}{c}\% \\
\text { acumulado }\end{array}$ \\
\hline 1 & Falta capacitación de estrategias de ventas. & 10 & 12 & 120 & $34,8 \%$ & $34,78 \%$ \\
\hline 2 & $\begin{array}{l}\text { No existen funciones definidas para los } \\
\text { vendedores. }\end{array}$ & 10 & 12 & 120 & $34,8 \%$ & $69,57 \%$ \\
\hline 3 & Falta de planificación de ventas & 5 & 9 & 45 & $13,0 \%$ & $82,61 \%$ \\
\hline 4 & Falta de objetivos para el grupo de trabajo. & 1 & 9 & 9 & $2,6 \%$ & $85,22 \%$ \\
\hline 5 & $\begin{array}{l}\text { Poco o nulo trabajo en equipo para la realización } \\
\text { de las ventas. }\end{array}$ & 1 & 9 & 9 & $2,6 \%$ & $87,83 \%$ \\
\hline 6 & $\begin{array}{l}\text { Falta de comunicación del área de ventas con el } \\
\text { área logística de la empresa }\end{array}$ & 1 & 9 & 9 & $2,6 \%$ & $90,43 \%$ \\
\hline 7 & $\begin{array}{l}\text { Falta de seguimiento, control y análisis de ventas } \\
\text { de productos específicos. }\end{array}$ & 1 & 9 & 9 & $2,6 \%$ & $93,04 \%$ \\
\hline 8 & Falta de motivación y presión para los vendedores. & 1 & 9 & 9 & $2,6 \%$ & $95,65 \%$ \\
\hline 9 & Ubicación no estratégica de la empresa. & 1 & 3 & 3 & $0,9 \%$ & $96,52 \%$ \\
\hline 10 & $\begin{array}{l}\text { Inadecuado control de los ambientes del área de } \\
\text { ventas. }\end{array}$ & 1 & 3 & 3 & $0,9 \%$ & $97,39 \%$ \\
\hline 11 & Información equivocada del cliente. & 1 & 3 & 3 & $0,9 \%$ & $98,26 \%$ \\
\hline 12 & $\begin{array}{l}\text { Falta de información de la satisfacción del cliente } \\
\text { después de la venta.. }\end{array}$ & 1 & 3 & 3 & $0,9 \%$ & $99,13 \%$ \\
\hline 13 & $\begin{array}{l}\text { Falta de asignación y priorización de funciones del } \\
\text { personal. }\end{array}$ & 1 & 3 & 3 & $0,9 \%$ & $100,00 \%$ \\
\hline
\end{tabular}


Figura 3. 4

Diagrama de Pareto de las causas raíces en la falta de estrategias en la venta de repuestos.

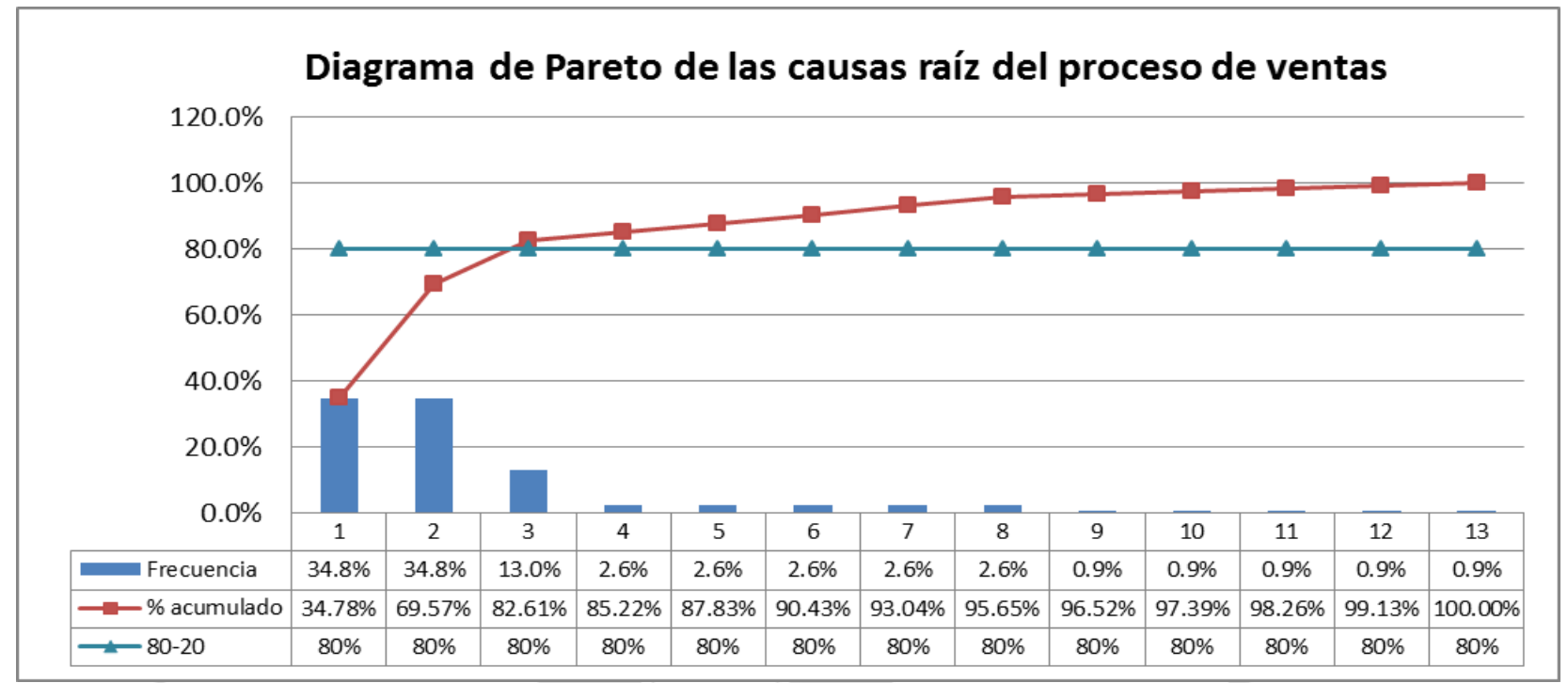

Elaboración propia

\subsection{Diagnóstico de los problemas principales}

\subsubsection{Planificación del diagnóstico}

\section{Objetivo y pronóstico}

Realizar una evaluación empresarial con base en la mejora de los procesos de compras y ventas, con el objetivo de reducir los costos de no calidad, realizar una efectiva gestión de compras y la utilización de estrategias para el incremento de las ventas, con la finalidad de maximizar la rentabilidad de la empresa Laboratorio Diesel Senatinos S.A.

\section{Método de diagnóstico}

El método de diagnóstico se realizará en función de la evaluación y recopilación de la información histórica de los montos y volúmenes de compras y ventas, principales productos y servicios vendidos, utilización de estrategias de ventas y negociación aplicadas, 
datos de las observaciones y reclamos de los clientes internos y externos en las áreas a evaluar.

\section{Medios de recopilación}

Los medios de recopilación para obtener la información de la realidad de la empresa serán: encuestas a clientes internos y externos, entrevistas personales con los responsables en la toma de decisiones (Gerentes, jefes y supervisores), entrevistas con líderes de opinión, lluvia de ideas, reuniones con los responsables de las áreas de compras y ventas, consulta a base de datos, y software interno. Con esta información se podrá analizar y evaluar cada una de los aspectos críticos de los problemas principales.

\section{Diagnóstico de los problemas de compras}

Es importante analizar cada una de las causas raíces de los principales problemas. Para ello es necesario evaluar cómo se encuentra actualmente el área de compras, cuál es el procedimiento para funciones específicas, qué gestión cumple cada comprador y cómo realiza el trabajo de cada orden de pedido, analizar el tipo de negociación, cómo se realiza la gestión de compras de inicio a fin, con la finalidad de determinar cómo se puede evaluar y mejorar cada actividad del proceso.

Para ello es necesario recabar información de la empresa, por ello se analizó los datos de volúmenes en montos de compras del último año (Enero a Diciembre 2014), los cuales son muy variados. De esta forma se determinó que el monto total de compras de repuestos anual asciende a S/. 3.063.148,93 con un valor promedio mensual de S/. 255.262,00 como lo muestra la tabla 3.4.

Asimismo, la cantidad promedio de órdenes de compra mensuales solicitadas es de 160 y la cantidad de items en promedio mensual es 831. Es decir, se debe generar en 7 órdenes de compras diarias con 5 ítems en promedio 
cada uno para gestionar el plan de compras.

Tabla 3.4

Monto de compras durante los últimos doce meses del 2014(S/.)

\begin{tabular}{|c|c|c|c|c|c|c|}
\hline \multicolumn{7}{|c|}{ COMPRAS TOTALES 2014} \\
\hline Mes & $\begin{array}{l}\text { Cantidad de } \\
\text { Ordenes de } \\
\text { compras }\end{array}$ & $\begin{array}{c}\text { Cant. De Ítems } \\
\text { solicitados }\end{array}$ & Mont & $\begin{array}{l}\text { de compras en } \\
\text { S/. }\end{array}$ & $\begin{array}{l}\text { Promedio } \\
\text { Ítems / } \\
\text { órdenes de } \\
\text { compra }\end{array}$ & $\begin{array}{l}\text { Promedio de } \\
\text { órdenes de } \\
\text { compra } \\
\text { diarias }\end{array}$ \\
\hline Enero & 167 & 939 & $\mathrm{~S} /$. & $227.915,77$ & 6 & 7 \\
\hline Febrero & 175 & 1.115 & $\mathrm{~S} /$. & $282.169,17$ & 6 & 7 \\
\hline Marzo & 195 & 869 & $\mathrm{~S} /$. & $265.953,86$ & 4 & 8 \\
\hline Abril & 124 & 675 & $\mathrm{~S} /$. & $247.283,69$ & 5 & 5 \\
\hline Mayo & 138 & 800 & $\mathrm{~S} /$. & $279.715,54$ & 6 & 6 \\
\hline Junio & 129 & 794 & $\mathrm{~S} /$. & $258.624,51$ & 6 & 5 \\
\hline Julio & 160 & 827 & $\mathrm{~S} /$. & $220.054,90$ & 5 & 7 \\
\hline Agosto & 142 & 749 & $\mathrm{~S} /$. & $269.452,78$ & 5 & 6 \\
\hline Septiembre & 166 & 791 & $\mathrm{~S} /$. & $288.008,66$ & 5 & 7 \\
\hline Octubre & 195 & 811 & $\mathrm{~S} /$. & $258.630,42$ & 4 & 8 \\
\hline Noviembre & 173 & 983 & $\mathrm{~S} /$. & $244.820,71$ & 6 & 7 \\
\hline Diciembre & 159 & 624 & $\mathrm{~S} /$. & $220.518,93$ & 4 & 7 \\
\hline TOTAL & 1923 & 9.977 & S/. & $3.063 .148,93$ & 62 & 80 \\
\hline $\begin{array}{l}\text { PROMEDIO } \\
\text { MENSUAL }\end{array}$ & 160 & 831,00 & $\mathbf{S} /$. & $255.262,00$ & 5 & 7 \\
\hline
\end{tabular}

Fuente: Laboratorio Diesel Senatinos S.A, Elaboración: Propia

El área de compras atiende diariamente diversos pedidos, para satisfacer tanto a los clientes internos como externos. Para ello, clasifica las compras en los siguientes tipos:

- De bienes, mercancías y materiales: son las familias de repuestos en todas sus categorías, los productos de venta de la empresa.

- Programadas, aquellas que pueden ser planeadas y ser solicitadas con anticipación para la reposición de productos; Poseen un nivel de riesgo.

- De emergencia, son aquellas que urgen y no se puede planear su compra de manera normal. Son prioritarias, por lo que se debe conseguir en el menor tiempo posible.

Los pedidos de compras son solicitados por diferentes áreas para satisfacer las necesidades de toda la empresa, siendo el que lidera con mayor representación el 
área de mantenimiento y reparación. La compra de repuestos automotrices representa el $84 \%$ de las compras globales de la empresa, con un valor promedio de S/.214.469,34, como se muestra en la tabla 3.5.

Tabla 3.5

Monto promedio mensual de pedidos de compras 2014

\begin{tabular}{|l|cr|c|}
\multicolumn{1}{c}{ Compras } & \multicolumn{2}{c|}{$\begin{array}{c}\text { Monto promedio } \\
\text { mensual S/. }\end{array}$} & $\begin{array}{c}\text { \% de } \\
\text { Representación }\end{array}$ \\
\hline Repuestos & S/. & $214.469,34$ & $84,0 \%$ \\
Materiales y útiles de oficina & S/. & $8.240,79$ & $3,2 \%$ \\
Marketing y publicidad & S/. & $7.551,59$ & $3,0 \%$ \\
Herramientas y equipos & S/. & $14.070,40$ & $5,5 \%$ \\
Insumos y Suministros & S/. & $10.929,89$ & $4,3 \%$ \\
\hline \multicolumn{1}{|c|}{ TOTAL } & S/. & $\mathbf{2 5 5 . 2 6 2 , 0 0}$ & $\mathbf{1 0 0 , 0 \%}$ \\
\hline
\end{tabular}

Fuente: Laboratorio Diesel Senatinos S.A.

Elaboración: Propia

\section{Figura 3.5}

Participación de pedidos de compra - Enero a Diciembre 2014

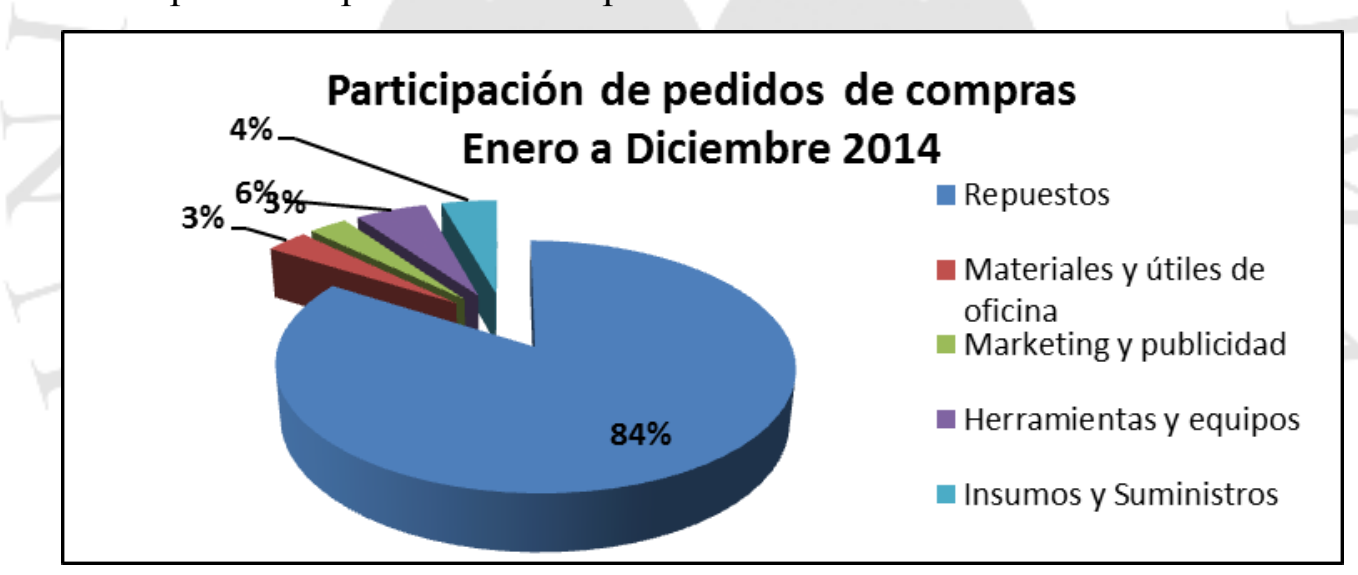

Fuente: Laboratorio Diesel Senatinos S.A.

Las principales compras que realiza Laboratorio Diesel Senatinos S.A. son repuestos y componentes para vehículos livianos y pesados, los cuales se venden directamente. Estos son divididos en familias o sistemas en el vehículo como se muestra en la figura 3.5. Para cada familia de repuestos corresponden diversas piezas y componentes. 
Figura 3.6

Distribución de principales familias de repuestos

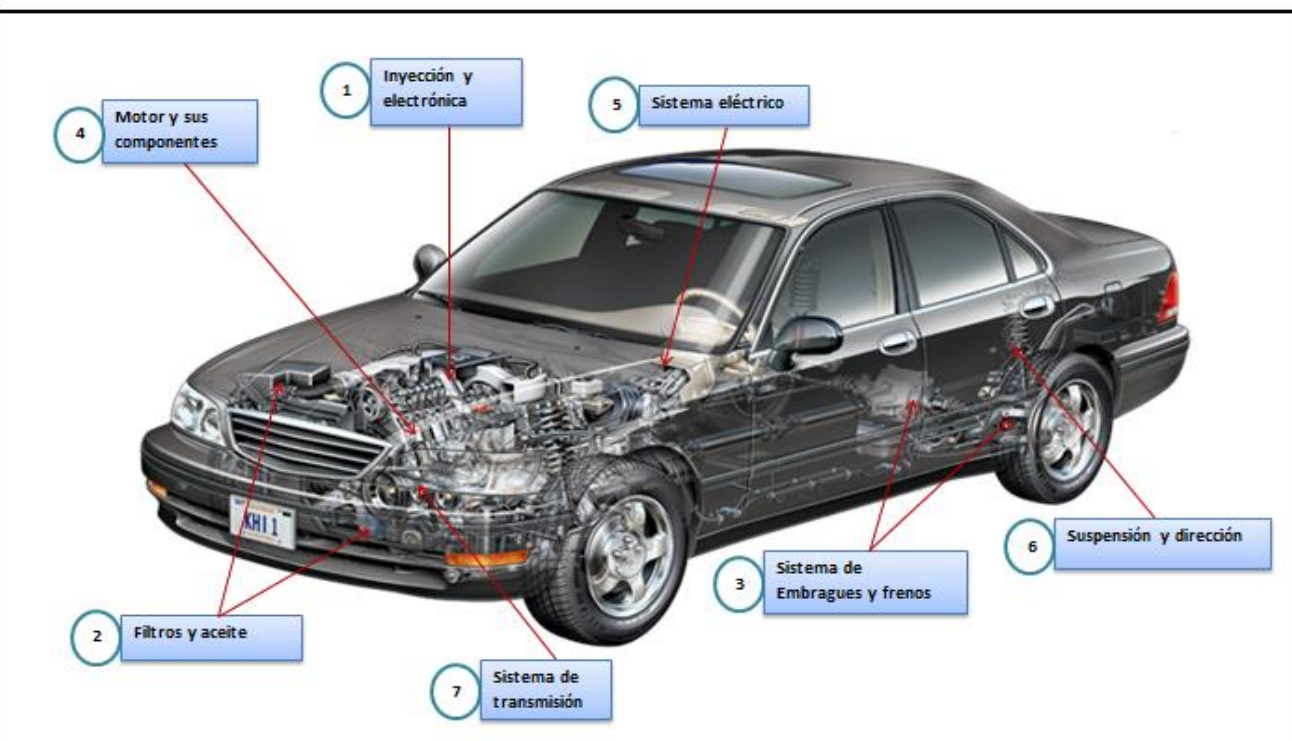

Elaboración propia

El monto promedio de compras mensuales de repuestos para cada una de las 7 familias se muestra en la figura 3.6. Cada familia se divide en sub familias dependiendo de la magnitud de componentes que la conforman, siendo la principal el sistema de inyección (ver tabla 3.6) con $42 \%$ que en valor promedio mensual representa $\mathrm{S} / .90,809.42$, debido a que la empresa es reconocida $\mathrm{y}$ especialista en realizar los servicios de mantenimiento, reparación y calibración de bombas de inyección así como de inyectores mecánicos, electrónicos y semi electrónicos de todas las marcas de vehículos, tanto para unidades livianas como para maquinaria pesada. 
Tabla 3.6

Monto promedio de compras por familia de repuestos 2014

\begin{tabular}{|c|c|c|c|c|}
\hline Nro. & Familias de repuestos & Monto & $\begin{array}{l}\text { dio mensual en } \\
\text { ras S/. }\end{array}$ & $\begin{array}{c}\% \text { de } \\
\text { representación }\end{array}$ \\
\hline 1 & Inyección y electrónica & $\mathrm{S} /$. & $90.809,42$ & $42,3 \%$ \\
\hline 2 & Embragues y frenos & $\mathrm{S} /$. & $40.162,86$ & $18,7 \%$ \\
\hline 3 & Filtros y aceites & $\mathrm{S} /$. & $30.577,00$ & $14,3 \%$ \\
\hline 4 & Motores y sus componentes & $\mathrm{S} /$. & $28.637,65$ & $13,4 \%$ \\
\hline 5 & Eléctrico y sus partes & $\mathrm{S} /$. & $9.498,12$ & $4,4 \%$ \\
\hline 6 & Amortiguadores y suspensión & $\mathrm{S} /$. & $8.232,30$ & $3,8 \%$ \\
\hline 7 & Mangueras y fajas & $\mathrm{S} /$. & $6.551,99$ & $3,1 \%$ \\
\hline \multicolumn{2}{|r|}{ TOTAL } & $\mathbf{S} /$. & $214.469,34$ & $100 \%$ \\
\hline
\end{tabular}

Fuente: Laboratorio Diesel Senatinos S.A

Elaboración: Propia

Figura 3.7

Porcentaje de representación de compras por familias de repuestos

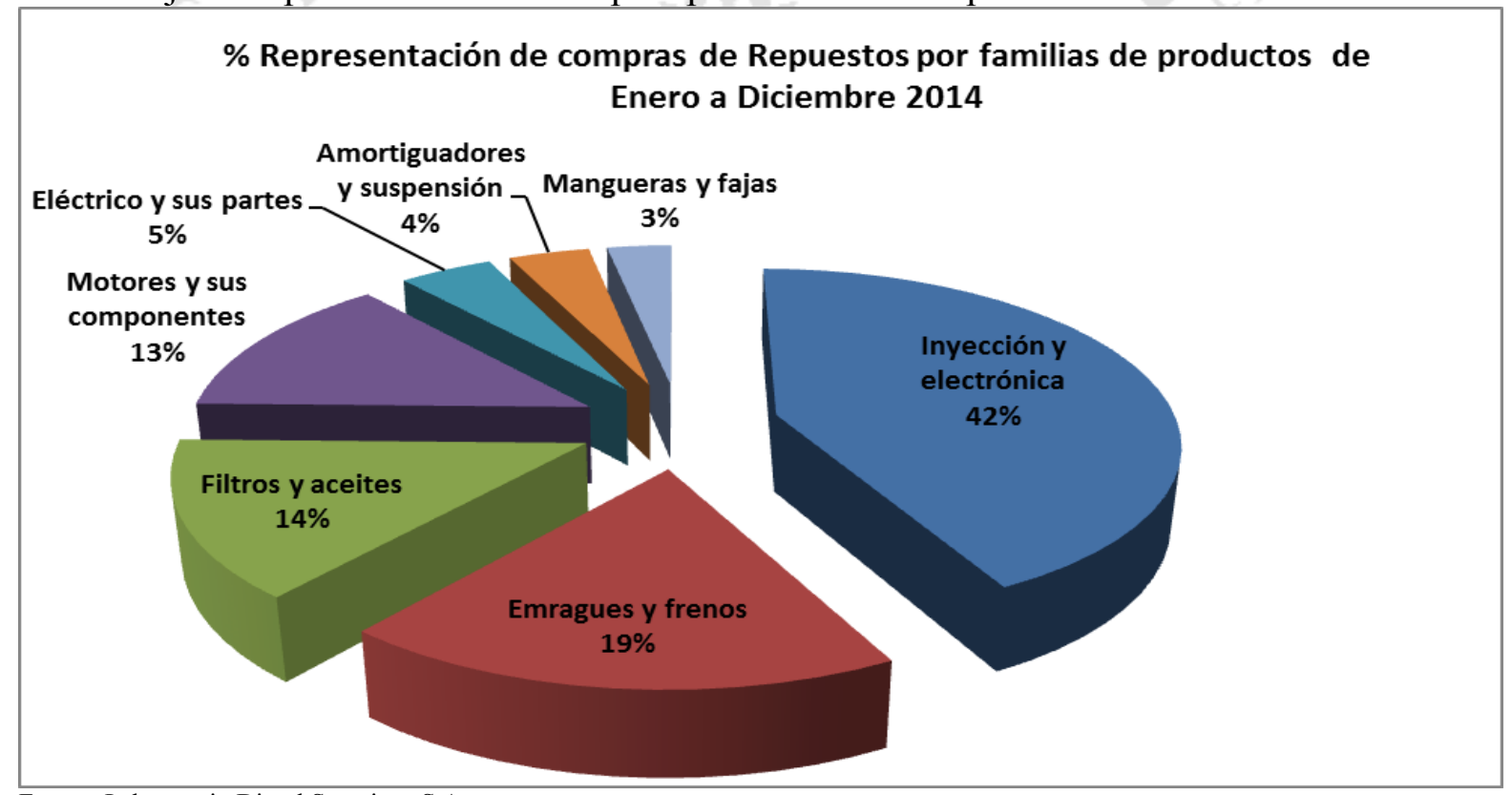

Fuente: Laboratorio Diesel Senatinos S.A

Elaboración: Propia

\section{Diagnóstico de los problemas de ventas}

La gestión de las ventas ha sido desatendida en su mayoría por falta de estrategias de ventas, La empresa no cuenta con una planificación ni metas de venta, debido a que las principales fuentes de ingreso son a través de venta de repuestos por servicio (mantenimiento preventivo o correctivo) y por mostrador. Asimismo, no existe una fuerza de venta motora, para impulsar las ventas y comercializar los productos y servicios que vende la empresa. 
Al tomar la información histórica de las ventas desde Enero 2014 a Diciembre 2014 se puede observar que el promedio mensual de órdenes de pedido de venta es de 227 que genera un monto de S/. 326.638,00 mensuales como se muestra en la tabla 3.7

Tabla 3.7

Ventas de repuestos Enero 2014 a Diciembre 2014

\begin{tabular}{|c|c|c|c|c|c|c|}
\hline \multicolumn{7}{|c|}{ VENTAS DE REPUESTOS 2014} \\
\hline Mes & $\begin{array}{l}\text { Cantidad de } \\
\text { órdenes de } \\
\text { ventas }\end{array}$ & $\begin{array}{l}\text { Cant. De Ítems } \\
\text { solicitados }\end{array}$ & \multicolumn{2}{|c|}{ Monto de ventas en S/. } & $\begin{array}{l}\text { Promedio } \\
\text { diario } \\
\text { Ítems } \\
\text { /Ordenes }\end{array}$ & $\begin{array}{l}\text { Promedio de } \\
\text { solicitudes } \\
\text { diarias }\end{array}$ \\
\hline Enero & 210 & 1.330 & $\mathrm{~S} /$. & $230.152,81$ & 6 & 5 \\
\hline Febrero & 252 & 1.246 & $\mathrm{~S} /$. & $290.222,51$ & 5 & 7 \\
\hline Marzo & 280 & 1.344 & $\mathrm{~S} /$. & $310.100,18$ & 7 & 9 \\
\hline Abril & 161 & 1.218 & $\mathrm{~S} /$. & $350.855,12$ & 6 & 8 \\
\hline Mayo & 196 & 1.001 & $\mathrm{~S} /$. & $390.502,20$ & 6 & 7 \\
\hline Junio & 182 & 1.134 & $\mathrm{~S} /$. & $360.420,40$ & 7 & 8 \\
\hline Julio & 231 & 1.190 & $\mathrm{~S} /$. & $305.096,08$ & 6 & 10 \\
\hline Agosto & 203 & 1.106 & $\mathrm{~S} /$. & $270.931,41$ & 5 & 7 \\
\hline Septiembre & 241 & 1.092 & $\mathrm{~S} /$. & $375.254,98$ & 5 & 9 \\
\hline Octubre & 273 & 1.162 & $\mathrm{~S} /$. & $375.258,02$ & 7 & 11 \\
\hline Noviembre & 252 & 1.330 & $\mathrm{~S} /$. & $350.539,83$ & 8 & 7 \\
\hline Diciembre & 238 & 1.232 & $\mathrm{~S} /$. & $310.318,50$ & 7 & 10 \\
\hline Total anual & 2.719 & 14.385 & S/. & $3.919 .652,02$ & 75 & 98 \\
\hline $\begin{array}{c}\text { Promedio de } \\
\text { ventas } \\
\text { mensual }\end{array}$ & 227 & 1.199 & S/. & $326.638,00$ & 6 & 8 \\
\hline Fuente: Laboratorio & . ה ס & & & & & \\
\hline
\end{tabular}

En la tabla 3.8 se puede observar la distribución de las ventas según las familias de repuestos del sistema automotriz, resaltando claramente el sistema de inyección de lo que Senatinos S.A es reconocida y especialista como el sistema de embragues y frenos en segundo lugar con montos de S/. 134.901,49 y S/. $58.228,51$ respectivamente. 
Tabla 3.8

Ventas de repuestos distribuidas por familia de sistema automotriz

\begin{tabular}{|c|c|c|c|c|}
\hline Nro. & Familias de repuestos & & $\begin{array}{l}\text { romedio } \\
\text { n ventas } \mathbf{S} / \text {. }\end{array}$ & $\begin{array}{c}\% \text { de } \\
\text { representación }\end{array}$ \\
\hline \multirow{7}{*}{$\begin{array}{l}1 \\
2 \\
3 \\
4 \\
5 \\
6 \\
7\end{array}$} & \multirow{7}{*}{$\begin{array}{l}\text { Inyección y electrónica } \\
\text { Embragues y frenos } \\
\text { Filtros y aceites } \\
\text { Motores y sus componentes } \\
\text { Eléctrico y sus partes } \\
\text { Amortiguadores y suspensión } \\
\text { Mangueras y fajas }\end{array}$} & $\mathrm{S} /$. & $134.901,49$ & \multirow{7}{*}{$\begin{array}{r}41,3 \% \\
17,8 \% \\
15,4 \% \\
13,4 \% \\
4,3 \% \\
3,9 \% \\
3,8 \%\end{array}$} \\
\hline & & $\mathrm{S} /$. & $58.228,51$ & \\
\hline & & & $50.161,96$ & \\
\hline & & $\mathrm{S} /$. & $43.615,31$ & \\
\hline & & $\mathrm{S} /$. & $14.139,05$ & \\
\hline & & $\mathrm{S} /$. & $12.864,48$ & \\
\hline & & $\mathrm{S} /$. & $12.574,82$ & \\
\hline & TOTAL & $\mathbf{S} /$ & $326.638,00$ & $100 \%$ \\
\hline
\end{tabular}

Elaboración: Propia

\subsubsection{Análisis de los indicadores}

En relación a la causa principal del problema "Deficiencia en la evaluación de precios al seleccionar la compra de un repuesto" se ha analizado 4 indicadores y recopilado información valiosa de la empresa para determinar los resultados de los indicadores y analizar cómo se encuentran actualmente.

Las consideraciones que se tomaron para obtener los indicadores son:

- No existe control en el número de cotizaciones que realiza un comprador a un proveedor, como consecuencia de realizar una orden de pedido en el "menor tiempo posible" o por la necesidad de atender rápidamente una solicitud de compra por la exigencia de carga de trabajo, el comprador sólo solicita una o dos cotizaciones, para evaluar ofertas y tomar la decisión de compra, cuando lo establecido para una buena compra y obtener un buen precio es por lo mínimo que se reciban de 3 a 5 cotizaciones. 
- El excesivo tiempo de búsqueda de proveedores, el personal de compras sólo se basa en la data histórica de los proveedores que en alguna oportunidad se les compraron algún producto, de esta forma para comprar repuestos de baja rotación el comprador puede tardar más de 30 minutos sólo en buscar a los proveedores idóneos para la compra del repuesto.

- No se considera el monto de ahorro en costos por el beneficio de conocimiento en codificación de productos, todos los repuestos son hallados según códigos, y por ello, la falta de conocimiento de algunos códigos de productos hace que los compradores se equivoquen en la selección del repuesto o que no busquen alternativas de equivalencia de códigos para hallar el repuesto solicitado a un menor precio. Asimismo, la empresa no recopila la información de los montos de ahorro, los estima.

- No se considera el monto de ahorro por el beneficio de una buena negociación, el comprador por lo general acepta los montos que estipulan los proveedores. No reconsidera plantear una contraoferta para minimizar los costos de compra. Por ello debe obtener un levantamiento de datos de los montos de ahorro por compra en negociación de cada comprador.

En las tablas 3.9 y 3.10 se detallan cada uno de los indicadores de evaluación de compras y ventas con la información histórica de la empresa recabada de Enero 2014 a Diciembre 2014. 
Tabla 3.9

Tabla de indicadores para la evaluación del proceso de compras

\begin{tabular}{|c|c|c|c|c|}
\hline Nro. & Indicadores & Representación de indicador & $\begin{array}{c}\text { Situación } \\
\text { actual }\end{array}$ & Objetivo \\
\hline 1 & $\begin{array}{l}\text { Nro. De cotizaciones } \\
\text { realizadas por orden de compra }\end{array}$ & $\frac{\text { Nro. de Pedido de cotizaciones a proveedores }}{\text { Nro. de órdenes de compra }}$ & $69.88 \%$ & $35.00 \%$ \\
\hline 2 & $\begin{array}{l}\text { \% de tiempo que el comprador } \\
\text { toma para la búsqueda a un } \\
\text { proveedor }\end{array}$ & $\frac{\text { Tiempo promedio de búsqueda de proveedor }}{\text { Tiempo de generar orden de compra }}$ & $62.5 \%$ & $20 \%$ \\
\hline 3 & $\begin{array}{l}\text { \% de ahorros en compras por } \\
\text { conocimiento en la codificación } \\
\text { de producto }\end{array}$ & $\frac{\text { Ahorro de compras por equivalencia de producto }}{\text { Montos de cotizaciones iniciales }}$ & $4.1 \%$ & $10.50 \%$ \\
\hline 4 & $\begin{array}{l}\text { \% de ahorro en compras por } \\
\text { negociación }\end{array}$ & $\begin{array}{l}\text { Ahorro de compras por negociación } \\
\text { Monto de los precios de cotizaciones iniciales }\end{array}$ & $1.27 \%$ & $3 \%$ \\
\hline
\end{tabular}

Elaboración propia

Tabla 3.10

Tabla de indicadores para la evaluación del proceso de ventas

\begin{tabular}{|c|c|c|c|c|c|}
\hline Nro. & Indicador & $\begin{array}{l}\text { Representación } \\
\text { del indicador }\end{array}$ & Descripción & $\begin{array}{l}\text { Situación } \\
\text { Actual }\end{array}$ & Objetivo \\
\hline 1 & $\begin{array}{l}\text { Eficiencia de las } \\
\text { visitas por vendedor }\end{array}$ & $\frac{\text { Número de pedidos }}{\text { Número de visitas }}$ & $\begin{array}{l}\text { El resultado entre } 0.75 \text { y } 1.0 \\
\text { indicará una buena gestión. }\end{array}$ & 0.33 & 0.83 \\
\hline 2 & $\begin{array}{l}\text { Incorporación de } \\
\text { clientes nuevos por } \\
\text { vendedor }\end{array}$ & $\begin{array}{l}\frac{\text { Número de clientes activos }}{\text { del vendedor }} \\
\text { Número de clientes iniciales }\end{array}$ & $\begin{array}{l}\text { El ideal es desde } 1,25 \text { y los } \\
\text { valores inferiores a } 1.0 \text { no } \\
\text { deben ser aceptados, pues } \\
\text { indica la pérdida de clientes. }\end{array}$ & 1.067 & 1.23 \\
\hline 3 & $\begin{array}{l}\text { Comportamiento de } \\
\text { los pedidos }\end{array}$ & $\begin{array}{l}\frac{\text { Número de pedidos }}{\text { aprobados }} \\
\begin{array}{l}\text { Número total de pedidos } \\
\text { realizados }\end{array}\end{array}$ & $\begin{array}{l}\text { El resultado ideal es } 1.0 \text { y lo } \\
\text { mínimo aceptable es } 0.9\end{array}$ & 0.960 & 0.99 \\
\hline
\end{tabular}

Elaboración propia

\subsubsection{Aplicación de los métodos de diagnóstico}

El método utilizado para hallar el diagnóstico de los problemas principales del proceso de compras como de ventas se requirió las siguientes herramientas y métodos:

- Diagrama de Ishikawa - Causa efecto, donde se realiza un análisis de minucioso de la causa raíz del problema. (Ver figuras 3.1 y 3.2) 
- Matrices de enfrentamiento de criticidad, para determinar cuáles son las causas principales del problema analizado en el diagrama de Ishikawa, con base en el impacto y la frecuencia de ocurrencia de cada una de ellas. (Ver figura 2.13 y 2.14 )

- Diagrama de Pareto, donde se observa gráficamente las causas raíces encontradas. (Ver figura 3.3 y 3.4 ) 


\section{CAPÍTULO IV: DETERMINACIÓN DE LA SOLUCIÓN PARA LOS PROBLEMAS ENCONTRADOS}

\subsection{Análisis FODA}

\subsubsection{Factores FODA}

Para enriquecer el conocimiento de los principales problemas en el proceso de compras y ventas se requiere realizar el análisis FODA.

A partir de las reuniones participativas realizadas en la empresa Laboratorio Diesel Senatinos S.A. se elaboró el análisis FODA, tomando como prioridad el análisis interno de los procesos de compras y ventas (Fortalezas y Debilidades) así como el análisis externo (Oportunidades y Amenazas).

\subsubsection{Determinación de las estrategias}

La Matriz FODA, nos indica cuatro estrategias alternativas conceptuales distintas:

- La estrategia DA, es la estrategia Debilidades Vs Amenaza. (Sobrevivencia)

- La estrategia DO, es la estrategia Debilidad vs Oportunidades. (Redireccionamiento)

- La estrategia FA, es la estrategia Fortalezas vs Amenazas. (Defensa)

- La estrategia FO, es la estrategia Fortalezas vs Oportunidades (Ataque)

En la figura 4.1 se puede observar el planteamiento de cada estrategia según la evaluación de la matriz FODA. La ejecución del presente proyecto se basará en las estrategias FA (defensa) y DO (re direccionamiento) con un plan de 
capacitación, herramientas e información para el mejor desempeño de las funciones de los recursos que posee la empresa a fin de obtener un eficiente resultado en cada una de las funciones que desempeñan.

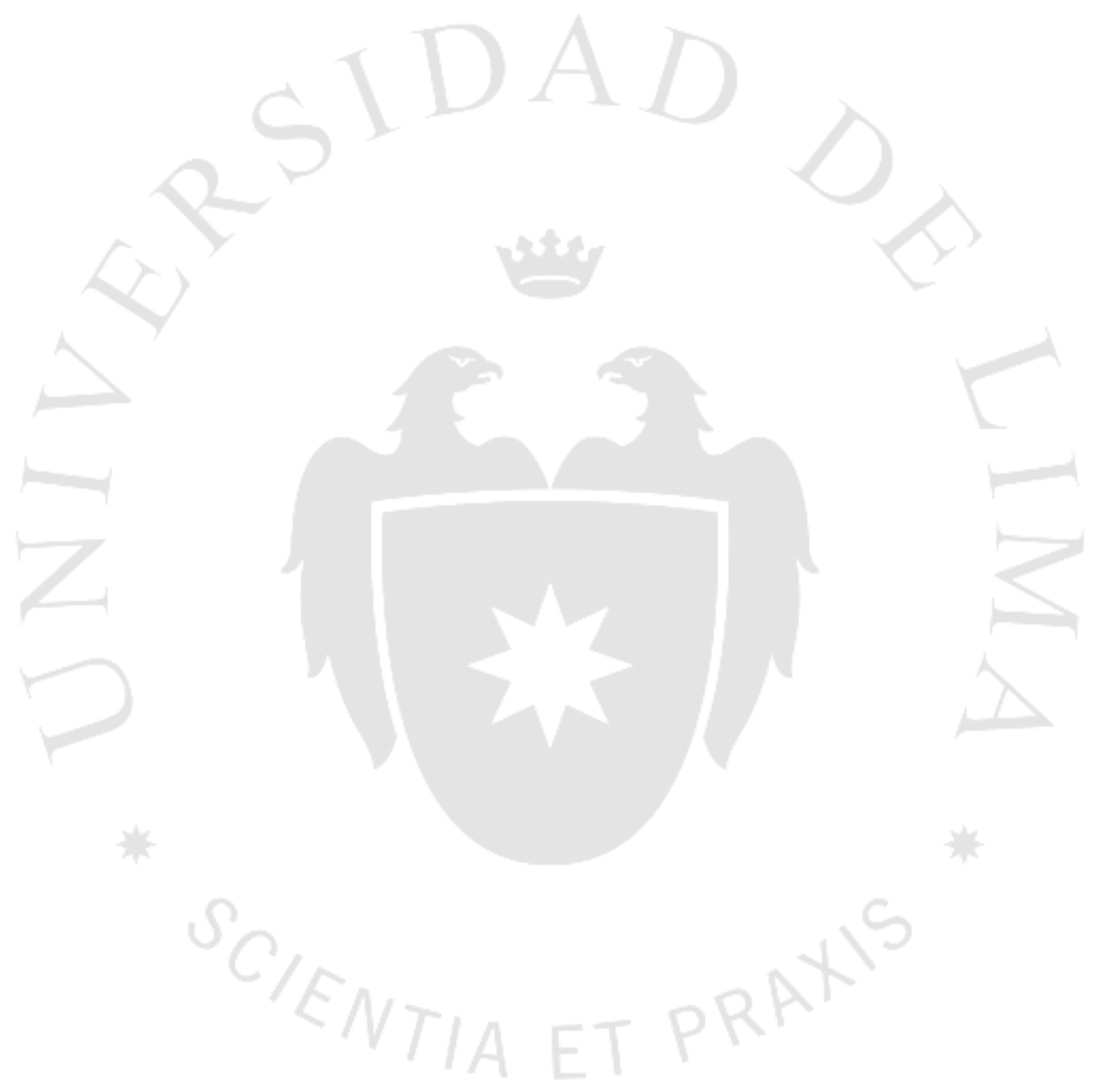


Figura 4. 1

Matriz de Estrategias - FODA

\begin{tabular}{|c|c|c|}
\hline $\begin{array}{l}\text { FACTORES } \\
\text { EXTERNOS }\end{array}$ & $\begin{array}{l}\text { Fortalezas: } \\
\text { - Experiencia y especialización en sistemas de inyección con más de } \\
29 \text { años en el mercado automotriz, para la venta de repuestos. } \\
\text { - Proveedores de repuestos en importación directa. } \\
\text { - Equipos de última tecnología en sistemas de inyección. } \\
\text { - Confianza de clientes antiguos en la calidad del servicio, por ende } \\
\text { compran todos sus repuestos en la empresa. } \\
\text { - Sistemas de información, catálogos para el despiece e } \\
\text { información de los repuestos.. } \\
\text { - Venta de productos especializados a la necesidad del cliente. } \\
\text { - Proveedores confiables con representación de marcas } \\
\text { reconocidas a nivel mundial. }\end{array}$ & $\begin{array}{l}\text { Debilidades: } \\
\text { - El enganche de las garantías con los talleres concesionarios a la } \\
\text { compra de un vehículo nuevo. } \\
\text { - Los compradores no poseen suficiente conocimiento en las } \\
\text { características técnicas de los repuestos. } \\
\text { - Costos elevados para la compra para stock de repuestos especializados. } \\
\text { - Escasos recursos económicos que limitan la reposición de repuestos } \\
\text { especializados. } \\
\text { - Deficiente dirección en la gestión de compras. } \\
\text { - Ausencia de campañas publicitarias que puedan brindar una mayor y } \\
\text { mejor información de los servicios que ofrece la empresa. } \\
\text { - Falta de capacitación a los vendedores para que puedan ofrecer } \\
\text { repuestos especializados. }\end{array}$ \\
\hline $\begin{array}{l}\text { Oportunidades: } \\
\text { - Crecimiento del parque automotor. } \\
\text { - Acuerdos internacionales que favorecen los costos en las } \\
\text { importaciones de vehículos, repuestos y autopartes. } \\
\text { - Reinicio de las revisiones técnicas. } \\
\text { - Incremento de la demanda de repuestos. }\end{array}$ & $\begin{array}{l}\text { Estrategias FO (de ataque) } \\
\text { - Ser los primeros en ofrecer los repuestos y componentes de los } \\
\text { vehículos nuevos que están ingresando al mercado automotriz. } \\
\text { - Obtener la representatividad de grandes compañías } \\
\text { internacionales fabricantes de repuestos. } \\
\text { - Promocionar y dar a conocer nuestra especialización en sistema } \\
\text { de inyección. } \\
\text { - Elaborar políticas de ventas para mejorar la participación en el } \\
\text { mercado de ventas de ventas de repuestos y mantenimiento de } \\
\text { vehículos. } \\
\text { - Mejorar el servicio al cliente interno y externo. } \\
\text { - Elaborar un programa de capacitación y formación profesional } \\
\text { para la venta de repuestos especializados }\end{array}$ & $\begin{array}{l}\quad \text { Estrategias DO (Redireccionamiento) } \\
\text { - Capacitar a los vendedores para la venta masiva de los repuestos } \\
\text { especializados. } \\
\text { - Elaborar plan de funciones y cuadro de indicadores para evaluar } \\
\text { a los vendedores. } \\
\text { - Elaborar una marca para la importación de repuestos } \\
\text { especializados. } \\
\text { - Mejorar la gestión administrativa, aplicando los procesos } \\
\text { administrativos. } \\
\text { - Desarrollar un manual de procedimientos para la } \\
\text { toma de decisiones en compras. } \\
\text {-Adquirir softwares o sistemas de información que posean } \\
\text { información de la mayoría de marcas de repuestos. }\end{array}$ \\
\hline $\begin{array}{l}\text { Amenazas: } \\
\text { - Mercado muy competitivo en la venta de repuestos automotrices. } \\
\text { - Crecimiento del mercado informal. } \\
\text { - Competencia en la venta de repuestos por las grandes casas } \\
\text { importadoras de repuestos y autopartes. } \\
\text { - Proveedores de repuestos y autopartes ofrecen productos a altos } \\
\text { precios en productos especializados. } \\
\text { - Cambios acelerados en las tecnologías vehiculares. }\end{array}$ & $\begin{array}{l}\text { Estrategias FA (de defensa): } \\
\text { - Replantear los costos de venta de repuestos. } \\
\text { - Realizar eficientes negociaciones con proveedores competitivos. } \\
\text { - Incorporar una estrategia de ventas, para la promoción de } \\
\text { repuestos. } \\
\text { - Importar repuestos de buena calidad y a bajos precios. } \\
\text { - Establecer alianzas con proveedores nacionales. } \\
\text { - Asesorar en las mejoras de las estrategias de ventas y compras }\end{array}$ & $\begin{array}{l}\text { Estrategias DA (de sobrevivencia): } \\
\text { - Implantar un modelo de gestión de calidad para elevar la } \\
\text { satisfacción del cliente y de esta manera lograr una ventaja } \\
\text { competitiva de la competencia. } \\
\text { - Establecer efectivas negociaciones con compañías que poseen } \\
\text { flotas de vehículos. } \\
\text { - Capacitar a los compradores para que puedan realizar buenas } \\
\text { negociaciones de la compra de repuestos. } \\
\text { - Replantear sistemas de atención. } \\
\text { - Realizar campañas de promoción para la venta de repuestos. }\end{array}$ \\
\hline
\end{tabular}

Elaboración propia 


\subsubsection{Definición de metas de la mejora}

Con la implementación del presente proyecto se pretende lograr las siguientes metas:

- Reducir el tiempo del proceso de pedido de compra con herramientas e información para el eficiente desempeño de los compradores.

- Minimizar la cantidad de reclamos de los clientes internos y externos en la entrega de los repuestos solicitados.

- Incrementar el ahorro por la buena gestión y negociación con proveedores de primera línea, con la finalidad de encontrar los mejores precios del mercado y excelencia en la calidad del producto.

- Reducir la cantidad de existencias en el almacén de productos y repuestos que tienen una baja rotación y a la vez no pertenecen a los sistemas de especialización automotriz que define a la empresa.

- Incrementar las ventas de los repuestos automotrices en base una buena atención al cliente, con información de calidad y veraz que genere confianza en cada uno de los clientes para la compra de los productos ofrecidos.

- Establecer perfiles adecuados para los vendedores con metas de ventas con base en un seguimiento de nivel de servicio en el desempeño de sus funciones.

\subsection{Determinación de las alternativas de solución para cada problema encontrado}

Teniendo como problema principal para el proceso de compras, "la deficiencia en la evaluación de precios al seleccionar la compra de un repuesto", se determinará las alternativas de solución a partir de resolver las dos principales causas, "falta de información para la búsqueda de proveedores" y atención de excesivas marcas de vehículos. De igual manera para el proceso de ventas, "falta de capacitación a los vendedores en 
estrategias de ventas" y "no existen funciones definidas para los vendedores".

\section{Principales causas raíces en el proceso de compras}

\section{$>$ Causa raíz Nro.1: Falta de información para la búsqueda de proveedores}

Si el comprador no posee la información necesaria del proveedor: quién es, qué productos vende, dónde está ubicado, si es importador, mayorista o minorista, que tipos de marca de repuestos vende, cuáles son sus repuestos estrellas, cuáles son sus precios aproximados, entre otros, no podrá obtener buenos resultados en las compras asignadas, consiguiendo deficiencias en la compra, precios elevados, riesgo en el cumplimiento y demora en la entrega los productos solicitados.

Actualmente, la única fuente de información que posee la empresa para la búsqueda de información de un proveedor es el software de la empresa Winstock, donde se registran todas las compras, incluyendo los datos mínimos del proveedor.

En la figura 4.2 se muestra los campos a completar para la información del proveedor. 
Figura 4. 2

Software Winstock - Información de proveedores - LADISE S.A

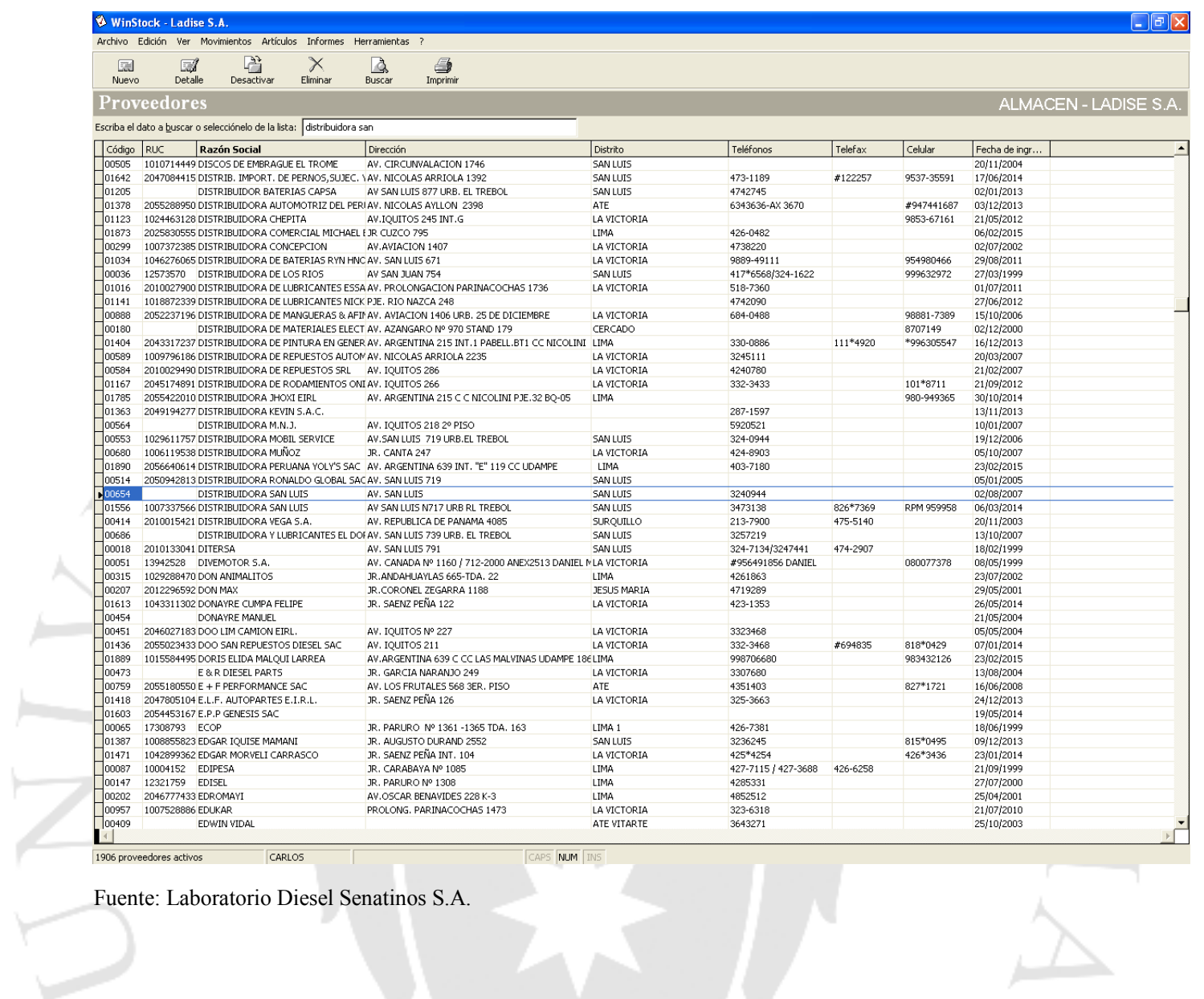

Solución: Realizar búsqueda de proveedor a través de Aduanas:

El $85 \%$ de los repuestos automotrices son importados de diferentes países de producción a gran escala, lo que quiere decir que los mejores precios se manejan con base en las importaciones directas de repuestos o en la compra a un proveedor que importe directamente. Mientras más se reduzca la cadena de comercialización para la compra de un producto, mejor precio se podrá obtener. El fin, es evitar comprar a revendedores o minoristas y realizar excelentes negociaciones con los importadores directos.

La información de los datos de las empresas importadoras de repuestos se encuentran en la página web de Aduanas y se pueden obtener sin costo 
alguno por ser información pública siguiendo una serie de pasos en relación a la partida arancelaria del producto buscado.

\section{Causa raíz Nro.2: Atención de excesivas marcas de vehículos}

La empresa Laboratorio Diesel Senatinos S.A. atiende a diversas marcas y modelos de vehículos, por ello es considerado un taller multimarca. Por ello, para la atención y venta de repuestos existe dificultad en tener stock para abastecer a todas las marcas y modelos de cada tipo de vehículo, considerando además que por cada año varía los componentes de una misma marca y modelo de vehículo.

Téngase en cuenta que la empresa atiende siete familias de sistemas automotrices y que cada una de ellas abarca una serie de subfamilias de repuestos y cada una, a su vez, se divide en una extensa lista de repuestos.

Se tendría que tener un almacén de dimensiones extraordinarias para poder alojar por lo menos mínimos stocks de cada repuesto, lo cual es imposible.

Solución: Especialización en la compra de repuestos de los principales sistemas automotrices y marcas de vehículos que atiende la empresa.

Se deberá clasificar las marcas de vehículos que tienen mayor demanda en servicios y venta de repuestos. De esta manera se podrá seleccionar cuales son las principales marcas de vehículo que se atienden.

De la misma forma es necesario que se tenga una especialización del sistema automotriz por lo que es reconocida la empresa. Se puede determinar para los servicios más frecuentes y el nivel de satisfacción alto y mínimo, en el nivel de reclamos. Debido a que es una empresa multimarca no podría tener un stock mínimo de repuestos de todos los sistemas del vehículo, considerando también que existen variedad de modelos y marcas. Es por ello 
que se propone la especialización en los sistemas de inyección y embragues. De esta manera se podría contar con stocks mínimos de la diversidad de marcas y modelos de repuestos únicamente de los sistemas de especialización. Por lo tanto, el cliente siempre podrá encontrar, en el momento necesario, el repuesto de su requerimiento, facilitando la atención de los servicios.

Se pretende obtener el reconocimiento de la empresa por la atención efectiva y especialización de ciertas marcas de vehículos. Con este cambio se lograría tener en el almacén un stock mínimo de repuestos de las familias de servicio que más se mueven en la empresa, lo que facilitaría tener los repuestos a la mano en el momento indicado para poder atender cualquier solicitud del cliente interno y externo.

Es imprescindible jerarquizar los servicios más demandados y que generen rentabilidad significativa a la empresa para focalizarse en ellos. De esta manera se puede cuantificar las necesidades de abastecimiento promedio.

\section{$\underline{\text { Principales causas raíces en el proceso de ventas }}$}

\section{Causa raíz Nro. 1: Falta de información de la especificaciones y funcionalidad en la venta del repuesto.}

El producto que se oferta a un cliente debe de ser conocido detalladamente por el vendedor, para crear confiabilidad y seguridad en la decisión de compra por parte del cliente. Debido a que la empresa maneja gran variedad de repuestos para diversos modelos de vehículos y para diferentes sistemas internos, es muy complejo que el vendedor pueda conocer cada funcionalidad por tipo. Por ello, en el acápite, se realiza la selección de sistemas especializados para la venta de repuestos y servicios 


\section{Solución Nro.1: Capacitación del personal de ventas en las funciones técnicas del repuesto.}

Es necesario brindar información, instruir y capacitar al personal de ventas para que tengan el conocimiento de la funcionabilidad de los repuestos que se ofertan, de esta manera se puedan desenvolver y brindar información certera al cliente. De nada sirve poseer los mejores productos de última tecnología y alta calidad, si no se cuenta con vendedores que posean una preparación adecuada para la venta de los mismos.

Para ello es necesario facilitar el acceso al conocimiento poniendo en disponibilidad, información relevante, a través de cursos y entrenamientos para ofertar los repuestos automotrices de los sistemas de embrague e inyección.

\section{Causa raíz Nro. 2: No existen funciones definidas para los vendedores}

Al no existir una fuerza de ventas en la empresa Laboratorio Diesel Senatinos S.A. los vendedores no cumplen funciones específicas de ventas, realizando funciones complementarias de otras áreas según la necesidad y disponibilidad que se le asigne. De igual manera, no existe un control del desempeño de funciones y responsabilidades en base a indicadores y metas de ventas. En consecuencia existe una falta de organización para el buen desempeño de las funciones de cada vendedor.

Solución Nro. 2: Elaborar perfiles y funciones para el puesto de vendedores con indicadores de evaluación de desempeño.

La empresa deberá impulsar la fuerza de ventas de repuestos con un plan de metas y objetivos que puedan impactar en el incremento de la rentabilidad. Para ello, es fundamental la asignación de metas, elaboración de perfiles y funciones para el puesto de vendedores, los cuales detallarán la descripción del puesto y el objetivo del mismo, así como los indicadores de evaluación para medir el desempeño del vendedor, detallando cada una de las actividades y responsabilidades a realizar. 
De esta manera el vendedor podrá comprender las responsabilidades de su puesto, minimizar los conflictos con otras áreas y planificar el tiempo en su desempeño para el logro de los objetivos asignados.

La fuerza de ventas deberá ser reforzada con el ingreso de dos trabajadores especialistas en ventas y comercialización. Así, uno apoyará a la atención de los clientes que solicitan repuestos por mostrador y a través de la web o vía telefónica, mientras el otro vendedor trabajará la mayor cantidad de tiempo en campo, consiguiendo nuevos clientes con visitas personales a talleres, compañías e instituciones públicas y privadas.

\subsection{Evaluación y selección de la mejor alternativa de mejora}

El análisis que se enfoca en el punto 4.2 se basa en alternativas de solución de bajo costo, fuerte impacto, mínimo tiempo de implementación y finalmente con el beneficio de durabilidad. Con todos estos factores analizados, se pudo obtener la solución que más se aproxima a brindar los beneficios que requiere la empresa y satisfacer la atención de los problemas principales ya mencionados en los puntos anteriores.

\subsection{Evaluación del alcance y limitaciones de la solución propuesta.}

El alcance de cada una las soluciones propuestas se detallan en la tabla 4.1 
Tabla 4.1

Alcances y limitaciones de las soluciones propuestas

\begin{tabular}{|c|c|c|c|c|c|}
\hline Proceso & Problema & $\begin{array}{c}\text { Causa } \\
\text { principal de } \\
\text { Problema }\end{array}$ & $\begin{array}{l}\text { Solución } \\
\text { propuesta }\end{array}$ & Alcance & Limitaciones \\
\hline \multirow[t]{2}{*}{ Compras } & \multirow{2}{*}{$\begin{array}{l}\text { Deficiencia } \\
\text { en la } \\
\text { evaluación de } \\
\text { precios al } \\
\text { seleccionar la } \\
\text { compra del } \\
\text { repuesto }\end{array}$} & $\begin{array}{l}\text { Falta de } \\
\text { información } \\
\text { para la } \\
\text { búsqueda de } \\
\text { nuevos } \\
\text { proveedores }\end{array}$ & $\begin{array}{l}\text { Realizar } \\
\text { búsqueda de } \\
\text { proveedor a } \\
\text { través de } \\
\text { Aduanas }\end{array}$ & $\begin{array}{l}\text { Concientizar a los compradores a } \\
\text { utilizar una herramienta que } \\
\text { permitirá acceder a información de } \\
\text { nuevos proveedores, en su } \\
\text { mayoría importadores directos de } \\
\text { repuestos. } \\
\text { De esta manera, se podrá lograr } \\
\text { una búsqueda efectiva y poder } \\
\text { realizar un análisis de precios } \\
\text { respecto a los valores FOB de } \\
\text { importación, para facilitar la } \\
\text { decisión de compra. }\end{array}$ & $\begin{array}{l}\text { No contar con } \\
\text { todos los } \\
\text { sistemas de } \\
\text { información de } \\
\text { las diferentes } \\
\text { marcas de } \\
\text { vehículos para la } \\
\text { obtención de } \\
\text { códigos de } \\
\text { repuestos. }\end{array}$ \\
\hline & & $\begin{array}{l}\text { Atención } \\
\text { excesiva } \\
\text { de marcas de } \\
\text { vehículos }\end{array}$ & $\begin{array}{l}\text { Atender repuestos } \\
\text { para las } \\
\text { principales } \\
\text { marcas de } \\
\text { vehículos que } \\
\text { atiende la } \\
\text { empresa } \\
\text { Laboratorio } \\
\text { Diesel Senatinos. }\end{array}$ & $\begin{array}{l}\text { Atender al cliente en el menor } \\
\text { tiempo posible, teniendo al } \\
\text { alcance la mayoría de repuestos } \\
\text { que se requieran. } \\
\text { Especializar a los compradores en } \\
\text { la compra de repuestos en las } \\
\text { marcas más representativas para la } \\
\text { empresa. }\end{array}$ & $\begin{array}{l}\text { Falta de control } \\
\text { en la } \\
\text { alimentación } \\
\text { correcta de la } \\
\text { data histórica de } \\
\text { las marcas de } \\
\text { vehículo } \\
\text { atendidos. }\end{array}$ \\
\hline \multirow[t]{2}{*}{ Ventas } & \multirow[t]{2}{*}{$\begin{array}{l}\text { Falta de } \\
\text { estrategias en } \\
\text { la venta de } \\
\text { repuestos }\end{array}$} & $\begin{array}{l}\text { Falta de } \\
\text { capacitación } \\
\text { a los } \\
\text { vendedores } \\
\text { en estrategias } \\
\text { de ventas }\end{array}$ & $\begin{array}{l}\text { Capacitación del } \\
\text { personal de } \\
\text { ventas en las } \\
\text { funciones } \\
\text { técnicas del } \\
\text { repuesto. }\end{array}$ & $\begin{array}{l}\text { Permitir captar nuevos clientes } \\
\text { con información de calidad y } \\
\text { veraz, brindándole información } \\
\text { precisa, facilitando su atención } \\
\text { en dar soluciones a sus } \\
\text { necesidades, ofreciendo un buen } \\
\text { producto, al precio justo y en el } \\
\text { menor tiempo de entrega posible. } \\
\text { De esta manera incrementar las } \\
\text { ventas de repuestos automotrices. }\end{array}$ & $\begin{array}{l}\text { La desconfianza } \\
\text { de los clientes en } \\
\text { la resistencia de } \\
\text { dejar de comprar } \\
\text { repuestos } \\
\text { "originales" en } \\
\text { las compañías } \\
\text { concesionarias. }\end{array}$ \\
\hline & & $\begin{array}{l}\text { No existen } \\
\text { funciones } \\
\text { definidas para } \\
\text { los } \\
\text { vendedores }\end{array}$ & $\begin{array}{l}\text { Elaborar perfiles } \\
\text { y funciones para } \\
\text { el puesto de } \\
\text { vendedores con } \\
\text { indicadores de } \\
\text { evaluación de } \\
\text { desempeño. } \\
\end{array}$ & $\begin{array}{l}\text { El buen desempeño de las } \\
\text { funciones de los colaboradores de } \\
\text { ventas, conocimiento de sus } \\
\text { responsabilidades y objetivos a } \\
\text { cumplir. }\end{array}$ & $\begin{array}{l}\text { Excesiva carga } \\
\text { de trabajo y falta } \\
\text { de planificación } \\
\text { de las ventas }\end{array}$ \\
\hline
\end{tabular}




\section{CAPÍTULO V: IMPLEMENTACIÓN DE LAS SOLUCIONES PROPUESTAS}

\subsection{Descripción detallada de cada una de las propuestas de solución}

$\underline{\text { Soluciones del proceso de compras }}$

\section{Realizar búsqueda de proveedor a través de Aduanas}

El sistema o website de Aduanas permite brindar al usuario toda la información de las importaciones definitivas que diariamente se realizan. Todos los productos nacionalizados están registrados por partida arancelaria y con el sistema de aduanas se puede obtener toda la información del producto que se está buscando, como: importador, valor FOB, flete, cantidades importadas, descripción y especificaciones del producto, fecha de llegada al país, frecuencia de compra, códigos de productos, entre otros. Para ello es necesario tener en consideración algunos conocimientos básicos en importaciones proporcionadas con una pequeña capacitación a los compradores. Toda búsqueda de producto se realiza con su respectiva partida arancelaria. Para ello se requiere seleccionar y clasificar todos los repuestos que se tienen en stock o saber si se cuenta con la información de códigos por familias y sub familias de productos. Con esta información se podrá realizar la búsqueda de las partidas arancelarias correctas.

Si el comprador posee el número de partida arancelaria y tiene el código del repuesto que está buscando, la probabilidad de encontrarlo es muy alta ya que obtiene un abanico de posibilidades para la cotización respectiva, ya que obtendrá la relación de importadores que compraron ese producto. 
Para la aplicación de esta solución es importante obtener la lista de números de partidas arancelarias que corresponde a los repuestos que la empresa comercializa.

En la siguiente tabla 5.1 se puede observar la lista de partidas arancelarias de uno de los principales productos de la empresa. Las partidas arancelarias se comportan como subfamilias debido a que dentro de ellas albergase una serie de repuestos que pertenecen a la familia. De esta forma la partida Nro. 8409.99.30.00 es la que corresponde a todas las importaciones de inyectores y sus partes, encontrándose con facilidad cualquier pieza que corresponda a la familia de inyectores.

\section{Tabla 5.1}

Partidas arancelarias de repuestos de sistemas de inyección

\begin{tabular}{|c|c|c|c|}
\hline \multicolumn{4}{|c|}{ Número de partidas arancelarias de algunas sub familias de repuestos en sistema de inyección } \\
\hline \multirow{2}{*}{$\begin{array}{c}\text { Familia } \\
\text { Subfamilia }\end{array}$} & Sistema de Inyección & \multirow{2}{*}{$\begin{array}{c}\text { Familia } \\
\text { Subfamilia }\end{array}$} & Sistema de Inyección \\
\hline & Inyector y sus partes & & Bombas y sus partes \\
\hline \multirow{15}{*}{$\begin{array}{c}\text { Nro. de } \\
\text { partida } \\
\text { arancelaria } \\
\mathbf{8 4 0 9 . 9 9 . 3 0 . 0 0}\end{array}$} & Toberas & \multirow{15}{*}{$\begin{array}{l}\text { Nro. de partida } \\
\text { arancelaria } \\
\mathbf{8 4 1 3 . 9 1 . 9 0 . 0 0}\end{array}$} & Cabezal \\
\hline & Discos intermedios & & válvulas \\
\hline & Inyector & & Elementos \\
\hline & Porta inyector & & Excéntrica \\
\hline & Kit de reparación de inyector & & Bomba de transferencia \\
\hline & Retén de inyector & & Kit de reparación de bomba \\
\hline & Válvula & & Bombín cebador \\
\hline & Riel de inyector & & Émbolo \\
\hline & sensor de presión & & Tapón de cabezal \\
\hline & Válvula limitadora de presión & & Espaciador \\
\hline & Cuerpo de inyector & & Eje de aceleración \\
\hline & Esfera o guía & & Cuerpo de bomba \\
\hline & Resorte de inyector & & Tapa de gobernador \\
\hline & Asiento de inyector & & Pistón de avance \\
\hline & & & Solenoide \\
\hline
\end{tabular}
con código de parte Nro. 105007-1120 que pertenece a la familia de 
sistema de inyección. Se tienen las especificaciones del producto que muestra la tabla 5.2. Para ello el comprador se encargará de ubicar a un proveedor que pueda brindar buenos precios cuyo producto cumplan con las especificaciones antes mencionadas. El comprador, deberá realizar la búsqueda con el número correcto de partida arancelaria, para obtener la relación de las empresas que importan el producto mencionado.

\section{Tabla 5.2}

Especificaciones técnicas del repuesto "Tobera 105007-1120"

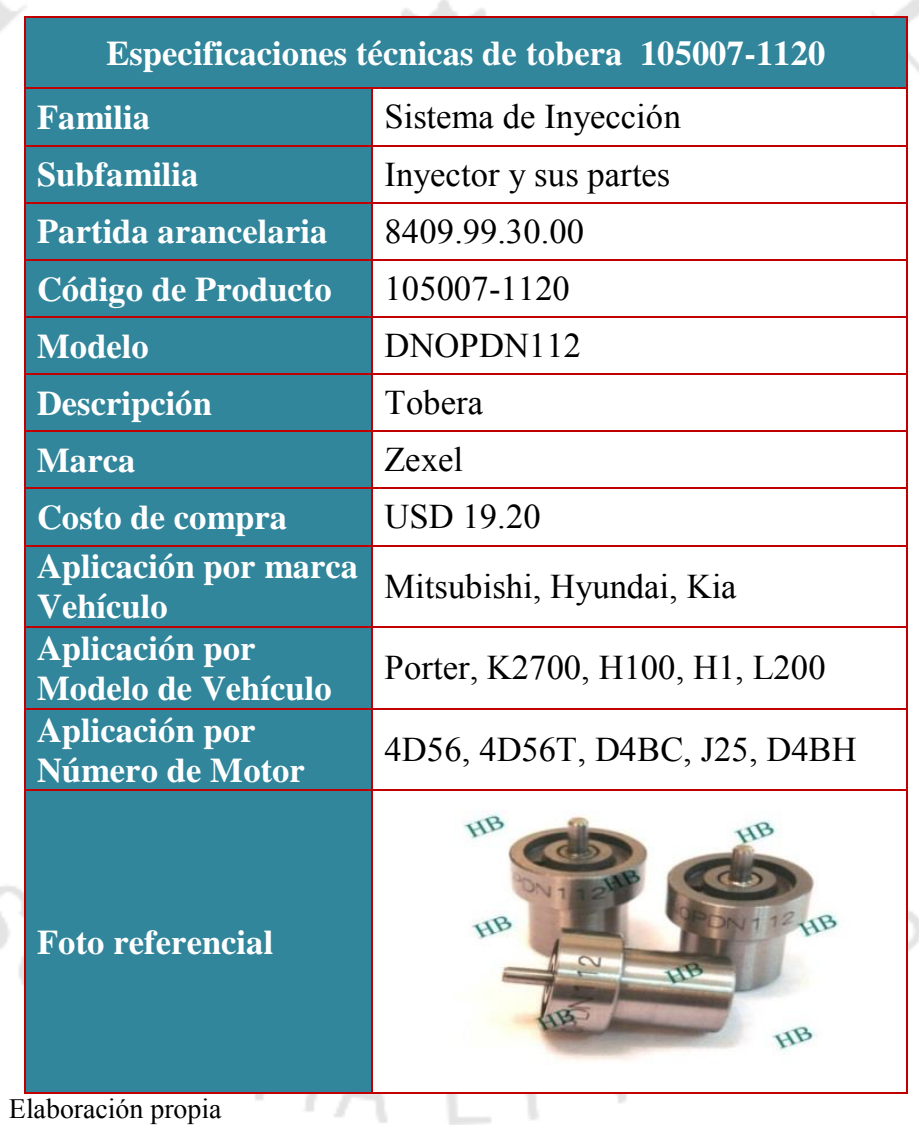

Al realizar la búsqueda en el website de Aduanas se puede obtener toda la información de las importaciones realizadas en el periodo que uno requiera, país de procedencia de producto, estado de producto, valor FOB, descripción, número de DUA, número de 
despacho, puerto de embarque, fecha de llegada, vía de transporte, cantidad de productos importados, peso, aduana de descarga, entre otros.

En el anexo Nro. 2 se puede observar el detalle de información de las empresas que importaron el repuesto que se colocó como ejemplo en el punto anterior.

Basándonos en el ejemplo anterior, como se observa en la tabla 5.3 podemos determinar que existen 5 empresas que importaron la tobera 105007-1120 en el periodo del 01 de Enero del 2014 al 31 de Diciembre del 2014, siendo la suma de unidades importadas 4,382 toberas, con un valor CIF promedio de 7.58 USD por unidad.

Tabla 5.3

Proveedores que importaron el repuesto "Tobera 105007-1120" entre Enero y Diciembre del 2014

\begin{tabular}{|c|c|c|c|}
\hline \multicolumn{4}{|c|}{ IMPORTACIONES EN EL PERIODO 01/01/2014 AL 31/12/2014 } \\
\hline $\begin{array}{l}\text { CNAN } \\
\text { CODIGO }\end{array}$ & $\begin{array}{c}8409993000 \\
105007-1120\end{array}$ & & \\
\hline Etiquetas de fila & $\begin{array}{c}\text { Suma de } \\
\text { UNID_FIQTY }\end{array}$ & $\begin{array}{l}\text { Promedio de } \\
\text { FOB UNIT } \\
\text { (USD) }\end{array}$ & $\begin{array}{l}\text { Promedio de } \\
\text { CIF UNIT } \\
\text { (USD) }\end{array}$ \\
\hline INVERSIONES TUYA \& CACERES SOCIEDAD & 62 & 10.58 & 10.75 \\
\hline PEVISA AUTO PARTS S.A. & 3230 & 7.34 & 7.38 \\
\hline REPUESTOS JAPONESES S.A. & 60 & 8.58 & 8.63 \\
\hline SISTEMA DE INYECCIËN DIESEL M \& F E.I.R. & 920 & 7.07 & 7.37 \\
\hline SISTEMA DE INYECCION DIESEL D \& RJ E.I.R & 110 & 6.31 & 6.60 \\
\hline Total general & 4382 & 7.42 & 7.58 \\
\hline
\end{tabular}

Con esta información el comprador tendrá 5 opciones de cotización, sabrá que el costo promedio para el importador es de 7.58 USD, tendrá conocimiento de un monto aproximado de precio de mercado, también podrá tener una idea del movimiento de rotación de 
este producto, si es demandado o no, entre otros análisis con el fin de llegar a una excelente negociación y obtener un buen precio para la compra del repuesto.

Al utilizar una correcta evaluación y negociación, el comprador de la empresa podrá generar una buena rentabilidad.

\section{Especialización en la compra de repuestos de los principales sistemas} automotrices y marcas de vehículos que atiende la empresa Laboratorio Diesel Senatinos.

La atención de pedidos de compras más complejos por lo general son de tipo "urgente" provienen de marcas de vehículos que no son muy comerciales y por ende los repuestos son escasos en el mercado y difíciles de hallar.

Para ello se propone que la empresa atienda a las principales marcas de vehículos según la información histórica de las marcas con más fluencia y que generen mayores ingresos para la empresa.

En la tabla 5.4 se puede observar la cantidad histórica de repuestos vendidos por marca de vehículo desde el 2009 hasta el 2014. Actualmente la empresa brinda servicios y venta de repuestos para 32 marcas de vehículos. Debe considerarse que por marca de vehículos existen por lo menos 35 modelos, y que los repuestos internos varían por año de fabricación de cada modelo de vehículo. Con este panorama, se pretende llegar a la especialización para la venta de repuestos y servicios de las marcas con mayor frecuencia de venta para la empresa.

De esta manera el comprador, también se puede especializar en la compra de repuestos, manejar códigos, equivalencias, aplicaciones, repuestos alternativos, entre otros conocimientos. 
Tabla 5.4

Repuestos vendidos por marca de vehículo 2009 al 2014

\begin{tabular}{|c|c|c|c|c|c|c|c|c|c|}
\hline \multicolumn{10}{|c|}{ Cantidad de repuestos vendidos por marca de vehículo } \\
\hline Nro. & Marcas & $\begin{array}{l}\text { Tipo de } \\
\text { unidad }\end{array}$ & 2009 & 2010 & 2011 & 2012 & 2013 & 2014 & Total \\
\hline 1 & Hyundai & Liviano & 1.374 & 1.107 & 2.024 & 2.526 & 2.576 & 3.149 & 12.756 \\
\hline 2 & Volvo & Pesado & 1.301 & 1.374 & 1.663 & 1.454 & 1.705 & 1.614 & 9.111 \\
\hline 3 & Toyota & Liviano & 739 & 1.028 & 1.374 & 1.424 & 1.574 & 1.579 & 7.718 \\
\hline 4 & kia & Liviano & 667 & 739 & 912 & 904 & 1.375 & 1.718 & 6.315 \\
\hline 5 & Chevrolet & Liviano & 166 & 276 & 599 & 1.054 & 1.408 & 1.689 & 5.192 \\
\hline 6 & Mitsubishi & Liviano & 659 & 739 & 723 & 1.091 & 767 & 936 & 4.915 \\
\hline 7 & Isuzu & Pesado & 323 & 228 & 235 & 449 & 525 & 659 & 2.419 \\
\hline 8 & Nissan & Liviano & 370 & 441 & 323 & 384 & 525 & 323 & 2.366 \\
\hline 9 & Scania & Pesado & 299 & 377 & 462 & 323 & 448 & 370 & 2.279 \\
\hline 10 & Suzuki & Liviano & 234 & 292 & 344 & 351 & 422 & 445 & 2.088 \\
\hline 11 & Volkswagen & Liviano & 179 & 244 & 292 & 275 & 211 & 269 & 1.470 \\
\hline 12 & Daewoo & Liviano & 163 & 130 & 299 & 165 & 221 & 213 & 1.191 \\
\hline 13 & Mercedes & Pesado & 38 & 52 & 65 & 87 & 305 & 448 & 995 \\
\hline 14 & Hino & Pesado & 72 & 194 & 85 & 227 & 211 & 158 & 947 \\
\hline 15 & Fiat & Liviano & 53 & 76 & 94 & 168 & 257 & 158 & 806 \\
\hline 16 & Sinotruck & Pesado & 0 & 31 & 115 & 196 & 211 & 214 & 767 \\
\hline 17 & Jac & Pesado & 8 & 38 & 109 & 125 & 144 & 282 & 706 \\
\hline 18 & JMC & Pesado & 0 & 0 & 87 & 189 & 140 & 206 & 622 \\
\hline 19 & Ford & Liviano & 67 & 80 & 93 & 109 & 87 & 129 & 565 \\
\hline 20 & Honda & Liviano & 49 & 36 & 85 & 92 & 124 & 181 & 567 \\
\hline 21 & Dong Feng & Pesado & 0 & 16 & 71 & 149 & 106 & 165 & 507 \\
\hline 22 & Mazda & Liviano & 0 & 0 & 87 & 63 & 142 & 209 & 501 \\
\hline 23 & Peugeot & Liviano & 23 & 38 & 32 & 45 & 87 & 63 & 288 \\
\hline 24 & Foton & Pesado & 0 & 0 & 31 & 23 & 87 & 143 & 284 \\
\hline 25 & Forland & Liviano & 0 & 0 & 36 & 45 & 69 & 74 & 224 \\
\hline 26 & Renault & Liviano & 11 & 20 & 26 & 40 & 53 & 49 & 199 \\
\hline 27 & Jeep & Liviano & 16 & 21 & 23 & 38 & 45 & 52 & 195 \\
\hline 28 & Mahindra & Liviano & 0 & 0 & 30 & 42 & 49 & 67 & 188 \\
\hline 29 & Chery & Liviano & 0 & 0 & 20 & 32 & 39 & 48 & 139 \\
\hline 30 & Great Wall & Liviano & 0 & 0 & 22 & 33 & 45 & 38 & 138 \\
\hline 31 & Yuejin & Pesado & 16 & 25 & 22 & 20 & 22 & 25 & 130 \\
\hline 32 & Subaru & Liviano & 6 & 13 & 17 & 9 & 26 & 22 & 93 \\
\hline & Total & & $\mathbf{8 . 8 4 2}$ & 9.625 & 12.411 & 14.144 & 16.019 & 17.709 & 66.681 \\
\hline
\end{tabular}

Fuente: Laboratorio Diesel Senatinos S.A.

Elaboración: propia 
De la misma forma se tiene que evaluar cuáles son los repuestos que tienen mayor rotación por tipo de familia, qué sistema del vehículo tiene mayor frecuencia de servicios y venta de repuestos.

Considerando la tabla 3.8 se puede observar que las principales ventas de repuestos corresponden a las familias, inyección y electrónica, embragues y frenos, y filtros y aceites. De esta manera no se requiere que la empresa sea reconocida por atender servicios y vender repuestos de la mayor cantidad de vehículos, sino por brindar servicios de especialización y contar con el stock suficiente para atender eficientemente a los mismos, así como comercializar y difundir la venta de repuestos de especialización para encaminarse a la distribución local y posteriormente nacional.

\section{Soluciones del proceso de ventas}

Capacitación del personal de ventas en las funciones técnicas del repuesto.

Las capacitaciones deben darse para brindar la mayor información del producto en relación a conocimientos técnicos, diferenciación y estándares de calidad, ya que el conocimiento es la principal herramienta para el desenvolvimiento profesional de una empresa, que generará confiabilidad y satisfacción en los clientes.

De esta manera, se pretende desarrollar las siguientes capacitaciones en base a los repuestos del sistema de inyección y embragues.

En las tablas 5.5 y 5.6 se detalla las capacitaciones de los sistema de inyección y embragues que incluyen módulos con aplicación de metodología práctica y teórica necesarias para obtener los conocimientos en el funcionamiento y utilización de los repuestos. 


\section{Tabla 5.5}

Programa de capacitación para la venta de repuestos - Sistema de Inyección



Fuente: Autorex Peruana S.A.

Elaboración: Propia 
Tabla 5.6

Programa de capacitación para la venta de repuestos - Sistema de Embragues

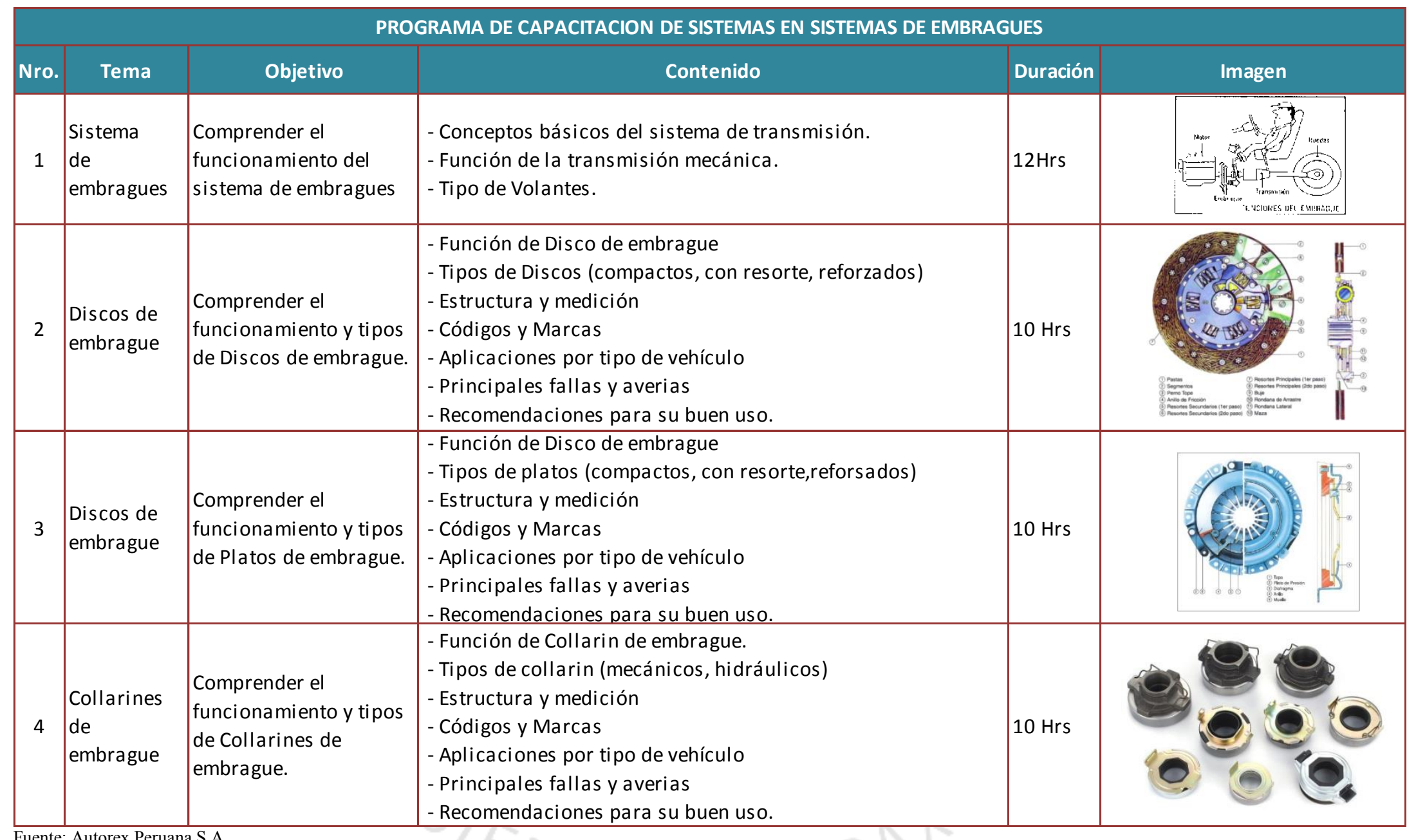

Fente: Autorex Peruana S.A

Elaboración: propia 
Elaborar perfiles $y$ funciones para el puesto de vendedores con indicadores de evaluación de desempeño.

Al implementar esta solución es necesario incorporar a dos vendedores con capacidad de ventas y comercialización de repuestos, uno para ser destinado a las visitas a campo con el fin de obtener nuevos clientes y reforzar la cartera de clientes asignada. El otro vendedor colaborará con las ventas en mostrador con la atención telefónica, personal y vía web.

Es por esta razón que se presentarán los perfiles y funciones del puesto de ventas para los nuevos vendedores y para el ejecutivo de ventas ya existente en la empresa.

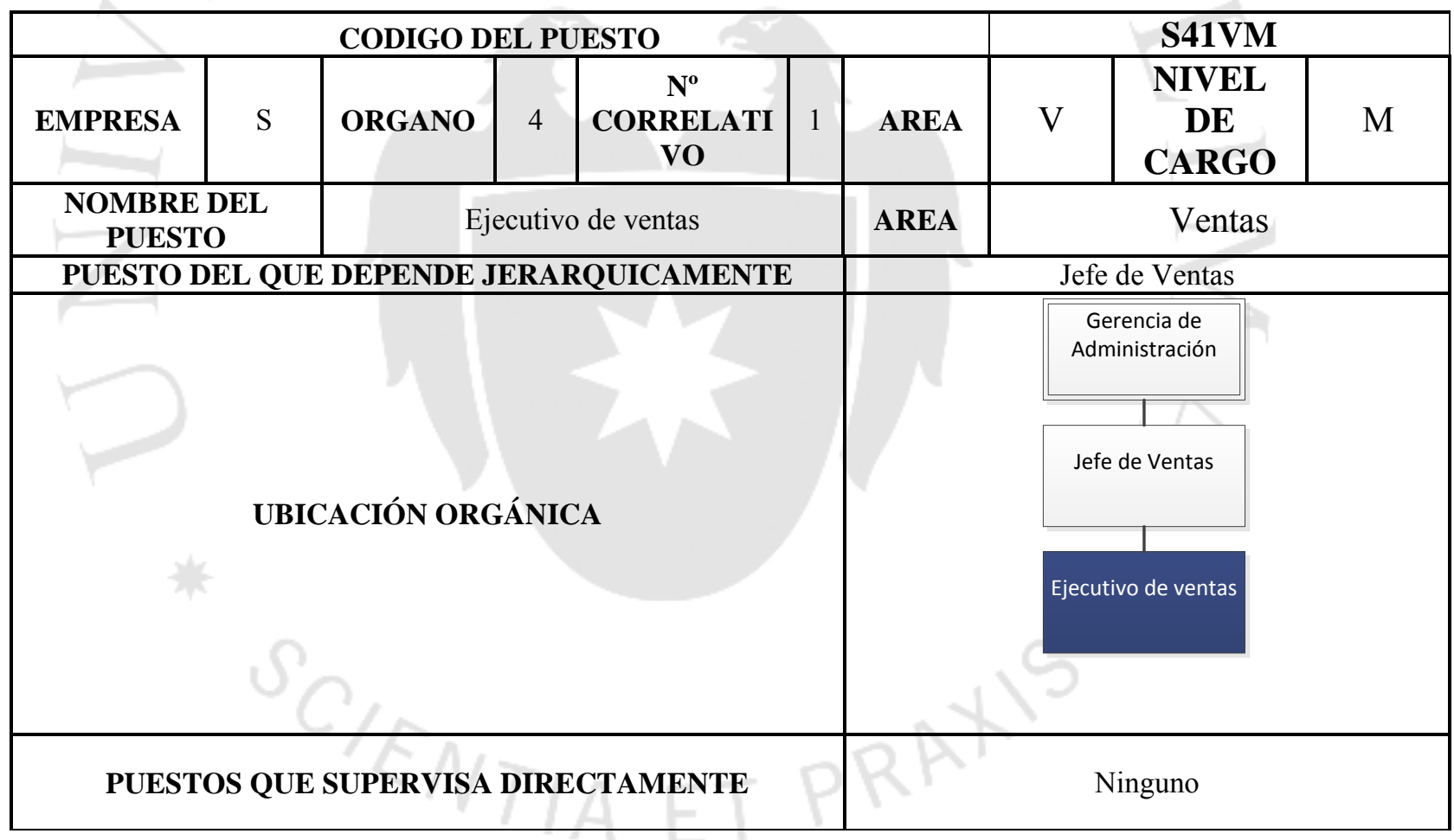

\section{OBJETIVOS}

$>$ Incrementar las ventas de los repuestos automotrices que ofrece la empresa

$>$ Posicionar a Senatinos como marca, especializada en la venta de repuestos automotrices.

$>$ Conocer los productos a vender 


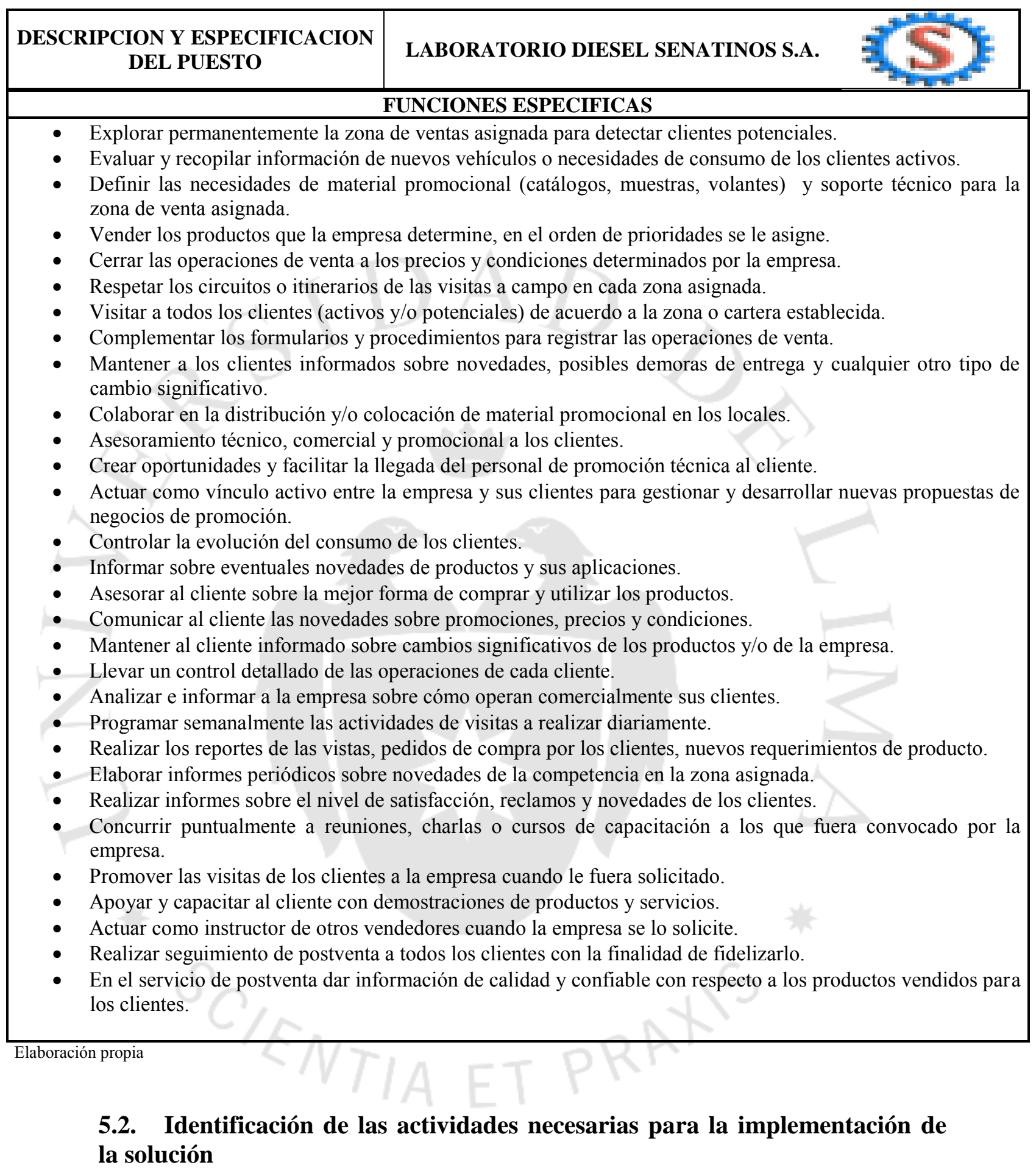

\section{$>$ Búsqueda de proveedores a través de sistema de aduanas}

1. Definir el periodo de implementación de la solución. 
Planificar con la gerencia general y los jefes del área de compras y logística para definir el periodo de implementación para la capacitación de los compradores.

2. Sensibilizar al personal de compras.

Se deberá comunicar a los compradores y a los integrantes del área de compras, lo que se quiere lograr con la implementación de la búsqueda de proveedores a través del sistema de aduanas, el tiempo que van a ahorrar en cada cotización, la información que obtendrán para el análisis de cada compra, y las excelentes negociaciones que obtendrán al realizar un análisis de precios. Todo ello, con la finalidad de ganar conocimiento, experiencia y mejorar la rentabilidad de la empresa obteniendo logros y crecimiento del área de trabajo.

3. Validar y clasificar cada tipo de repuesto por familias y sub familias.

Cada repuesto debe tener una ubicación dentro de una familia y subfamilia. Con ello, se identificará a que sector del vehículo pertenece y se facilitará la búsqueda de partidas arancelarias a la cual pertenece.

4. Realizar la lista de número de partidas arancelarias para cada tipo de repuesto.

5. Diseñar el manual y procedimientos.

Elaborar un manual instructivo de los conceptos claves y el procedimiento de cada paso a seguir para la utilización del sistema de Aduanas, que incluyan casos y tipos de búsqueda. 
6. Capacitar en el proceso de búsqueda de proveedores a través del sistema de Aduanas.

Instruir a cada uno de los compradores cómo hacer efectiva la búsqueda de proveedores y obtener información de las importaciones de repuestos.

7. Evaluar el manejo y resultado de la utilización del sistema de aduanas por cada uno de los compradores.

8. Realizar las acciones correctivas o preventivas, de ser necesario, según el resultado de la evaluación.

9. Registrar la data de los nuevos proveedores.

Recolectar la información necesaria de los nuevos proveedores, en cuanto a los productos comprados.

10. Verificar el cumplimiento del nuevo procedimiento de búsqueda para analizar ocurrencias.

Especialización en la compra de repuestos de los principales sistemas automotrices y marcas de vehículos que atiende la empresa.

1. Definir el periodo de implementación de la solución.

Planificar con la gerencia general y los jefes de área de la empresa para definir el periodo de implementación.

2. Sensibilizar al personal de compras y almacén.

El personal debe ser informado de los objetivos $y$ beneficios de la implementación. De esta manera se sentirá motivado a colaborar en cada una de las actividades designadas. 
3. Listar las familias y subfamilias de las marcas de vehículos seleccionados.

Realizar una recopilación de información de los repuestos de las marcas de vehículos de los sistemas seleccionados, en cuanto a códigos de producto, especificaciones, equivalencias, costos y volumen.

4. Seleccionar y clasificar los repuestos que pertenecen a las familias y subfamilias seleccionadas (sistema de inyección, embragues y mantenimiento)

5. Separar los repuestos que no pertenecen en aplicación a las marcas de los vehículos seleccionados.

6. Reorganizar las ubicaciones de los repuestos seleccionados.

Cada repuesto seleccionado será reubicado por áreas de sistemas o familias con su respectiva codificación.

7. Inventariar y promocionar los repuestos que han sido separados.

Se debe contabilizar y tomar fotos para la publicación y promoción de remate o venta de los repuestos que no pertenecen a los sistemas de especialización.

8. Realizar reuniones con los jefes y técnicos especializados de los sistemas de inyección y embrague.

Recopilar la información de las funciones técnicas de cada subfamilia del sistema de inyección y embragues.

9. Actualizar los sistemas internos de la empresa con la ubicación, cantidad y códigos de repuestos seleccionados 
10. Realizar acciones correctivas y/o preventivas, de ser necesario.

\section{Capacitación del personal de ventas en las funciones técnicas del repuesto.}

1. Definir los contenidos de cada tema de la capacitación con la alta dirección, gerencia y los responsables del área.

2. Definir los objetivos de cada tema, curso y entrenamiento en relación a los resultados esperados de cada vendedor.

3. Seleccionar y elegir a los tutores o consultoras que impartirán la enseñanza, así como el material a utilizar para guía práctica de los vendedores.

4. Elaborar el plan de reglas a cumplir, control de asistencia, puntualidad, comportamiento.

5. Establecer los niveles de medición para la evaluación de los intervinientes.

6. Realizar la charla de sensibilización y objetivos de la capacitación a cada uno de los vendedores.

7. Dictar los temas teóricos y prácticos de los cursos seleccionados para la capacitación.

8. Evaluar a los vendedores en cuanto a los resultados de aprendizaje de los temas dictados en cada módulo.

9. Ejecutar la prueba piloto, con la realización de simulaciones y pruebas. 
10. Medir los resultados, en cuanto a conocimientos, habilidades, actitudes y conductas para hacer más eficiente el trabajo y evaluar si se llegó al objetivo esperado.

11. Realizar acciones correctivas y/o preventivas, de ser el caso.

\section{Elaborar perfiles y funciones para el puesto de vendedores con indicadores de evaluación de desempeño.}

1. Reunión con los responsables del área de ventas para definir las necesidades y objetivos.

2. Elaboración de los perfiles y funciones de los vendedores.

3. Elaboración de indicadores de desempeño.

4. Aprobación y corrección de perfiles, funciones e indicadores.

5. Convocatoria para cubrir 2 puestos de ejecutivos de ventas.

6. Evaluación y análisis de los postulantes.

7. Entrevista de los postulantes finales con el jefe de ventas.

8. Capacitación y brindar funciones a nuevos vendedores.

9. Seguimiento y evaluación del desempeño de los vendedores.

10. Elaboración de reportes de los resultados de evaluación del desempeño de los colaboradores.

11. Acciones correctivas y/o preventivas de ser necesario. 


\subsection{Presupuesto general para la implementación de la solución.}

Se ha planteado el presupuesto para cada uno de los procesos a mejorar. Para el caso de la implementación de mejora del proceso de compras el costo será mínimo ya que se llevará a cabo con los recursos de la empresa, es decir, la implementación se realizará con mismos colaboradores del área de compras, y se contará con el apoyo de los jefes de mayor experiencia de las áreas de operaciones y mantenimiento. De esta manera es necesario contabilizar las horas hombre invertidas de cada colaborador que participe, así como el costo de materiales y equipos a utilizar.

Se debe tomar en consideración que los cálculos de los costos de hora hombre de cada colaborador han sido calculados en función al factor que se detalla en el anexo Nro. 3, ya que así se sabe con exactitud el valor real invertido en cada trabajador. En la tabla 5.7 se observa que se requiere de S/.13.064,05 para la implantación de la solución "Búsqueda de proveedor a través del sistema de Aduanas"

De la misma forma, en la tabla 5.8 se puede observar que el monto total para la implementación de la solución "Especialización en la compra de repuestos de los principales sistemas automotrices y marcas de vehículos que atiende la empresa" es de S/. 5.960,73 


\section{Tabla 5.7}

Presupuesto para la implementación de solución - Proceso de Compras

\begin{tabular}{|c|c|c|c|c|c|c|c|}
\hline Solución & Descripción de inversión para la mejora & Cant & Unidad & & $\begin{array}{l}\text { to por } \\
\text { nidad } \\
\text { S/. } \\
\end{array}$ & & $\begin{array}{l}0 \text { total } \\
\text { S/. }\end{array}$ \\
\hline \multirow{11}{*}{$\begin{array}{l}\text { Búsqueda } \\
\quad \text { de } \\
\text { proveedor a } \\
\text { través del } \\
\text { sistema de } \\
\text { Aduanas }\end{array}$} & $\begin{array}{l}\text { Capacitación para el manejo y utilización } \\
\text { del sistema de Aduanas a través de la } \\
\text { website de Sunat. }\end{array}$ & \multirow[t]{2}{*}{4} & \multirow{2}{*}{$\begin{array}{l}\text { Capacitación } \\
\text { por } \\
\text { Trabajador }\end{array}$} & & \multirow[t]{2}{*}{520,00} & \multirow[t]{2}{*}{$\mathrm{S} /}$. & \multirow[t]{2}{*}{$2.080,00$} \\
\hline & (6 módulos teóricos +6 módulos prácticos) & & & & & & \\
\hline & $\begin{array}{l}\text { Costo de las horas hombre de (2) } \\
\text { compradores invertidas en la capacitación }\end{array}$ & \multirow{2}{*}{72} & \multirow{2}{*}{$\begin{array}{l}\text { Horas } \\
\text { invertidas de } \\
\text { compradores }\end{array}$} & \multirow{2}{*}{$\mathrm{S} /}$. & \multirow{2}{*}{11,78} & \multirow{2}{*}{$\mathrm{S} /}$. & \multirow{2}{*}{848,16} \\
\hline & $\begin{array}{l}\text { ( } 3 \text { horas/módulo)x } 12 \text { módulos x } 2 \\
\text { compradores }\end{array}$ & & & & & & \\
\hline & $\begin{array}{l}\text { Costo de las horas hombre del jefe de } \\
\text { compras y jefe de logística invertidas en la } \\
\text { capacitación }\end{array}$ & \multirow[t]{2}{*}{72} & \multirow{2}{*}{$\begin{array}{l}\text { Horas } \\
\text { invertidas de } \\
\text { jefes }\end{array}$} & \multirow[t]{2}{*}{$\mathrm{S} /}$. & \multirow[t]{2}{*}{19,60} & \multirow[t]{2}{*}{$\mathrm{S} /}$. & \multirow[t]{2}{*}{$1.411,20$} \\
\hline & (3 horas/módulo)x 12 módulos x 2 jefes & & & & & & \\
\hline & $\begin{array}{l}\text { Materiales destinados para las } \\
\text { capacitaciones }\end{array}$ & \multirow{2}{*}{1} & \multirow{2}{*}{$\begin{array}{l}\text { Materiales de } \\
\text { escritorio } \\
\text { varios }\end{array}$} & \multirow{2}{*}{$\mathrm{S} /}$. & \multirow{2}{*}{755,00} & \multirow{2}{*}{$\mathrm{S} /}$. & \multirow{2}{*}{755,00} \\
\hline & $\begin{array}{l}3 \text { cientos de hojas Bond } 75,00 \mathrm{gm} \mathrm{A} 4+ \\
\text { Impresiones laser }+ \text { bolígrafos }+ \text { manuales }\end{array}$ & & & & & & \\
\hline & $\begin{array}{l}\text { Clasificación y búsqueda de partidas } \\
\text { arancelarias de cada ítem. }\end{array}$ & \multirow[b]{2}{*}{479,6} & \multirow[b]{2}{*}{$\begin{array}{l}\text { Horas } \\
\text { invertidas por } \\
\text { dos } \\
\text { compradores }\end{array}$} & \multirow[b]{2}{*}{$\mathrm{S} /$} & \multirow[b]{2}{*}{11,78} & \multirow[b]{2}{*}{$\mathrm{S} /}$. & \multirow[b]{2}{*}{$5.649,69$} \\
\hline & $\begin{array}{l}\text { İtems de repuestos de baja rotación }(1,240 \\
): 10 \text { partidas/hora } \\
\text { İtems de repuestos de mediana rotación } \\
(3,260): 18 \text { partidas / hora } \\
\text { İtems de repuestos de alta rotación }(7,842) \text { : } \\
48 \text { partidas / hora }\end{array}$ & & & & & & \\
\hline & $\begin{array}{l}\text { Repotenciación de los procesadores de cada } \\
\text { colaborador, para la agilizar la carga de } \\
\text { información de aduanas }\end{array}$ & 4 & $\begin{array}{l}\text { Repotenciar } \\
\text { procesador }\end{array}$ & $\mathrm{S} /$. & 580,00 & $\mathrm{~S} /$. & $2.320,00$ \\
\hline \multicolumn{6}{|c|}{ Total S/. } & S/. & $13.064,05$ \\
\hline
\end{tabular}


Tabla 5.8

Presupuesto para la implementación de solución - Proceso de compras

\begin{tabular}{|c|c|c|c|c|c|c|c|}
\hline Solución & $\begin{array}{c}\text { Descripción de inversión para la } \\
\text { mejora }\end{array}$ & Cant & Unidad & & $\begin{array}{l}\text { por } \\
\text { dad } \\
\text {. }\end{array}$ & & total \\
\hline \multirow{4}{*}{$\begin{array}{l}\text { Especialización } \\
\text { en la compra de } \\
\text { repuestos de los } \\
\text { principales } \\
\text { sistemas } \\
\text { automotrices y } \\
\text { marcas de } \\
\text { vehículos que } \\
\text { atiende la } \\
\text { empresa }\end{array}$} & $\begin{array}{l}\text { Costo de horas hombre del jefe de } \\
\text { logística invertidos para la ejecución de la } \\
\text { mejora } \\
\text { (Estandarizar, preparar capacitación, } \\
\text { capacitación a compradores y corrección } \\
\text { y pruebas) }\end{array}$ & 22 & $\begin{array}{l}\text { Horas } \\
\text { Hombre }\end{array}$ & $\mathrm{S} /$. & 19,60 & $\mathrm{~S} /$. & 431,20 \\
\hline & $\begin{array}{l}\text { Costo de las horas hombre de los } \\
\text { compradores invertidas en la } \\
\text { capacitación } \\
3 \text { horas/ modulo x } 3 \text { módulos x } 2 \\
\text { compradores }\end{array}$ & 18 & $\begin{array}{c}\text { Horas por } \\
\text { compradore } \\
\text { s }\end{array}$ & $\mathrm{S} /$. & 11,78 & $\mathrm{~S} /$. & 212,04 \\
\hline & $\begin{array}{l}\text { Selección y clasificación de repuestos por } \\
\text { familia de producto. }\end{array}$ & \multirow[t]{2}{*}{451,4} & \multirow{2}{*}{$\begin{array}{l}\text { Horas } \\
\text { hombre }\end{array}$} & \multirow[t]{2}{*}{$\mathrm{S} /}$. & \multirow[t]{2}{*}{11,78} & \multirow[t]{2}{*}{$\mathrm{S} /}$. & \multirow[t]{2}{*}{$5.317,4 \mathrm{C}$} \\
\hline & $0.08 \mathrm{hrs} /$ item x 5643 items & & & & & & \\
\hline \multicolumn{6}{|c|}{ Total S/. } & $\mathrm{S} /$. & $5.960,73$ \\
\hline
\end{tabular}

Elaboración propia

Para el caso del presupuesto en la mejora de los procesos de ventas consideramos un monto de S/. 22.711,94 en la implantación de la solución “Capacitación del personal de ventas" y "Elaborar perfiles y funciones para el puesto de vendedores con indicadores de evaluación de desempeño." con la incorporación de dos nuevos vendedores para reforzar la fuerza de ventas como se observa en la tabla 5.9. Los costos de las capacitaciones por cada módulo se indican el anexo Nro. 4. 
Tabla 5.9

Presupuesto para la implementación de solución - Proceso de ventas

\begin{tabular}{|c|c|c|c|c|c|}
\hline Solución & $\begin{array}{l}\text { Descripción de inversión para la } \\
\text { mejora }\end{array}$ & Cantidad & $\begin{array}{l}\text { Unidad } \\
(\mathbf{S} / .)\end{array}$ & $\begin{array}{l}\text { Costo por } \\
\text { unidad } \\
\text { (S/.) }\end{array}$ & $\begin{array}{l}\text { Costo total } \\
(\mathbf{S} / .)\end{array}$ \\
\hline \multirow{10}{*}{$\begin{array}{l}\text { Capacitación } \\
\text { del personal de } \\
\text { ventas }\end{array}$} & $\begin{array}{l}\text { Capacitación del personal de ventas en } \\
\text { la función técnica de los repuestos. }\end{array}$ & \multirow{2}{*}{4} & \multirow{2}{*}{$\begin{array}{c}\text { capacitación } \\
\text { por colaborador }\end{array}$} & \multirow{2}{*}{$2.650,00$} & \multirow{2}{*}{$10.600,00$} \\
\hline & $\begin{array}{l}\text { Costo x capacitación (ver anexo Nro. } 4 \text { ) } \\
\text { número de colaboradores a capacitar } 4\end{array}$ & & & & \\
\hline & $\begin{array}{l}\text { Costo de las horas hombre de los } \\
\text { vendedores invertidas en la } \\
\text { capacitaciones asignadas }\end{array}$ & \multirow[t]{2}{*}{324} & \multirow{2}{*}{$\begin{array}{c}\text { Horas } \\
\text { invertidas por } \\
\text { vendedores }\end{array}$} & \multirow[t]{2}{*}{9,42} & \multirow[t]{2}{*}{$3.052,08$} \\
\hline & $\begin{array}{l}72 \text { horas/vendedor x } 3 \text { vendedores }+36 \\
\text { horas/vendedor x } 3 \text { vendedores }\end{array}$ & & & & \\
\hline & $\begin{array}{c}\text { Costo de las horas hombre del jefe de } \\
\text { ventas invertidas en la capacitaciones } \\
\text { asignadas }\end{array}$ & \multirow[t]{2}{*}{134} & \multirow{2}{*}{$\begin{array}{c}\text { Horas } \\
\text { invertidas por } \\
\text { jefes de ventas }\end{array}$} & \multirow[t]{2}{*}{15,69} & \multirow[t]{2}{*}{$2.102,46$} \\
\hline & $\begin{array}{l}92 \text { horas/jefe x } 1 \text { jefe }+42 \text { horas/jefe x } 1 \\
\text { jefe }\end{array}$ & & & & \\
\hline & Contratación de dos vendedores & \multirow[b]{2}{*}{2} & \multirow{2}{*}{$\begin{array}{l}\text { Honorarios por } \\
\text { vendedor } \\
\text { incorporado }\end{array}$} & \multirow[b]{2}{*}{$1.808,00$} & \multirow[b]{2}{*}{$3.616,00$} \\
\hline & $\begin{array}{c}1 \text { vendedor de mostrador }+1 \text { vendedor } \\
\text { de visita }\end{array}$ & & & & \\
\hline & Costo de adquirir computadoras nuevas & \multirow{2}{*}{2} & \multirow{2}{*}{ computadora } & \multirow{2}{*}{$1.200,00$} & \multirow{2}{*}{$2.400,00$} \\
\hline & Computadora/ vendedor $\mathrm{x} 2$ vendedores & & & & \\
\hline \multirow{4}{*}{$\begin{array}{l}\text { Elaborar } \\
\text { perfiles y } \\
\text { funciones para } \\
\text { el puesto de } \\
\text { vendedores con } \\
\text { indicadores de } \\
\text { evaluación de } \\
\text { desempeño. }\end{array}$} & $\begin{array}{l}\text { Costo de horas hombre del jefe de } \\
\text { ventas invertidos en preparar perfiles, } \\
\text { funciones e indicadores. }\end{array}$ & \multirow[t]{2}{*}{24} & \multirow[t]{2}{*}{ Horas Hombre } & \multirow[t]{2}{*}{15,69} & \multirow[t]{2}{*}{376,56} \\
\hline & (4hrs/día x 3 día/semana x 2 semanas) & & & & \\
\hline & $\begin{array}{l}\text { Costo de horas hombre del jefe de } \\
\text { ventas invertidos en hacer reportes, } \\
\text { seguimiento y evaluación de vendedores }\end{array}$ & \multirow[t]{2}{*}{36} & \multirow[t]{2}{*}{ Horas Hombre } & \multirow[t]{2}{*}{15,69} & \multirow[t]{2}{*}{564,84} \\
\hline & (4hrs/día x 3 día/semana x 3 semanas) & & & & \\
\hline \multicolumn{5}{|c|}{ Total S/. } & $22.711,94$ \\
\hline
\end{tabular}

Elaboración: propia

Finalmente se puede concluir que la inversión total de la implementación del presente proyecto asciende a un monto de S/. 41.736,72 (ver tabla 5.10).

Tabla 5.10

Costo total de implementación de mejora

\begin{tabular}{|c|c|cc|}
\hline \multirow{2}{*}{ Tipo } & $\begin{array}{c}\text { Costo de } \\
\text { Implementación }\end{array}$ & \multicolumn{2}{|c|}{$\begin{array}{c}\text { Monto } \\
\text { S/. }\end{array}$} \\
\hline \multirow{2}{*}{ Procesos } & Compras & S/. & $19.024,78$ \\
& Ventas & S/. & $22.711,94$ \\
\cline { 2 - 4 } & Total & S/. & $\mathbf{4 1 . 7 3 6 , 7 2}$ \\
\hline
\end{tabular}

Elaboración: propia 


\subsection{Cronograma de implementación}

La implementación del proyecto se ejecutará en el periodo de 12 meses, iniciando con la implementación de las mejoras en el proceso de compras con una duración de 28 semanas como se muestra las tablas 5.11 y 5.12, posteriormente en el mes 6 se iniciará con la implementación de las mejoras en el proceso de ventas

\section{Tabla 5.11}

Cronograma de implementación para la solución de mejora en el proceso de compras

\begin{tabular}{|c|c|c|c|c|c|c|c|c|c|c|c|c|c|c|c|c|c|c|c|c|c|c|c|c|c|c|c|c|c|}
\hline \multirow{3}{*}{$\begin{array}{l}\text { Actividades de para la implementacion de las } \\
\text { soluciones propuestas }\end{array}$} & \multirow{3}{*}{$\begin{array}{c}\text { Duración } \\
\text { en } \\
\text { semanas }\end{array}$} & \multicolumn{28}{|c|}{ Programación (Semanas) } \\
\hline & & \multicolumn{4}{|c|}{ Mes 1} & \multicolumn{4}{|c|}{ Mes 2} & \multicolumn{4}{|c|}{ Mes 3} & \multicolumn{4}{|c|}{ Mes 4} & \multicolumn{4}{|c|}{ Mes 5} & \multicolumn{4}{|c|}{ Mes 6} & \multicolumn{4}{|c|}{ Mes 7} \\
\hline & & 1 & 2 & 3 & 4 & 5 & 6 & 7 & 8 & 9 & 10 & 11 & 12 & 13 & 14 & 15 & 16 & 17 & 18 & 19 & 20 & 21 & 22 & 23 & 24 & 25 & 26 & 27 & 28 \\
\hline \multicolumn{30}{|l|}{$\begin{array}{l}\text { Solución: Búsqueda de proveedores a través del } \\
\text { sistema de aduanas }\end{array}$} \\
\hline 1. Definir el periodo de implementación de la solución. & 1 & & & & & & & & & & & & & & & & & & F & & +1 & & & & & & & & \\
\hline 2. Sensibilizar al personal de compras & 1 & & & & & & & & & & & & & & & & & & 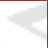 & & & & & & & & & & \\
\hline $\begin{array}{l}\text { 4. Realizar la lista de número de partidas } \\
\text { arancelarias para cada tipo de repuesto. }\end{array}$ & 4 & & & & & & & & & & & & & & & & & & & & & & & & & & & & \\
\hline 5. Diseñar el manual y procedimientos. & 3 & & & & & & & & & & & & & & & & & & & & & & & & & & & & \\
\hline $\begin{array}{l}\text { 6. Capacitacitar en el proceso de la búsqueda de } \\
\text { proveedores a través del sistema de Aduanas. }\end{array}$ & 4 & & & & & & & & & & & & & & & & & & & & & & & & & & & & \\
\hline $\begin{array}{l}\text { 7. Evaluar el manejo y resultado de la utilización del } \\
\text { sistema de aduanas a cada uno de los compradores. }\end{array}$ & 2 & & & & & & & & 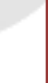 & & & & & & & & & tal & & & & & & & & & & & \\
\hline $\begin{array}{l}\text { 8. Realizar las acciones correctivas o preventivas de } \\
\text { ser necesario según el resultado de la evaluación. }\end{array}$ & 2 & & & & & & & & & & & & & $\forall$ & & & & & & & & & & & & & & & \\
\hline 9. Registrar la data de los nuevos proveedores. & 2 & & & & & & & & & & & 7 & & s. & & & & & & & & & & & & & & & \\
\hline $\begin{array}{l}\text { 10. Verificar el cumplimiento del nuevo procedimiento } \\
\text { de búsqueda para analizar ocurrencias. }\end{array}$ & 1 & 7 & & & & & & 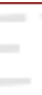 & & & 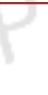 & 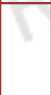 & & & & & & & & & & & & & & & & & \\
\hline
\end{tabular}


Tabla 5.12

Cronograma de implementación para la solución de mejora en el proceso de compras

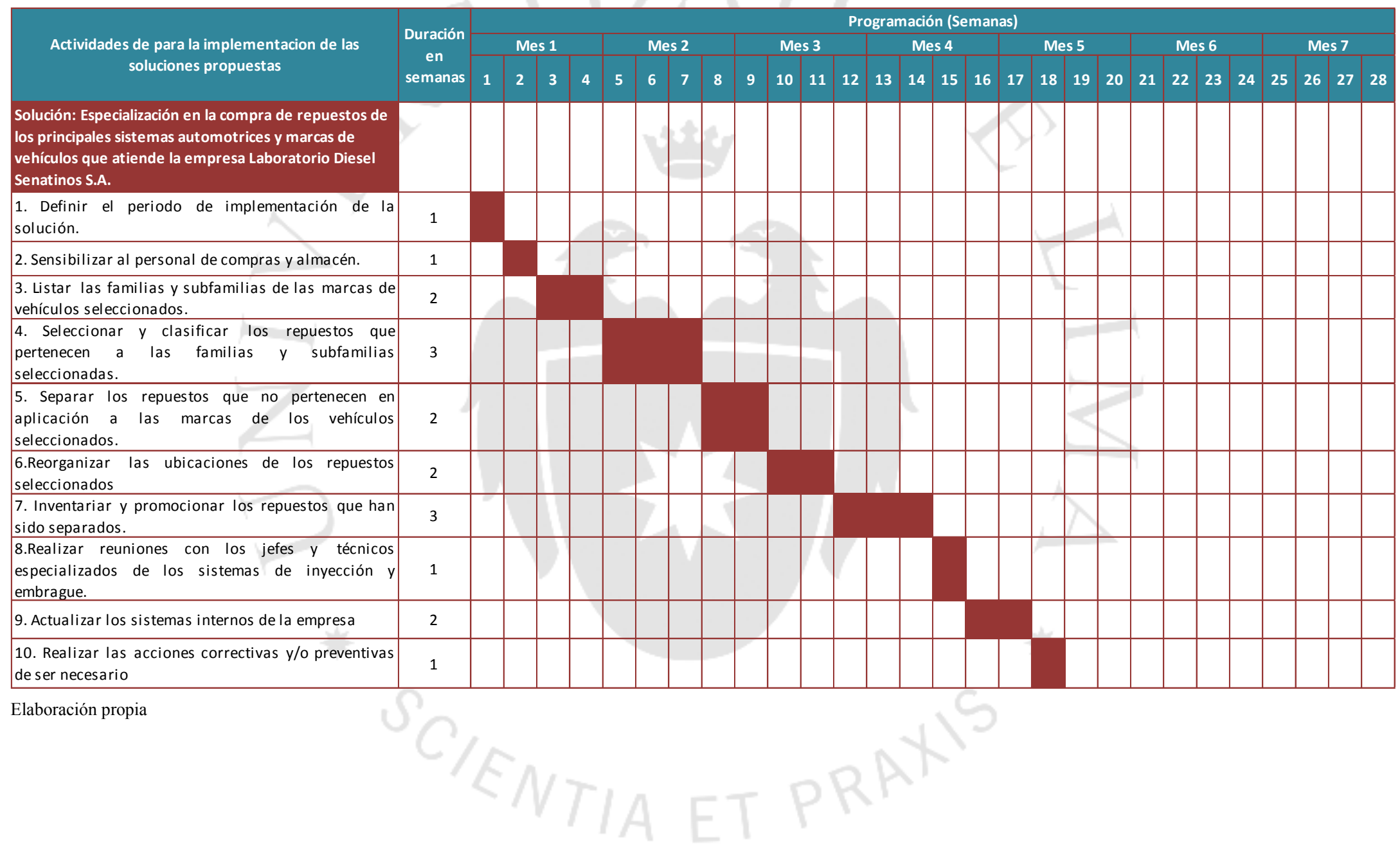


Las actividades de la primera solución para la implementación de la mejora en el proceso de ventas se realizan paralelamente a partir de la semana 9 juntamente con la implementación de la segunda solución como se observa en las tablas 5.13 y 5.14 .

Tabla 5.13

Cronograma de implementación para la solución de mejora en el proceso de ventas

\begin{tabular}{|c|c|c|c|c|c|c|c|c|c|c|c|c|c|c|c|c|c|c|c|c|c|c|c|c|c|c|c|c|c|}
\hline \multirow{3}{*}{$\begin{array}{l}\text { Actividades de para la implementacion de las } \\
\text { soluciones propuestas }\end{array}$} & \multirow{3}{*}{$\begin{array}{c}\text { Duración } \\
\text { en } \\
\text { semanas }\end{array}$} & \multicolumn{28}{|c|}{ Programación (Semanas) } \\
\hline & & \multicolumn{4}{|c|}{ Mes 6} & \multicolumn{4}{|c|}{ Mes 7} & \multicolumn{4}{|c|}{ Mes 8} & \multicolumn{4}{|c|}{ Mes9 } & \multicolumn{4}{|c|}{ Mes 10} & \multicolumn{4}{|c|}{ Mes 11} & \multicolumn{4}{|c|}{ Mes 12} \\
\hline & & 1 & 2 & 3 & 4 & 5 & 6 & 7 & 8 & 9 & 10 & 11 & 12 & 13 & 14 & 15 & 16 & 17 & 18 & 19 & 20 & 21 & 22 & 23 & 24 & 25 & 26 & 27 & 28 \\
\hline $\begin{array}{l}\text { Solución: Elaborar perfiles y funciones para el puesto } \\
\text { de vendedores con indicadores de evaluación de } \\
\text { desempeño }\end{array}$ & & & & & & & & & & & & & & & & & & & & & & & & & & & & & \\
\hline $\begin{array}{l}\text { 1. Reunión con los responsables del área de ventas } \\
\text { para definir las necesidades y objetivos. }\end{array}$ & 1 & & & & & & & & & & & & & & & & & & $=$ & -1 & & & & & & & & & \\
\hline $\begin{array}{l}\text { 2. Elaboración de los perfiles y funciones de los } \\
\text { vendedores }\end{array}$ & 2 & & & & & & & & & & & & & & & & & & & 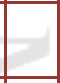 & & & & & & & & & \\
\hline 3. Elaboración de indicadores de desempeño. & 2 & & & & & & & & & & & & & & & & & & & & & & & & & & & & \\
\hline $\begin{array}{l}\text { 4. Aprobación y corrección de perfiles, funciones e } \\
\text { indicadores }\end{array}$ & 2 & & & & & & & & & & & & & & & & & & & 1 & & & & & & & & & \\
\hline $\begin{array}{l}\text { 5. Convocatoria para cubrir } 2 \text { puestos de ejecutivos } \\
\text { de ventas. }\end{array}$ & 2 & & & & & & & & & & & & & & & & & & & & & & & & & & & & \\
\hline 6. Evaluación y análisis de los postulantes. & 1 & & & & & & & & & & & & & & & & & & & & & & & & & & & & \\
\hline $\begin{array}{l}\text { 7. Entrevista de los postulantes finales con el Jefe de } \\
\text { Ventas. }\end{array}$ & 1 & & & & & & & & & & & & & & & & & & & & & & & & & & & & \\
\hline $\begin{array}{l}\text { 8. Capacitación y brindar funciones a nuevos } \\
\text { vendedores }\end{array}$ & 1 & & & & & & & & & & & & & & & & & & & & & & & & & & & & \\
\hline $\begin{array}{l}\text { 9. Seguimiento y evaluación del desempeño de los } \\
\text { vendedores }\end{array}$ & 3 & & & & & & & & & & & & & & & & & & & & & & & & & & & & \\
\hline $\begin{array}{l}\text { 10. Elaboración de reportes de los resultados de } \\
\text { evaluación del desempeño de los colaboradores. }\end{array}$ & 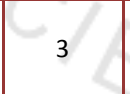 & & & & & & & & & & & 2 & & & 8 & & & & & & & & & & & & & & \\
\hline $\begin{array}{l}\text { 11. Acciones correctivas y/o preventivas de ser } \\
\text { necesario }\end{array}$ & 1 & & r & & & & & & & & & & & & & & & & & & & & & & & & & & \\
\hline
\end{tabular}


Tabla 5.14

Cronograma de implementación para la solución de mejora en el proceso de ventas

\begin{tabular}{|c|c|c|c|c|c|c|c|c|c|c|c|c|c|c|c|c|c|c|c|c|c|c|c|c|c|c|c|c|c|}
\hline \multirow{3}{*}{$\begin{array}{l}\text { Actividades de para la implementacion de las } \\
\text { soluciones propuestas }\end{array}$} & \multirow{3}{*}{$\begin{array}{l}\text { Duración } \\
\text { en } \\
\text { semanas }\end{array}$} & \multicolumn{28}{|c|}{ Programación (Semanas) } \\
\hline & & \multicolumn{4}{|c|}{ Mes 6} & \multicolumn{4}{|c|}{ Mes 7} & \multicolumn{4}{|c|}{ Mes 8} & \multicolumn{4}{|c|}{ Mes9 } & \multicolumn{4}{|c|}{ Mes 10} & \multicolumn{4}{|c|}{ Mes 11} & \multicolumn{4}{|c|}{ Mes 12} \\
\hline & & 1 & 2 & 3 & 4 & 5 & 6 & 7 & 8 & 9 & 10 & 11 & 12 & 13 & 14 & 15 & 16 & 17 & 18 & 19 & 20 & 21 & 22 & 23 & 24 & 25 & 26 & 27 & 28 \\
\hline $\begin{array}{l}\text { Solución: Capacitación del personal de ventas en las } \\
\text { funciones técnicas del repuesto }\end{array}$ & & & & & & & & & & & & & & & & & & & & & & & & & & & & & \\
\hline $\begin{array}{l}\text { 1. Definir los contenidos de cada tema de la } \\
\text { capacitación con la alta dirección, gerencia y los } \\
\text { responsables del área. }\end{array}$ & 1 & & & & & & & 6 & & & & & & & & & & & & & & & & & & & & & \\
\hline $\begin{array}{l}\text { 2. Definir los objetivos de cada tema, curso y } \\
\text { entrenamiento de cada capacitación }\end{array}$ & 1 & & & & & & & & & & & & & & & & & & & & & & & & & & & & \\
\hline $\begin{array}{l}\text { 3. Seleccionar y el egir a los tutores o consultoras que } \\
\text { realizarán la enseñanza. }\end{array}$ & 1 & & & & & & & & & & & & & & & & & & & & & & & & & & & & \\
\hline $\begin{array}{l}\text { 4. Elaborar el plan de reglas a cumplir, control de } \\
\text { asistencia, puntualidad, comportamiento. }\end{array}$ & 1 & & & & & & & & & & & & & & & & & & & & & & & & & & & & \\
\hline $\begin{array}{l}\text { 5. Establecer de los niveles de medición para la } \\
\text { evaluación de los intervinientes. }\end{array}$ & 1 & & & & & & & & & & & & & & & & & & & & & & & & & & & & \\
\hline $\begin{array}{l}\text { 6. Realizar la charla de sensibilización y objetivos de } \\
\text { la capacitación a cada uno de los vendedores. }\end{array}$ & 1 & & & & & & & & & & & & & & & & & & & & & & & & & & & & \\
\hline $\begin{array}{l}\text { 7. Dictar de los temas teóricos y prácticos de los } \\
\text { cursos seleccionados para la capacitación. }\end{array}$ & 4 & & & & & 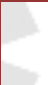 & & & 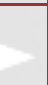 & & & & & & & & & & & & & & & & & & & & \\
\hline $\begin{array}{l}\text { 8. Evaluar a los vendedores en cuanto a los } \\
\text { resultados de aprendizaje de los temas dictados en } \\
\text { cada módulo. }\end{array}$ & 1 & & & & & 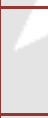 & & & & & & & & & & & & & & & & & & & & & & & \\
\hline $\begin{array}{l}\text { 9. Ejecutar de prueba piloto, con la realización de } \\
\text { simulaciones y pruebas. }\end{array}$ & 2 & & & & & & & & & & & & & & & & & & & & & & & & & & & & \\
\hline $\begin{array}{l}\text { 10. Medir los resultados, en cuanto a conocimientos, } \\
\text { habilidades, actitudes y conductas de cada } \\
\text { participante. }\end{array}$ & 2 & & & & & & & & & & & & & & & & & & & & & & & & & & & & \\
\hline $\begin{array}{l}\text { 11. Realizar acciones correctivas y/o preventivas de } \\
\text { ser el caso. }\end{array}$ & & & & & & & & & & & & & & & & & & & & & & & & & & & & & \\
\hline
\end{tabular}




\subsection{Propuesta de mecanismo y/o indicadores de gestión para garantizar la continuidad de la mejora.}

Con la siguiente investigación se pretende garantizar la continuidad de la mejora a través de indicadores que midan el desempeño de los procesos del área.

El jefe de Compras deberá realizar un seguimiento continuo del desempeño de los compradores. Para ello se debe considerar los indicadores de la tabla 5.15 con los cuales se evaluará el desempeño de cada comprador.

El reporte de los indicadores deberá ser expuesto a la gerencia general para ser medidos y comparados en la rentabilidad general de la empresa y poder evaluar la implementación de la mejora propuesta.

Tabla 5.15

Indicadores de gestión para la evaluación de la mejora en el proceso de compras

\begin{tabular}{|c|c|c|c|}
\hline Indicadores & Representación de indicador & $\begin{array}{l}\text { Situación } \\
\text { actual }\end{array}$ & Objetivo \\
\hline $\begin{array}{l}\text { Nro. cotizaciones } \\
\text { realizadas por orden de compra }\end{array}$ & $\frac{\text { Nro. de órdenes de compra }}{\text { Pedido de cotizaciones a proveedores }}$ & $69.88 \%$ & $35 \%$ \\
\hline $\begin{array}{l}\text { \% de tiempo que el comprador } \\
\text { toma para la búsqueda a un } \\
\text { proveedor }\end{array}$ & $\frac{\text { Tiempo promedio de búsqueda de proveedor }}{\text { Tiempo de generar orden de compra }}$ & $62.5 \%$ & $20 \%$ \\
\hline $\begin{array}{l}\text { \% de ahorros en compras por } \\
\text { conocimiento en la codificación de } \\
\text { producto }\end{array}$ & $\frac{\text { Ahorro de compras por equivalencia de producto }}{\text { Montos de cotizaciones iniciales }}$ & $4.1 \%$ & $10.50 \%$ \\
\hline $\begin{array}{l}\text { \% de ahorro en compras por } \\
\text { negociación }\end{array}$ & $\frac{\text { Ahorro de compras por negociación }}{\text { Montos de precios de cotizaciones iniciales }}$ & $1.27 \%$ & $3 \%$ \\
\hline
\end{tabular}

Elaboración propia

De esta manera el número de cotizaciones por órdenes de compra deberá aumentar como mínimo de 3 a 5 y obtener una reducción respecto a la situación actual. El tiempo promedio de búsqueda de proveedor deberá ser 
de menos de 10 minutos. Asimismo, comprador debe ser conocedor de los códigos de productos y equivalencia. Todo ello con el fin de generar mayor rentabilidad a la empresa.

De igual forma se realizará la evaluación con los indicadores del proceso de ventas como se muestra en la tabla 5.16.

\section{Tabla 5.16}

Indicadores de gestión para la evaluación en la mejora del proceso de ventas

\begin{tabular}{|c|c|c|c|c|c|}
\hline Nro. & Indicador & $\begin{array}{l}\text { Representación } \\
\text { del indicador }\end{array}$ & Descripción & $\begin{array}{l}\text { Situación } \\
\text { Actual }\end{array}$ & Objetivo \\
\hline 1 & $\begin{array}{l}\text { Eficiencia de las } \\
\text { visitas por vendedor }\end{array}$ & $\frac{\text { Número de pedidos }}{\text { Número de visitas }}$ & $\begin{array}{l}\text { El resultado entre } 0.75 \text { y } 1.0 \\
\text { indicará una buena gestión. }\end{array}$ & 0.33 & 0.83 \\
\hline 2 & $\begin{array}{l}\text { Incorporación de } \\
\text { clientes nuevos por } \\
\text { vendedor }\end{array}$ & $\begin{array}{l}\frac{\text { Número de clientes activos }}{\text { Nel vendedor }} \\
\text { Número de clientes iniciales }\end{array}$ & $\begin{array}{l}\text { El ideal es desde } 1,25 \text { y los } \\
\text { valores inferiores a } 1.0 \text { no } \\
\text { deben ser aceptados, pues } \\
\text { indica la pérdida de clientes. }\end{array}$ & 1.067 & 1.23 \\
\hline 3 & $\begin{array}{l}\text { Comportamiento de } \\
\text { los pedidos }\end{array}$ & $\begin{array}{l}\frac{\text { Número de pedidos }}{\text { aprobados }} \\
\begin{array}{l}\text { Número total de pedidos } \\
\text { realizados }\end{array}\end{array}$ & $\begin{array}{l}\text { El resultado ideal es } 1.0 \text { y lo } \\
\text { mínimo aceptable es } 0.9\end{array}$ & 0.960 & 0.99 \\
\hline
\end{tabular}

Elaboración propia 


\section{CAPÍTULO VI: EVALUACIÓN DE LA PROPUESTA Y BENEFICIOS ESPERADOS}

\subsection{Evaluación cualitativa de la solución propuesta}

Los beneficios de la implementación de las soluciones propuestas incluyen:

$>$ Incremento de la Rentabilidad, como consecuencia de la mejora en la gestión de los proceso de compras y ventas: minimizar los costos de compras con una excelente negociación con los proveedores, reducir tiempos de trabajo, mediante el uso eficaz y eficiente de los recursos de la empresa y reducir costos por las decisiones de compra en base al conocimiento de la especialización de repuestos automotrices.

$>$ Aumento de la productividad, con la mejora de los procesos internos del área de compras y de ventas, se obtiene como resultado la eficiencia en las funciones de los colaboradores con la utilización al máximo de los recursos, información y técnicas que brinda la empresa, con el fin que de cada uno de ellos comprenda la importancia de su trabajo y lo que genera para la empresa logrando además un beneficio tanto personal como económico.

Incremento en las ventas, como resultado de las estrategias de ventas para fidelizar a los clientes e incentivar el ingreso de nuevos clientes, con base en metas de ventas, mejoramiento del proceso interno, promociones, publicidad y reconocimiento por desempeño de servicios y venta de repuestos con la finalidad de obtener la satisfacción y confianza de los clientes.

Reducción de costos de no calidad, con la especialización de la venta de servicios y repuestos sólo se tendrá el stock necesario para las marcas 
de vehículos seleccionadas, lo que permitirá reducir el costo logístico, en espacio y mantenimiento, al minimizar la cantidad de repuestos de baja rotación.

Mejoramiento de la organización interna, como resultado de la comunicación fluida entre los trabajadores y responsables de las áreas de compras y ventas, logrando un buen desempeño a través del conocimiento de cada una las actividades que vincula un área con otra.

Mejora en la motivación y el trabajo en equipo, como consecuencia de las mejoras implantadas, el nuevo conocimiento alcanzado, la utilización de técnicas y herramientas que faciliten el desempeño en las actividades de trabajo con la finalidad de que el esfuerzo pueda ser reflejado en alcanzar las metas y objetivos esperados.

$>$ Aumento de la satisfacción y confianza de los clientes actuales y potenciales, como resultado del cumplimiento de tiempos en las entregas de servicios y productos ofrecidos. Confianza por la imagen ganada en la atención y especialización de los servicios y productos.

\subsection{Determinación de escenarios para la solución propuesta}

Los posibles escenarios de los resultados de la implementación de la solución se detallarán con base en resultados pesimistas, esperados y optimistas.

\section{> Implementación con resultados pesimistas,}

Se podría determinar y evaluar el caso de que la solución implementada se logre desarrollar y finalizar con variaciones en los tiempos programados, así como los nuevos procedimientos a incorporarse sólo se desarrollen de manera funcional y no sean documentados y que no se realice un correcto seguimiento y supervisión de las mejoras aplicadas obteniendo como resultado una 
implementación de mejora con resultados por debajo de los objetivos esperados.

\section{$>$ Implementación con resultados esperados,}

Se determinaría en el caso que se cumplan los plazos de la programación en la implementación de la solución y que el resultado del trabajo del personal involucrado sea satisfactorio con el compromiso y cumplimiento de las metas esperadas para el área. A su vez exista un correcto seguimiento de los indicadores del área que permita la evaluación del desempeño del grupo de trabajo.

\section{Implementación con resultados optimistas,}

En este último escenario se ejecuta y cumple correctamente cada uno de los procedimientos, actividades y funciones de la implementación de mejora de los procesos del área de compras y ventas, se cumplen los tiempos establecidos, existe un control y seguimiento en los indicadores de desempeño de los trabajadores y del área. Los objetivos se cumplen con un nivel superior a lo esperado, de la misma forma, todos los nuevos procedimientos son correctamente documentados y el grupo de trabajo se desarrolla satisfactoriamente con visión de nuevas ideas de mejora para la obtención de mayores logros en los resultados del área, se cumplen con todos los estándares y se desarrolla una actitud positiva para la integración de todos los procesos de la empresa.

\subsection{Estimación de los resultados de la implementación}

La estimación de los resultados de la implementación de la mejora en los procesos de compras y ventas de la empresa Laboratorio Diesel Senatinos S.A. se evaluará con base en el escenario esperado, que se explica en el punto 6.2. 
El nivel de satisfacción de los clientes se incrementará en 5.1\% según la estimación del jefe de ventas, al mejorar uno de los principales problemas, en referencia al cumplimiento con el tiempo de entregas de los repuestos para desarrollar la ejecución de los servicios que la empresa atiende a diario, y de esta manera cumplir con los plazos de entrega a los clientes. Es por ello que el nivel de servicio aumentará en $9.6 \%$.

La mejora en la eficiencia del personal en cuanto al conocimiento de herramientas de búsqueda de códigos y proveedores, información de códigos de repuestos, entrenamiento en pactar buenas negociaciones, entendimiento de la función de los principales repuestos que vende la empresa, generará una disminución en los costos de compra en 9.19\% que se canalizarán directamente en favor de la rentabilidad de la empresa considera además, que la mejor comunicación y relación con los proveedores, así como el seguimiento y control en sus indicadores de desempeño, permitirá incrementar en $15.8 \%$ el cumplimiento de las entregas establecidas de los repuestos y disminuir en $1.3 \%$ los productos defectuosos o equivocados entregados por parte de ellos.

Debido a la disminución en los costos de compra de repuestos a causa de la buena gestión del personal involucrado, la productividad de la mano de obra se incrementará en $12.02 \%$ y la productividad total en $1.97 \%$.

Todos los beneficios señalados lograrán que se puedan cumplir los objetivos organizacionales esperados por la empresa, determinando, que la mejora de los procesos del área de compras y ventas es la mejor opción para llevar al crecimiento, posicionamiento y rentabilidad de la empresa Laboratorio Diesel Senatinos S.A. 
En la siguiente tabla 6.1 se podrá observar los resultados de los indicadores esperados con la implementación de la mejora propuesta y la variación porcentual respecto a los indicadores antes de la implementación.

\section{Tabla 6.1}

Indicadores de gestión con la implementación del proyecto

\begin{tabular}{|c|c|c|c|c|c|}
\hline \multicolumn{6}{|c|}{ CUADRO DE INDICADORES } \\
\hline Objetivos & Indicadores & Unidades & $\begin{array}{l}\text { Indicador } \\
\text { Actual }\end{array}$ & $\begin{array}{l}\text { Indicador } \\
\text { Objetivo }\end{array}$ & $\begin{array}{c}\text { Incremento } \\
\text { del } \\
\text { indicador }\end{array}$ \\
\hline \multirow{3}{*}{$\begin{array}{l}\text { Incrementar la } \\
\text { satisfacción del } \\
\text { cliente }\end{array}$} & $\begin{array}{l}\text { Nivel de satisfacción } \\
\text { del cliente }\end{array}$ & $\%$ de satisfacción & $75.4 \%$ & $80.5 \%$ & $5.1 \%$ \\
\hline & Nivel de servicio & $\begin{array}{l}\text { (Total de entregas cumplidas al } \\
\text { cliente en los plazos pactados/ } \\
\text { total de entregas al cliente en el } \\
\text { año)*100\% }\end{array}$ & $85.4 \%$ & $95.0 \%$ & $9.6 \%$ \\
\hline & $\begin{array}{l}\% \text { de reclamos por } \\
\text { venta de repuesto }\end{array}$ & $\frac{\text { Nro. De Reclamo x rpto vendido }}{\text { Total de Repuestos vendidos }}$ & $6.82 \%$ & $1.50 \%$ & $1.30 \%$ \\
\hline \multirow{3}{*}{$\begin{array}{l}\text { Lograr un } \\
\text { eficiente } \\
\text { sistema de } \\
\text { gestión en las } \\
\text { compras }\end{array}$} & Productividad Total & $\frac{\text { Ventas de repuestos }}{\text { Costo de ventas de repuestos }}$ & 1.247 & 1.272 & $1.97 \%$ \\
\hline & $\begin{array}{l}\text { Productividad de la } \\
\text { mano de obra }\end{array}$ & costo de la mano de obra & 9.256 & 10.520 & $12.02 \%$ \\
\hline & $\begin{array}{l}\text { Ahorro por buena } \\
\text { gestión de compras }\end{array}$ & $\frac{\text { Ahorro en costos de compras }}{\text { Total de costos de compra }}$ & $2.51 \%$ & $11.7 \%$ & $9.19 \%$ \\
\hline \multirow{2}{*}{$\begin{array}{l}\text { Lograr una } \\
\text { excelente } \\
\text { relación y } \\
\text { confianza con } \\
\text { los proveedores }\end{array}$} & $\begin{array}{l}\text { \% de cumplimiento de } \\
\text { los proveedores en la } \\
\text { entrega de las fechas } \\
\text { establecidas }\end{array}$ & $\frac{\text { Entregas cumplidas }}{\text { Total de entregas }}$ & $79.2 \%$ & $95 \%$ & $15.8 \%$ \\
\hline & $\begin{array}{c}\% \text { de productos } \\
\text { defectuosos entregados } \\
\text { por los proveedores }\end{array}$ & $\frac{\text { Productos defectuosos }}{\text { Total de repuestos adquiridos }}$ & $2.30 \%$ & $1.00 \%$ & $1.30 \%$ \\
\hline
\end{tabular}

\subsection{Análisis económico y financiero de la propuesta}

Implementación de mejora en el proceso de compras

El ahorro o beneficio anual por la implementación de la mejora en el proceso de compras, se calcula en función a cinco conceptos de reducción de costos: 


\section{Reducción de costos en tiempo de búsqueda de proveedores}

Con la clasificación de los productos (repuestos automotrices) según su nivel de rotación, se calcula el tiempo que tardan los compradores en encontrar al proveedor idóneo para realizar la compra adecuada, como se muestra en la tabla 6.2.

Tabla 6.2

Tiempo que tardan los compradores en encontrar al proveedor

\begin{tabular}{|l|c|c|c|c|c|}
\multicolumn{6}{|c|}{ Tiempo de Búsqueda de Proveedor empleado por compradores } \\
\hline \multicolumn{1}{|c|}{ Tipo de producto } & $\begin{array}{c}\text { Promedio de } \\
\text { Items Diarios }\end{array}$ & $\begin{array}{c}\text { Tiempo (min) } \\
\text { proveedor }\end{array}$ & $\begin{array}{c}\text { Nro. Mínimo } \\
\text { de proveedores }\end{array}$ & $\begin{array}{c}\text { Total de Tiempo } \\
\text { x proveedor } \\
\text { (min) }\end{array}$ & $\begin{array}{c}\text { Total Tiempo } \\
\text { Diario } \\
\text { (min) }\end{array}$ \\
\hline Altamente rotativo & 19 & 2,5 & 3 & 7,5 & 142,50 \\
Medianamente & 13 & 6,9 & 3 & 20,7 & 269,10 \\
Bajamente rotativo & 3 & 30,5 & 2 & 61 & 183,00 \\
\hline \multicolumn{1}{|c|}{ Total } & 35 & 39,9 & 8 & 89,2 & 594,60 \\
\hline \multicolumn{7}{r|}{ Tiempo de Búsqueda de Proveedor Horas / día } & & $\mathbf{9 , 9 1}$ \\
\hline
\end{tabular}

Fuente: Laboratorio Diesel Senatinos S.A.

Elaboración: Propia

En la tabla 6.3 se observa los costos que genera un comprador en buscar y hallar a un proveedor, donde se aplica dos escenarios, con y sin la implementación de la mejora propuesta. Con un "escenario esperado" se puede alcanzar la disminución del 55\% del tiempo comúnmente empleado, que representa monetariamente S/. 17,534.04 al año.

Tabla 6.3

Ahorro de costos por tiempo de búsqueda de proveedores

\begin{tabular}{|l|l|c|c|c|c|}
\hline \multicolumn{7}{c}{ Ahorro de costo por tiempo de búsqueda de proveedor } \\
\multicolumn{1}{|c|}{ Aplicación } & \multicolumn{1}{c|}{ Recurso } & Costo x hora & $\begin{array}{c}\text { Tiempo (hrs) } \\
\text { al día }\end{array}$ & Costo x día & $\begin{array}{c}\text { Costo x Año } \\
\text { (24 ds y 12 ms) }\end{array}$ \\
\hline $\begin{array}{l}\text { Sin Mejora } \\
\begin{array}{l}\text { Mejora: } \\
\text { Reducción de tiempo } \\
\text { "esperado" en 55\% }\end{array}\end{array}$ & Compradores & 11,17 & 9,91 & 110,69 & $31.880,07$ \\
\hline \multicolumn{1}{|c|}{ Ahorro } & Compradores & 11,17 & 4,46 & 49,81 & $14.346,03$ \\
\hline
\end{tabular}

Elaboración propia 
Reducción de costos por la disminución de horas extras de compradores

Con la implementación de la mejora en el proceso de compras se obtiene la disminución de la carga laboral de los compradores, por ende, en un "escenario esperado" se plantea la reducción de las horas extras hasta un $85 \%$ como se muestra en tabla 6.5 con un ahorro anual de S/. $9,441.09$

Tabla 6.4

Horas extras de trabajo de compradores - 2014

\begin{tabular}{|c|cccccccc|c|c|c|c|c|c|}
\hline \multicolumn{11}{c|}{ Horas extras por exceso de trabajo de compradores - Anual $\mathbf{2 0 1 4}$} \\
\hline Meses & $\mathbf{1}$ & $\mathbf{2}$ & $\mathbf{3}$ & $\mathbf{4}$ & $\mathbf{5}$ & $\mathbf{6}$ & $\mathbf{7}$ & $\mathbf{8}$ & $\mathbf{9}$ & $\mathbf{1 0}$ & $\mathbf{1 1}$ & $\mathbf{1 2}$ & Total (hrs) \\
\hline Comprador 1 & 32,0 & 31,3 & 35,2 & 34,0 & 33,5 & 29,0 & 32,8 & 30,5 & 42,0 & 32,1 & 34,2 & 29,1 & 395,7 \\
Comprador 2 & 35,0 & 29,4 & 32,0 & 37,5 & 40,3 & 30,2 & 29,6 & 35,2 & 35,5 & 29,5 & 36,2 & 29,4 & 399,8 \\
\hline Total (hrs) & 67,0 & 60,7 & 67,2 & 71,5 & 73,8 & 59,2 & 62,4 & 65,7 & 77,5 & 61,6 & 70,4 & 58,5 & 795,5 \\
\hline
\end{tabular}

Fuente: Laboratorio Diesel Senatinos S.A.

Elaboración: Propia

Tabla 6.5

Costo de horas extras de compradores

\begin{tabular}{|c|c|c|c|}
\hline \multicolumn{3}{|c|}{ Cálculo de costo de horas extras } & \multirow[b]{2}{*}{$\begin{array}{l}\text { Reducción } \\
\text { de } 85 \% \text { de } \\
\text { horas extras }\end{array}$} \\
\hline $\begin{array}{c}\text { Horas extras } \\
\text { anuales }\end{array}$ & $\begin{array}{c}\text { Costo de } \\
\text { hora extra } \\
\mathrm{S} / .\end{array}$ & $\begin{array}{l}\text { Monto total } \\
\text { anual } \\
\text { S/. }\end{array}$ & \\
\hline 795,5 & 13,96 & S/. 11.107,17 & $\mathrm{S} / .9 .441,09$ \\
\hline
\end{tabular}

\section{Ahorro por eliminación de compra errada de repuesto}

Se obtiene a raíz de las capacitaciones de los compradores en el manejo de los códigos de los repuestos en los sistemas automotrices de especialización. Por lo que genera que cada producto se compre sin riesgo a que sea equívoco al tener conocimiento de los códigos originales y alternativos. 
La eliminación anual de las compras erradas representa $\mathrm{S} /$. 7,830.10 como se muestra en la tabla 6.6.

\section{Ahorro de costo en devolución de repuestos de mínima rotación rechazados por clientes insatisfechos.}

Al disminuir los tiempos de búsqueda y hallar el repuesto correcto en el tiempo acordado con el cliente, se estima reducir el costo total en las devoluciones de repuestos al mejorar el nivel de cumplimiento en los tiempos de entrega de los productos y o servicios. En la tabla 6.6 se muestra el monto anual a ahorrar en los costos de devolución S/. 12,989.45.

Tabla 6.6

Costo de compra errada y devolución de repuestos

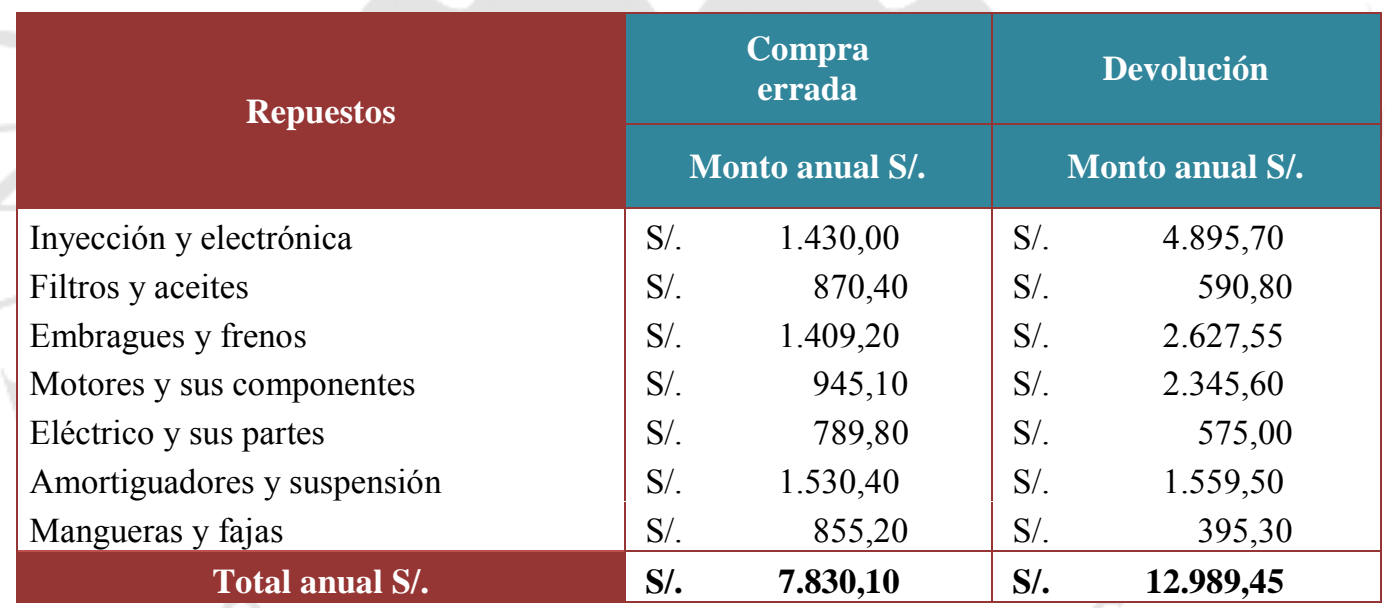

Fuente: Laboratorio Diesel Senatinos S.A.

Elaboración: Propia

\section{Reducción de costos logísticos}

Al minimizar los errores de compras y disminuir los tiempos en las compras urgentes, cuyos repuestos son de mínima o nula rotación se obtiene un ahorro anual en los costos logísticos de S/. 3.512,60 como se observa en la tabla 6.7. 
Tabla 6.7

Costos logísticos de repuestos de mínima rotación

\begin{tabular}{|l|r|}
\hline \multicolumn{1}{|c|}{$\begin{array}{c}\text { Costos Logísticos de repuestos devueltos o } \\
\text { cuyas compras fueron erradas } \\
\text { Enero - Diciembre 2014 }\end{array}$} & \multicolumn{1}{c|}{$\begin{array}{c}\text { Montos en } \\
\text { S/. }\end{array}$} \\
\hline Búsqueda de proveedor & 480,50 \\
Emisión de orden de compra & 390,40 \\
Almacenamiento el repuesto & $1.135,00$ \\
Mantenimiento de repuesto & 560,30 \\
Mantenimiento y Limpieza de almacén & 450,40 \\
Transporte Total anual S/. & 496,00 \\
\hline \multicolumn{2}{|c|}{ Thente: Laboratorio Diesel Senatinos S.A. } \\
Elaboración: Propia
\end{tabular}

En resumen, los beneficios económicos con la implementación de la mejora en los procesos de compras se detallan en la tabla 6.8, con un beneficio total de S/. 51.307,28.

Tabla 6.8

Beneficios por implementación de mejora en el proceso de compras.

\begin{tabular}{|c|c|}
\hline \multicolumn{2}{|l|}{$\begin{array}{c}\text { BENEFICIO } \\
\text { (AHORRO ANUAL EN COSTOS) }\end{array}$} \\
\hline Conceptos al 2014 & Monto S/. \\
\hline $\begin{array}{l}\text { Reducción de costos en tiempo de búsqueda de } \\
\text { proveedores }\end{array}$ & $17.534,04$ \\
\hline $\begin{array}{l}\text { Reducción de costos por la disminución de horas extras } \\
\text { de compradores }\end{array}$ & $9.441,09$ \\
\hline Ahorro por eliminación de compra errada de repuesto & $7.830,10$ \\
\hline $\begin{array}{l}\text { Ahorro de costo en devolución de repuestos de mínima } \\
\text { rotación rechazados por clientes insatisfechos. }\end{array}$ & $12.989,45$ \\
\hline Reducción de costos logísticos & $3.512,60$ \\
\hline Total & $\mathbf{5 1 . 3 0 7 , 2 8}$ \\
\hline
\end{tabular}




\section{$\underline{\text { Implementación de mejora en el proceso de ventas }}$}

Al considerar un escenario esperado. La implementación de la mejora en el proceso de ventas da como resultado el incremento en las ventas de repuestos de la siguiente manera: $6 \%$ en la familia de sistema de inyección, a razón que es la especialidad de la empresa tanto en servicios como en repuestos donde se concentra la capacidad y experiencia de sus colaboradores. El incremento de ventas de repuestos en la familia embragues ascendería a 4,5\% por contar con los stocks necesarios para la atención de las marcas de vehículos livianos (Hyundai, Toyota, Kia, Chevrolet, Mitsubishi, Nissan y Suzuki). Asimismo, el aumento del $2 \%$ se verá reflejado en las familias de repuestos filtros y aceites como en mangueras y fajas, debido a los servicios de mantenimiento preventivo de las marcas de vehículos antes mencionadas. En la tabla 6.9 se observa un beneficio por incremento en las ventas de S/. 69.037,6.

Tabla 6.9

Beneficios por implementación de mejora en el proceso de ventas

\begin{tabular}{|l|c|c|c|c|c|c|}
\hline Familia & $\begin{array}{c}\text { Ventas } \\
\text { anuales } \\
\text { S/. }\end{array}$ & $\begin{array}{c}\text { Utilidad } \\
\text { promedio } \\
\text { por } \\
\text { familia }\end{array}$ & $\begin{array}{c}\% \\
\text { Incremento } \\
\text { de ventas } \\
\text { esperado }\end{array}$ & $\begin{array}{c}\text { Ventas } \\
\text { anuales } \\
\text { S/. }\end{array}$ & $\begin{array}{c}\text { Incremento } \\
\text { de ventas } \\
\text { S/. }\end{array}$ & $\begin{array}{c}\text { Beneficio } \\
\text { por } \\
\text { incremento } \\
\text { en ventas } \\
\text { S/. }\end{array}$ \\
\hline Inyección & $1.618 .817,93$ & $22,2 \%$ & $6 \%$ & $1.715 .947,0$ & $97.129,1$ & $21.562,7$ \\
\hline Embragues & $698.742,14$ & $15,8 \%$ & $4,5 \%$ & $730.185,5$ & $31.443,4$ & $4.968,1$ \\
\hline Otros & $601.943,93$ & $6,8 \%$ & $2 \%$ & $626.021,7$ & $24.077,8$ & $42.506,9$ \\
\hline \multicolumn{7}{|c|}{ Total Incremento en las ventas (S/.) } \\
\hline
\end{tabular}

Con la implementación del presente proyecto se espera obtener un beneficio total de S/. 120,344.87 con las soluciones planteadas para los procesos de compras y ventas. Como se muestra en la tabla 6.10. 
Tabla 6.10

Beneficios totales de implementación de la mejora

\begin{tabular}{|c|l|c|}
\hline \multicolumn{3}{|c|}{ BENEFICIOS TOTALES } \\
$\begin{array}{c}\text { Implementación } \\
\text { de mejora }\end{array}$ & \multicolumn{1}{|c|}{ Detalle } & Monto S/ \\
\hline Proceso de compras & Reducción de costos & $51.307,28$ \\
\hline Proceso de ventas & $\begin{array}{l}\text { Incremento de ventas en } \\
\text { repuestos }\end{array}$ & $69.037,58$ \\
\hline \multicolumn{2}{|c|}{ Beneficio del proyecto } & $\mathbf{1 2 0 . 3 4 4 , 8 7}$ \\
\hline
\end{tabular}

Elaboración propia

A partir del total de beneficios cuantificados (tabla 6.10), y los costos de implementación de la mejora en los proceso de compras y ventas (tabla 5.10) se elabora un flujo de caja proyectado en 5 años. Como se muestra en la tabla 6.11. Por consiguiente, se puede determinar el valor presente neto (VAN) S/. 253.506.87 y una tasa interna de retorno (TIR) 186\%, lo que indica que el proyecto es viable y rentable.

Tabla 6.11

Flujo de Caja

\begin{tabular}{|l|c|c|c|c|c|c|}
\hline $\begin{array}{l}\text { Cuadro de Flujo } \\
\text { de Caja }\end{array}$ & Año 0 & Año 1 & Año 2 & Año 3 & Año 4 & Año 5 \\
\hline Beneficio & & $120.344,87$ & $123.955,21$ & $126.434,32$ & $128.963,00$ & $131.542,27$ \\
\hline $\begin{array}{l}\text { Costos de } \\
\text { implementación }\end{array}$ & $41.736,72$ & $43.392,00$ & $44.693,76$ & $46.034,57$ & $47.415,61$ & $48.838,08$ \\
\hline Flujo de efectivo & $\mathbf{- 4 1 . 7 3 6 , 7 2}$ & $\mathbf{7 6 . 9 5 2 , 8 7}$ & $\mathbf{7 9 . 2 6 1 , 4 5}$ & $\mathbf{8 0 . 3 9 9 , 7 5}$ & $\mathbf{8 1 . 5 4 7 , 3 9}$ & $\mathbf{8 2 . 7 0 4 , 1 9}$ \\
\hline
\end{tabular}

\begin{tabular}{|l|l|}
\hline TASA & \multicolumn{1}{|c|}{$11 \%$} \\
\hline VAN & S/. $253.506,87$ \\
\hline TIR & $186 \%$ \\
\hline
\end{tabular}




\subsection{Impacto de la solución propuesta}

\subsubsection{Impacto Social}

Al implementar las mejoras propuestas sé generará motivación e interés por la mejora continua en el desempeño de las funciones de cada uno de los trabajadores, a través de las capacitaciones e información técnica incentivando el desarrollo profesional.

Los colaboradores lograrán observar y comprender lo valioso e importante que se genera con la buena gestión en su trabajo al mejorar la comunicación y trabajo en equipo, con ello podrán obtener información en el momento preciso sin presión del tiempo por desconocimiento de un producto. Al mejorar la planificación del área, se reducirán los cuellos de botella provocados por una mala previsión de las compras y ventas.

\subsubsection{Impacto ambiental}

La solución propuesta no generará ningún impacto negativo ambiental con la implementación ni con el desarrollo del proyecto. Debido a que está enfocada a capacitaciones, aplicación de nuevas técnicas de utilización de herramientas y entrenamiento del personal, no se requerirá de ningún agente nocivo en materiales, equipos o maquinaria que afecten o alteren el desempeño del trabajo de los colaboradores. En conclusión, el impacto del proyecto no producirá algún efecto contraproducente frente al entorno interno o externo de la empresa. 


\section{CONCLUSIONES}

Se llegaron a evaluar cada uno de los procesos de la empresa mediante el análisis factorial de Klein, este método determina de manera cualitativa la efectividad de la empresa y extrae las principales áreas y procesos en estado crítico. Con los resultados que se obtienen del análisis factorial de Klein se determina que las áreas con mayor criticidad y problemática en sus procesos son las áreas de compras y ventas con valores de $40 \%$ y $42 \%$ respectivamente.

Las causas raíces principales identificadas para el problema principal del área de compras fueron la falta de información para la búsqueda de proveedores y la atención de excesivas marcas de vehículos; y para el problema principal del área de ventas fueron la falta de capacitación de estrategias de ventas y que no existen funciones definidas para los vendedores.

Según la investigación para las mejoras de los procesos de compras y ventas en la empresa, se ha determinado como de suma importancia la comunicación integral no solo de las dos áreas mencionadas sino también de todas áreas que abarca la empresa analizada, para llegar a tener una mejor cohesión y resultados óptimos.

Las capacitaciones brindadas a los colaboradores en las áreas de compra y venta, serán beneficiosas para la empresa ya que reducirán considerablemente los costos por baja calidad y las pérdidas de ventas potenciales. Esto generará beneficios económicos de la empresa.

$>$ A través de los indicadores de gestión planteados se podrá controlar el nivel de desempeño de los colaboradores de compras, el nivel de satisfacción de los clientes por la compra de sus repuestos y /o servicios y medir el desempeño de los proveedores.

$>$ El costo de la implementación de las mejoras en los proceso de compra y venta, podrán ser realizadas de forma satisfactoria y sin riesgo de pérdidas, porque al llegar a analizar los indicadores de viabilidad económica del proyecto dieron 
resultados muy alentadores. Se tendría un $\mathrm{VAN}=\mathrm{S} / .253 .506,87$ y un $\mathrm{TIR}=186 \%$, ya que el VAN al ser mayor que cero y el TIR al ser mayor que la TASA $=11 \%$, serían viables para tener un buen resultado económico.

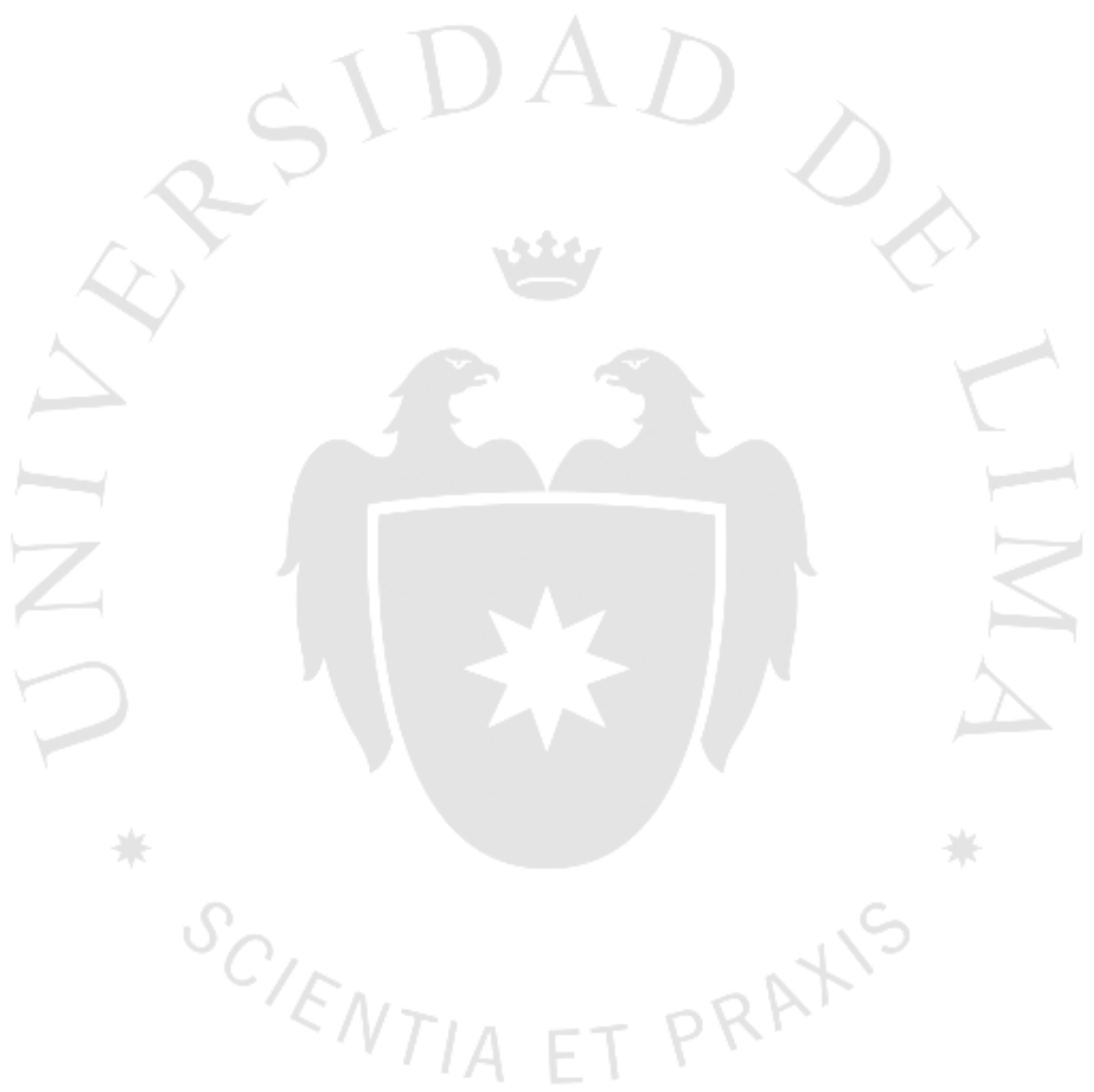




\section{RECOMENDACIONES}

Realizar un estudio para que el personal se comprometa con los objetivos que se desea alcanzar, principalmente en las áreas que se están haciendo las mejoras.

$>$ La empresa deberá implementar las mejoras en las áreas de compra y venta para tener una optimización seria en sus servicios y a la vez tener una alta rentabilidad que beneficie a la empresa analizada.

$>$ La capacitación que se da al personal en las diferentes áreas deberá ser constante, porque el recurso humano es lo más importante que tiene toda empresa. Esto genera motivación en los colaboradores llegará a mantener a la empresa en una posición ventajosa.

Aunque el crecimiento económico no es de lo mejor, esto no ha provocado que el crecimiento del sector automotriz se detenga, por lo tanto se debe aprovechar este momento para poder captar nuevos clientes.

La empresa debe ser consciente que las mejoras deben ser continuas para tener un buen desempeño laboral y económico. Por lo tanto la empresa tendrá que velar por los indicadores de gestión, es decir, ser actualizados permanentemente para monitorear y dirigir de forma clara y precisa como se está comportando la empresa en el mercado automotriz. 


\section{REFERENCIAS}

Bonilla Pastor, E., Diaz, B., Kleeberg, F., Noriega, M. T., (2010). Mejora continua de los procesos: Herramientas y técnicas. Universidad de Lima.

Comunidad Andina. (2004-2013). Parque vehicular en la comunidad.

Ministerio de Transportes y Comunicaciones. (2014). Parque vehicular nacional estimado, según clase de vehículo.

Ministerio de Transportes y comunicaciones. (2014). Proyecciones del parque vehicular estimado, según departamentos.

Senatinos. (s.f). Historia. Recuperado de

http://www.senatinos.com.pe/ $\sim$ senatino/cms.php?id_cms=8

Thibaut, Jean Pierre. (1994) .Manual de diagnóstico en la empresa. Ed. Madrid: Paraninfo. 


\section{BIBLIOGRAFÍA}

Ballou, Ronald H. (2004). Logística. Administración de la cadena de suministro. (5 ed.). Naucalpan de Juaréz México: Pearson.

Beltrán Barco, A. (2013). Evaluación privada de proyectos ( $3^{\mathrm{a}}$ ed.). Lima: Pearson.

Beltrán Barco, Arlette. (2000). Ejercicios de evaluación privada de proyectos. Tercera edición. Lima: Universidad del Pacífico, Centro de Investigación.

Brojt, D. (2004). PROJECT MANAGEMENT: Un enfoque de liderazgo y ejecución de proyectos en la empresa para aplicar el lunes por la mañana. Argentina:Granica

Ferreiro de Babot, Pablo. (2001). Gobierno de personas en la empresa. Ed. Piura: PAD, Escuela de Dirección de Universidad de Piura

Hill, Charles W.L., Gareth, R. J. (2011). Administración estratégica: un enfoque integral. 9va. ed. México D.F.: Cengage Learning.

Mariñas Tapia, A. C. (2005). Mejora en el área de servicios en la Empresa San Borja Autos Seleccionados S.A. Universidad de Lima.

Peralta Vidal, Fernando Enrique. (2012). Mejora integral de un taller de servicios del sector automotriz. Lima: Universidad de Lima. 


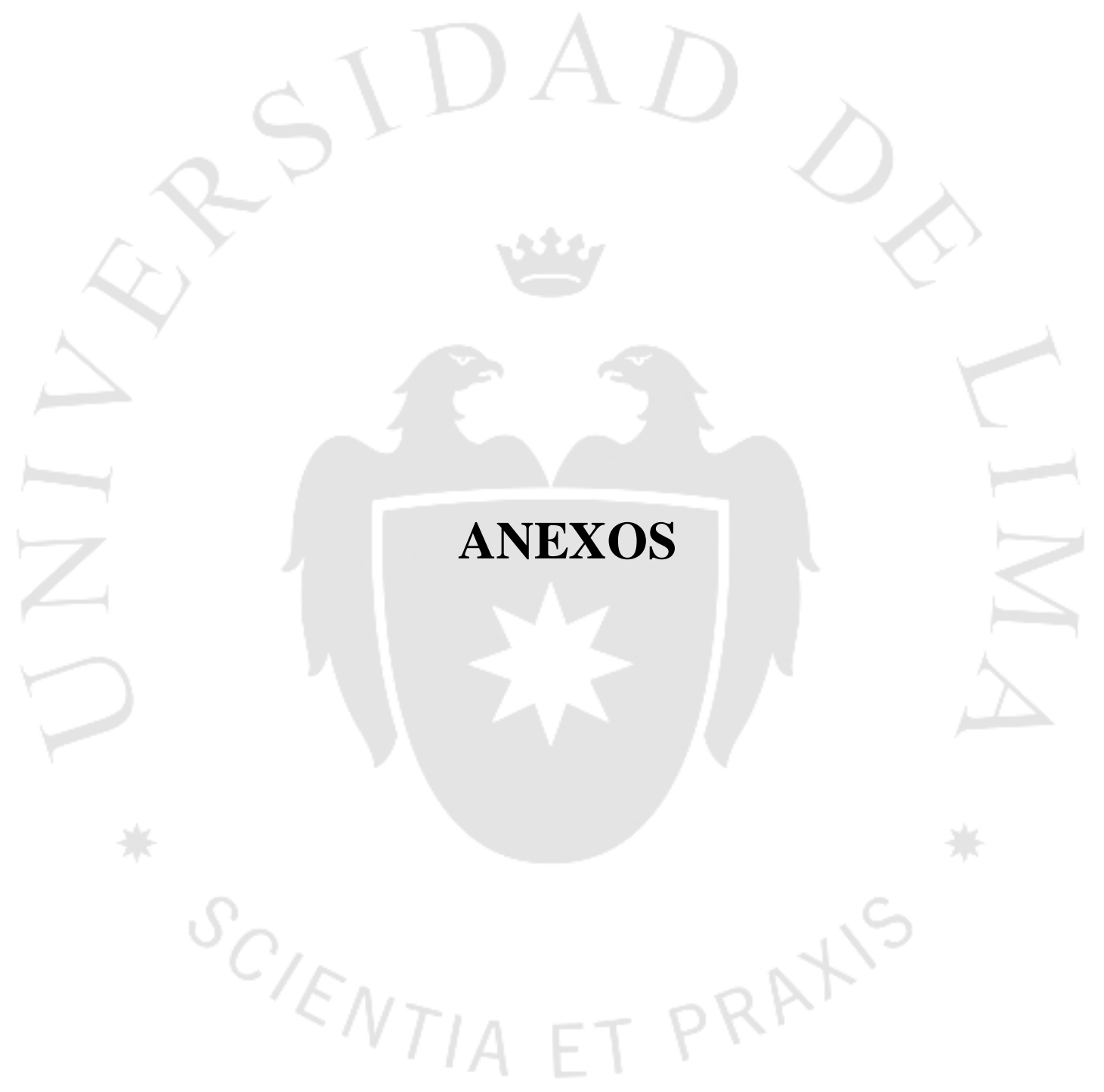


ANEXO 1: Tabla de convenios firmados con países, que favorecen los montos de aranceles

\begin{tabular}{|c|c|c|c|c|c|c|}
\hline PAIS & CONVENIO INTERNACIONAL & P.NALADISA & FECHA DE VIGENCIA & $\begin{array}{c}\text { ARANCE } \\
\text { L } \\
\text { BASE }\end{array}$ & $\begin{array}{l}\text { PORCENTAJE } \\
\text { LIBERADO ADV }\end{array}$ & $\begin{array}{l}\text { OBSERVA } \\
\text { CION }\end{array}$ \\
\hline ALEMANIA & 812 - ACUERDO COMERCIAL PERU - UNION EUROPEA & & $01 / 03 / 2013-31 / 12 / 9999$ & $0 \%$ & $100 \%$ & \\
\hline ARGENTINA & $\begin{array}{l}358 \text { - ALADI, ACE } 58 \text { PERU - ARGENTINA, BRASIL, } \\
\text { URUGUAY Y PARAG }\end{array}$ & 84099900 & 01/01/2014-31/12/9999 & --- & $100 \%$ & \\
\hline AUSTRIA & 812 - ACUERDO COMERCIAL PERU - UNION EUROPEA & & 01/03/2013-31/12/9999 & $0 \%$ & $100 \%$ & \\
\hline BELGICA & 812 - ACUERDO COMERCIAL PERU - UNION EUROPEA & & $01 / 03 / 2013-31 / 12 / 9999$ & $0 \%$ & $100 \%$ & \\
\hline BOLIVIA & 100 - COMUNIDAD ANDINA DE NACIONES & & 03/09/2012-31/12/9999 & $---\%$ & $100 \%$ & \\
\hline BRASIL & $\begin{array}{l}358 \text { - ALADI, ACE } 58 \text { PERU - ARGENTINA, BRASIL, } \\
\text { URUGUAY Y PARAG }\end{array}$ & 84099900 & 01/01/2011-31/12/9999 & --- & $100 \%$ & Pistones \\
\hline BRAZIL & $\begin{array}{l}504 \text { - ACUERDO DE ALCANCE REGIONAL NRO. } 4 \text { - PAR } \\
4 \text { PERU-BRA-CH }\end{array}$ & & $16 / 09 / 2000-31 / 12 / 9999$ & --- & $6 \%$ & \\
\hline BULGARIA & 812 - ACUERDO COMERCIAL PERU - UNION EUROPEA & & 01/03/2013-31/12/9999 & $0 \%$ & $100 \%$ & \\
\hline CANADA & 803 - TLC PERU - CANADA & & $01 / 01 / 2012-31 / 12 / 9999$ & $0 \%$ & $100 \%$ & \\
\hline CHILE & 338 - ACUERDO DE LIBRE COMERCIO PERU - CHILE & 84099900 & 04/10/1999-31/12/2016 & --- & $100 \%$ & \\
\hline CHILE & $\begin{array}{l}504 \text { - ACUERDO DE ALCANCE REGIONAL NRO. } 4 \text { - PAR } \\
4 \text { PERU-BRA-CH }\end{array}$ & & $16 / 09 / 2000-31 / 12 / 9999$ & --- & $10 \%$ & \\
\hline CHINA & 805 - TRATADO DE LIBRE COMERCIO PERU - CHINA & & 01/01/2012-31/12/9999 & $0 \%$ & $100 \%$ & \\
\hline CHIPRE & 812 - ACUERDO COMERCIAL PERU - UNION EUROPEA & & 01/03/2013-31/12/9999 & $0 \%$ & $100 \%$ & \\
\hline COLOMBIA & 100 - COMUNIDAD ANDINA DE NACIONES & & 03/09/2012-31/12/9999 & $---\%$ & $100 \%$ & \\
\hline COREA & 806 - TRATADO DE LIBRE COMERCIO PERU - COREA & & 01/01/2012-31/12/9999 & $0 \%$ & $100 \%$ & \\
\hline COSTA RICA & $\begin{array}{l}813 \text { - TRATADO DE LIBRE COMERCIO PERU - COSTA } \\
\text { RICA }\end{array}$ & & 01/06/2013-31/12/9999 & $0 \%$ & $100 \%$ & \\
\hline DINAMARCA & 812 - ACUERDO COMERCIAL PERU - UNION EUROPEA & & 01/03/2013-31/12/9999 & $0 \%$ & $100 \%$ & \\
\hline ECUADOR & 100 - COMUNIDAD ANDINA DE NACIONES & & 03/09/2012-31/12/9999 & $---\%$ & $100 \%$ & \\
\hline EE.UU. & $\begin{array}{l}802 \text { - ACUERDO DE PROMOCION COMERCIAL PERU - } \\
\text { EE.UU. }\end{array}$ & & 01/01/2012-31/12/9999 & $4 \%$ & $100 \%$ & \\
\hline ESLOVAQUIA & 812 - ACUERDO COMERCIAL PERU - UNION EUROPEA & & $01 / 03 / 2013-31 / 12 / 9999$ & $0 \%$ & $100 \%$ & \\
\hline ESLOVENIA & 812 - ACUERDO COMERCIAL PERU - UNION EUROPEA & & 01/03/2013-31/12/9999 & $0 \%$ & $100 \%$ & \\
\hline ESPAÑA & 812 - ACUERDO COMERCIAL PERU - UNION EUROPEA & & $01 / 03 / 2013-31 / 12 / 9999$ & $0 \%$ & $100 \%$ & \\
\hline ESTONIA & 812 - ACUERDO COMERCIAL PERU - UNION EUROPEA & & $01 / 03 / 2013-31 / 12 / 9999$ & $0 \%$ & $100 \%$ & \\
\hline FINLANDIA & 812 - ACUERDO COMERCIAL PERU - UNION EUROPEA & & $01 / 03 / 2013-31 / 12 / 9999$ & $0 \%$ & $100 \%$ & \\
\hline FRANCIA & 812 - ACUERDO COMERCIAL PERU - UNION EUROPEA & & $01 / 03 / 2013-31 / 12 / 9999$ & $0 \%$ & $100 \%$ & \\
\hline GRECIA & 812 - ACUERDO COMERCIAL PERU - UNION EUROPEA & & $01 / 03 / 2013-31 / 12 / 9999$ & $0 \%$ & $100 \%$ & \\
\hline
\end{tabular}




\begin{tabular}{|c|c|c|c|c|c|}
\hline HUNGRIA & 812 - ACUERDO COMERCIAL PERU - UNION EUROPEA & 01/03/2013-31/12/9999 & $0 \%$ & $100 \%$ & \\
\hline IRLANDA & 812 - ACUERDO COMERCIAL PERU - UNION EUROPEA & 01/03/2013-31/12/9999 & $0 \%$ & $100 \%$ & \\
\hline ISLANDIA & 807 - ACUERDO DE LIBRE COMERCIO PERU - AELC & 01/01/2012-31/12/9999 & $0 \%$ & $100 \%$ & \\
\hline ITALIA & 812 - ACUERDO COMERCIAL PERU - UNION EUROPEA & 01/03/2013-31/12/9999 & $0 \%$ & $100 \%$ & \\
\hline JAPON & $\begin{array}{l}810 \text { - ACUERDO DE ASOCIACION ECONOMICA PERU - } \\
\text { JAPON }\end{array}$ & 01/03/2012-31/12/9999 & $0 \%$ & $100 \%$ & \\
\hline LETONIA & 812 - ACUERDO COMERCIAL PERU - UNION EUROPEA & 01/03/2013-31/12/9999 & $0 \%$ & $100 \%$ & \\
\hline LIECHTENST & 807 - ACUERDO DE LIBRE COMERCIO PERU - AELC & 01/01/2012-31/12/9999 & $0 \%$ & $100 \%$ & \\
\hline LITUANIA & 812 - ACUERDO COMERCIAL PERU - UNION EUROPEA & 01/03/2013-31/12/9999 & $0 \%$ & $100 \%$ & \\
\hline $\begin{array}{l}\text { LUXEMBURG } \\
\text { O }\end{array}$ & 812 - ACUERDO COMERCIAL PERU - UNION EUROPEA & $01 / 03 / 2013-31 / 12 / 9999$ & $0 \%$ & $100 \%$ & \\
\hline MALTA & 812 - ACUERDO COMERCIAL PERU - UNION EUROPEA & 01/03/2013-31/12/9999 & $0 \%$ & $100 \%$ & \\
\hline MEXICO & $\begin{array}{l}809 \text { - ACUERDO DE INTEGRACION ECONOMICA PERU } \\
\text { - MEXICO }\end{array}$ & 01/02/2012-31/12/9999 & $4 \%$ & $100 \%$ & $\begin{array}{l}\text { EXCEPTO } \\
\text { REMANUFA } \\
\text { CTURADOS }\end{array}$ \\
\hline NORUEGA & 807 - ACUERDO DE LIBRE COMERCIO PERU - AELC & $01 / 07 / 2012-31 / 12 / 9999$ & $0 \%$ & $100 \%$ & \\
\hline PAISES BAJ & 812 - ACUERDO COMERCIAL PERU - UNION EUROPEA & 01/03/2013-31/12/9999 & $0 \%$ & $100 \%$ & \\
\hline PANAMA & 811 - TRATADO DE LIBRE COMERCIO PERU - PANAMA & 01/05/2012-31/12/9999 & $0 \%$ & $100 \%$ & \\
\hline POLONIA & 812 - ACUERDO COMERCIAL PERU - UNION EUROPEA & 01/03/2013-31/12/9999 & $0 \%$ & $100 \%$ & \\
\hline PORTUGAL & 812 - ACUERDO COMERCIAL PERU - UNION EUROPEA & 01/03/2013-31/12/9999 & $0 \%$ & $100 \%$ & \\
\hline REINO UNID & 812 - ACUERDO COMERCIAL PERU - UNION EUROPEA & 01/03/2013-31/12/9999 & $0 \%$ & $100 \%$ & \\
\hline REPUBLICA & 812 - ACUERDO COMERCIAL PERU - UNION EUROPEA & 01/03/2013-31/12/9999 & $0 \%$ & $100 \%$ & \\
\hline RUMANIA & 812 - ACUERDO COMERCIAL PERU - UNION EUROPEA & 01/03/2013-31/12/9999 & $0 \%$ & $100 \%$ & \\
\hline SINGAPUR & $\begin{array}{l}804 \text { - ACUERDO DE LIBRE COMERCIO PERU - } \\
\text { SINGAPUR }\end{array}$ & 01/01/2012-31/12/9999 & $4 \%$ & $100 \%$ & \\
\hline SINGAPUR & $\begin{array}{l}804 \text { - ACUERDO DE LIBRE COMERCIO PERU - } \\
\text { SINGAPUR }\end{array}$ & 01/01/2012-31/12/9999 & $4 \%$ & $100 \%$ & \\
\hline SUECIA & 812 - ACUERDO COMERCIAL PERU - UNION EUROPEA & 01/03/2013-31/12/9999 & $0 \%$ & $100 \%$ & \\
\hline SUIZA & 807 - ACUERDO DE LIBRE COMERCIO PERU - AELC & $01 / 01 / 2012-31 / 12 / 9999$ & $0 \%$ & $100 \%$ & \\
\hline TAILANDIA & 808 - PROTOCOLO PERU - TAILANDIA & $31 / 12 / 2011-31 / 12 / 9999$ & $4 \%$ & $100 \%$ & \\
\hline URUGUAY & $\begin{array}{l}358 \text { - ALADI, ACE } 58 \text { PERU - ARGENTINA, BRASIL, } \\
\text { URUGUAY Y PARAG }\end{array}$ & 01/01/2011-31/12/9999 & --- & $100 \%$ & \\
\hline VENEZUELA & $\begin{array}{l}229 \text { - ACUERDO DE ALCANCE PARCIAL DE } \\
\text { NATURALEZA COMERCIAL PERU }\end{array}$ & 23/09/2013-31/12/9999 & --- & $100 \%$ & \\
\hline
\end{tabular}

Fuente: Superintendencia Nacional de Aduanas y Administración Tributaria 
ANEXO 2: Base de datos aduanas - partida arancelaria nro. 8409993000/búsqueda de importador de repuesto "tobera1050071120"

\begin{tabular}{|c|c|c|c|c|c|c|c|c|c|c|c|c|c|c|c|}
\hline & INYECTOR & 24118 & & AN & & 56 & & & & & & & & & 105007-1120 \\
\hline 109993000 & INYECTORES Y DEN & 20130129235 & EREA DEL CALJP & JAPAN & 1,000 & 700 & 6,000 & 2,000 & 209,000 & 6,967 & 1,000 & 2,000 & $0,000 \mathrm{U}$ & TOBERA,DENSO,093400-6760, TOBERA REPUESTO PARA SISTEMA DE INYECCIC & C105007-1120 \\
\hline 8409993000 & INYECTORES Y DEN & 20130226118 & MARITIMA DELJP & JAPAN & 1306,000 & 7,256 & 7,000 & 1,000 & 16,000 & 7,311 & 22,000 & 23,000 & $180,000 \mathrm{U}$ & TOBERA, DENSO, 093400-6760 TOBERA REPUESTOS PARA MOTORES DIESEL & $105007-1120$ \\
\hline 099993000 & INYECTORES Y DEN & 20130304235 & AEREA DEL CALJP & JAPAN &, 000 & 8,500 & 9,000 & 3,000 & 3,000 & 8,825 & 3,000 & 3,000 & $0,000 \mathrm{U}$ & TOBERA,ZEXEL,105007-1120, TOBERA REPUESTO PARA SISTEMA DE INYECCIOI & $105007-1120$ \\
\hline 109993000 & INYECTORES Y DEN & $20130307 / 118$ & IARITIMA DELJP & JAPAN & 000 & 2,000 & 2,000 & 6,000 & 8,000 & 12,160 & 5,000 & 5,000 & $50,000 \mathrm{U}$ & TOBERA,DENSO,S/M, CODIGO : 105007-1120 & 105007 \\
\hline 09993000 & INYECTORES Y DEI & 20130402118 & IARITIMA DELJP & JAPAN & 61,000 & 256 & 4,000 & 000 & 68,000 & 7,300 & 14,000 & 15,000 & $160,000 \mathrm{U}$ & TOBERA, DENSO, 093400-6760 TOBERA REPUESTOS PARA MC & $105007-1120$ \\
\hline 8409993000 & INYECTORES Y DEN & 20130417235 & EREA DEL CALJP & JAPAN & 8,000 & 700 & 10,000 & 2,000 & 31,000 & 25 & 3,000 & 3,000 & $40,000 \mathrm{U}$ & TOBERA,DENSO,093400-6760, TOBERA REPUESTO PARA SISTEMA DE INYECCIC & C105007-1120 \\
\hline 09993000 & INYECTORES Y DEN & 20130423 & MARITIMA DELJP & JAPAN & 1161,000 & 7,256 & 5,000 & 2,000 & 168,000 & 7,300 & 14,000 & 14,000 & $160,000 \mathrm{U}$ & TOBERA, DENSO, 093400-6760 TOBERA REPUESTOS PARA MOTORES DIESEL & $105007-1120$ \\
\hline 09993000 & INYECTORES Y DEN & 20130820235 & AEREA DEL CALCN & CHINA & 409,000 & 408 & 35,000 & 4,000 & 49,000 & 3,742 & 5,000 & 5,000 & $120,000 \mathrm{U}$ & TOBERA,S/M,DNOPDN112, TOBERA REPUESTO PARA SISTEMA DE INYECCION & $105007-1120$ \\
\hline 09993000 & INYECTORES Y DEN & 20130923235 & CALJP & JAPAN & 000 & 700 & 6,000 & 000 & 9,000 & 6,961 & 000 & 2,000 & $0,000 \mathrm{U}$ & NYECCIC & $\mathrm{c} 1050$ \\
\hline 09993000 & INYECTORES Y DEN & 20131005118 & MARITIMA DELJP & JAPAN & 0,000 & 9,167 & 0,000 & 1,000 & 2,000 & 333 & 1,000 & 1,000 & $12,000 \mathrm{U}$ & TOBERA,DENSO,S/M, CODIGO : 093400-6760 & $105007-1120$ \\
\hline 8409993000 & INYECTORES Y DEN & 20131118235 & AEREA DEL CALJJP & JAPAN & 378,000 & 6,300 & 8,000 & 3,000 & 391,000 & 6,517 & 3,000 & 3,000 & $60,000 \mathrm{U}$ & TOBERA,DENSO,093400-6760, TOBERA REPUESTO & $105007-1120$ \\
\hline 109993000 & INYECTORES Y DEN & 20131127118 & DELJP & JAPAN & 000 & 400 & 2,000 & 1,000 & 0,000 & 7,444 & 8,000 & 8,000 & $90,000 \mathrm{U}$ & , 093400-6760 TOBER & $105007-1120$ \\
\hline 09993000 & INYECTORES Y DEN & 20131210118 & AARITIMA DELJP & JAPAN & 6,000 & 7,400 & 2,000 & 1,000 & 0,000 & 7,44 & 5,000 & 6,000 & $0,000 \mathrm{U}$ & NSO, 093400-6760 TOBERA REPUEST & $105007-1120$ \\
\hline 09993000 & INYECTORES Y DEI & 20140120118 & DELJP & JAPAN & 840 & 7,409 & 270 & 160 & 1,270 & 7,459 & 920 &, 290 & $00 \mathrm{U}$ & TOBE & $105007-1120$ \\
\hline 09993000 & INYECTORES Y DEN & 20140116235 & CALJP & JAPAN & 00 & 6,110 & 8,550 & 2,680 & 630 & 6,991 & 3,400 & 3,460 & $40,000 \mathrm{U}$ & TOBERA,DENSO,093400-6760, TOBERA REPUESTO & 20 \\
\hline 099993000 & INYECTORES Y DEN & 20140602235 & STAJP & JAPAN & 180 & & 9,830 & 12,080 & 90 & 29 & 12,250 & 12,250 & $140,000 \mathrm{U}$ & TOB & -1120 \\
\hline 409993000 & INYECTORES Y DEI & 20140506 (118 & MARITIMA DELJP & JAPAN & 6,800 & 7,4 & 2,190 & 1,160 & 0,150 & 7,446 & 8,900 & 8,900 & $90,000 \mathrm{U}$ & , 093400-6760 TOBERA REPUEST & $105007-1120$ \\
\hline 109993000 & INYECTORES Y DEN & 20140416118 & DELJP & JAPAN & 85,050 & , 407 & 5,010 & 2,060 & 92,120 & 7,45 & 12,480 & 13,130 & $160,000 \mathrm{U}$ & NSO, 093400-6760 TOBERA REPUESTC & $105007-1120$ \\
\hline 09993000 & INYECTORES Y DEI & 20140331235 & STAJJP & JAPAN & 500 & 3,638 & ,850 & 460 & 8,810 & 8,995 & 730 & 730 & $00 \mathrm{U}$ & TOBER & N105007-1120 \\
\hline 09993000 & INYECTORES Y DEN & 20140306 & MARITIMA DELJP & JAPAN & 5,460 & 7,405 & 2,200 & 1,160 & 69,820 & 7,442 & 6,100 & 6,420 & $90,000 \cup$ & TOBERA & $105007-1120$ \\
\hline 09993000 & INYECTORES Y DEI & 20140219 & EELJP & JAPAN & & & 0,650 & & & & 350 & 5,350 & 0 & TOBE & E1050 \\
\hline 109993000 & INYECTORES Y DEN & 20140213235 & AEREA & JAPAN & 520 & 725 & 5,770 & 4,040 & 3,330 & 7,056 & 5,690 & 5,800 & $60,000 \mathrm{U}$ & TOBE & $105007-1120$ \\
\hline 099993000 & INYECTORES Y DEN & 20140602235 & AEREA Y POSTAJP & JAPAN & 88,180 & 8,630 & 9,830 & 2,080 & 50,090 & 8,92 & 12,250 & 12,250 & $140,000 \mathrm{U}$ & TOBER & N105007-1120 \\
\hline 09993000 & INYECTORES Y DEI & 20140506 ' 118 & DELJP & JAPAN & 800 & 7,409 & 2,190 & 1,160 & 150 & 7,446 & 8,900 & 8,900 & $90,000 \mathrm{U}$ & O, 093400-6760 TOBERA REPUESTOS PA & $105007-1120$ \\
\hline 109993000 & INYECTORES Y DEN & 20140416118 & DELJP & JAPAN & 1185,050 & 7,407 & 5,010 & 2,060 & 92,120 & 7,451 & 12,480 & 13,130 & $160,000 \mathrm{U}$ & TOBERA, DENSO, 093400-6760 TOBERA REPUESTOS PAF & $105007-1120$ \\
\hline 09993000 & INYECTORES Y DEN & 20140331235 & AERE & JAPAN & & 8,6 & 10,850 & 3,460 & & 8,995 & 730 & 30 & $0 u$ & TOBER & N105007-1120 \\
\hline 09993000 & INYECTORES Y DEN & 20140306 "118 & DELJP & JAPAN & 460 & 7,4 & 2,200 & 160 & 820 & 1,4 & 100 & 6,420 & & TOB & 1050 \\
\hline 409993000 & INYECTORES Y DEN & 20140219 & MARITIMA DELJP & JAPAN & 510 & & 50 & 0,310 & 2,470 & 8,624 & 50 & 5,350 & $00 \mathrm{U}$ & 60, REPUES & E105007-1120 \\
\hline 3409993000 & INYECTORES Y DEN & 20140213235 & AEREA Y POSTAJP & JAPAN & 3,520 & 6,725 & 5,770 & 040 & 3,330 & 056 & 5,690 & 5,800 & $60,000 \mathrm{U}$ & ENSO,093400-6760 TOBERA REPUESTO PARA SISTEMA DE INYECCIO & $105007-1120$ \\
\hline 8409993000 & INYECTORES Y DEN & 20140819118 & MARITIMA DELJP & JAPAN & 1451,990 & 7,260 & 6,820 & 2,530 & 1461,340 & 7,307 & 17,040 & 17,310 & $200,000 \mathrm{U}$ & TOBERA, DENSO, 093400-6760 TOBERA REPUESTOS PARA MOTORES DIESEL & $105007-1120$ \\
\hline 09993000 & INYECTORES Y DEN & 20140731235 & AEREA & JAPAN & 630 & 6,7 & 5,450 & 2,020 & 100 & 6,9 & 1,960 & 1,960 & $30,000 \mathrm{U}$ & IYECCIO & $105007-1120$ \\
\hline 9993000 & INYECTO & 20140923 & DELJ]P & JAPAN & & 7,1 & 23,640 & 13,730 & & 1,2 & 93,480 & 99,730 & $1100,000 \mathrm{U}$ & TOBE & $105007-1120$ \\
\hline 09993000 & INYECTORES Y DEN & 20140929235 & AERE & JAP, & & & & & & & & & & TOB: & \\
\hline 8409993000 & INYECTORES Y DEN & 20141023 & MARITIMA DELUS & UNITED STA & 171,670 & 8,584 & 0,630 & 0,260 & 2,560 & 28 & 4,360 & 4,590 & $20,000 \mathrm{U}$ & TOBERA,DENSO,093400-6760, REPUESTOS PARA BOMBA DE INYECCION DIESE & E105007-1120 \\
\hline 8409993000 & INYECTORES Y DEN & 20141215 "118 & MARITIMA DELJP & JAPAN & 2177,890 & 7,2 & 18,450 & 3,790 & 2200,130 & 7,33 & 22,620 & 23,560 & $300,000 \mathrm{U}$ & TOBERA, DENSO, 093400-6760 TOBERA REPUESTOS PARA MOTORES DIESEL & $105007-1120$ \\
\hline 409993000 & INYECTORES Y DEN & 20141229235 & AEREA Y POSTAJP & JAPAN & 504,460 & 0, & 12,420 & 5,050 & 930 & 6,5 & 5,490 & 5,490 & $80,000 \mathrm{U}$ & TOBERA,DENSO,093400-6760 TOBERA REPUESTO PARA SISTEMA DE INYECCIO & $105007-1120$ \\
\hline 9993000 & INYECTORES Y DEN & 20141229235 & AEREA Y POSTAJP & JAPAN & 189,430 & 6,3 & 7,88 & 1,890 & 9,200 & 6,644 & 3,0 & 3, & $0 \mathrm{U}$ & TOBE & 1120 \\
\hline 9993000 & INYECTORES Y DEN & 20141229235 & STAJJP & JAPAN & 90 & 6,315 & 5,250 & & 00 & 0,0 & 2,000 & 2,000 & $20,000 \mathrm{U}$ & TOB & \\
\hline
\end{tabular}


Base de Datos Aduanas - Partida arancelaria Nro. 8409993000 /Búsqueda de importador de repuesto "Tobera 1050071120"

\begin{tabular}{|c|c|c|c|c|c|c|c|c|c|c|c|c|c|}
\hline CODIGOAT & It & ESC & FECH_LLES & NUME & $|\mathrm{N}| \mathrm{T}$ & IV VIAT_DESC & $=$ & SEST_D P & TIPIV & LIBR_TRIBU & FIMPORTADOR & DCPAIS- & DPAIS_PROC \\
\hline $105007-1120$ & USLAX & CHERRYVILLE & 20130111 & 037185 & 56 & 1 MARITIMO & & 10 NUEVO & 4 & 20100084768 & PEVISA AUTO PARTS S.A. & US & UNITED STATES \\
\hline $105007-1120$ & USMIA & CHERRYVILLE & 20130128 & 014815 & 19 & 4 AEREA & & 10 NUEVO & 4 & 20544707541 & SISTEMA DE INYECCIËN DIESEL M \& F E.I.R. & US & UNITED STATES \\
\hline $105007-1120$ & USLAX & CHERRYVILLE & 20130222 & 086413 & 88 & 1 MARITIMO & & 10 NUEVO & 4 & 20100084768 & PEVISA AUTO PARTS S.A. & US & UNITED STATES \\
\hline $105007-1120$ & USMIA & CHERRYVILLE & 20130303 & 034264 & 1 & 4 AEREA & & 10 NUEVO & 4 & 20544707541 & SISTEMA DE INYECCIËN DIESEL M \& F E.I.R. & US & UNITED STATES \\
\hline $105007-1120$ & USPEF & CHERRYVILLE & 20130305 & 102642 & 54 & 1 MARITIMO & & 10 NUEVO & 4 & 20503415772 & INVERSIONES TUYA \& CACERES SOCIEDAD ANON & US & UNITED STATES \\
\hline $105007-1120$ & USLAX & CHERRYVILLE & 20130329 & 138700 & 103 & 1 MARITIMO & & \begin{tabular}{l|l|}
10 & NUEVO \\
\end{tabular} & 4 & 20100084768 & PEVISA AUTO PARTS S.A. & US & UNITED STATES \\
\hline $105007-1120$ & USMIA & CHERRYVILLE & 20130416 & 060047 & 14 & 4 AEREA & & 10 NUEVO & 4 & 20544707541 & SISTEMA DE INYECCIËN DIESEL M \& F E.I.R. & US & UNITED STATES \\
\hline $105007-1120$ & USLAX & CHERRYVILLE & 20130420 & 172969 & 99 & 1 MARITIMO & & 10 NUEVO & 4 & 20100084768 & PEVISA AUTO PARTS S.A. & US & UNITED STATES \\
\hline $105007-1120$ & USMIA & CHERRYVILLE & 20130817 & 128901 & 2 & 5 POSTAL & & \begin{tabular}{l|l|}
10 & NUEVO \\
\end{tabular} & 4 & 20544707541 & SISTEMA DE INYECCIËN DIESEL M \& F E.I.R. & US & UNITED STATES \\
\hline $105007-1120$ & USMIA & CHERRYVILLE & 20130920 & 147606 & 9 & 4 AEREA & & 10 NUEVO & 4 & 20544707541 & SISTEMA DE INYECCIËN DIESEL M \& F E.I.R. & US & UNITED STATES \\
\hline $105007-1120$ & USPEF & CHERRYVILLE & 20131003 & 445695 & 45 & 1 MARITIMO & & 10 NUEVO & 4 & 20503415772 & INVERSIONES TUYA \& CACERES SOCIEDAD ANON & US & UNITED STATES \\
\hline $105007-1120$ & USMIA & CHERRYVILLE & 20131117 & 178619 & 14 & 4 AEREA & & \begin{tabular}{l|l|}
10 & NUEVO \\
\end{tabular} & 4 & 20544694112 & SISTEMA DE INYECCION DIESEL D \& RJ E.I.R & US & UNITED STATES \\
\hline $105007-1120$ & USLAX & CHERRYVILLE & 20131123 & 530794 & 66 & 1 MARITIMO & & 10 NUEVO & 4 & 20100084768 & PEVISA AUTO PARTS S.A. & US & UNITED STATES \\
\hline $105007-1120$ & USLAX & CHERRYVILLE & 20131214 & 546411 & 79 & 1 MARITIMO & & 10 NUEVO & 4 & 20100084768 & PEVISA AUTO PARTS S.A. & US & UNITED STATES \\
\hline $105007-1120$ & USLAX & LOS ANGELES & 20140106 & 023245 & 83 & 1 MARITIMO & & 10 NUEVO & 4 & 20100084768 & PEVISA AUTO PARTS S.A. & US & UNITED STATES \\
\hline $105007-1120$ & USMIA & MIAMI & 20140115 & 006844 & 42 & 4 AEREA & & 10 NUEVO & 4 & 20544707541 & SISTEMA DE INYECCIËN DIESEL M \& F E.I.R. & US & UNITED STATES \\
\hline $105007-1120$ & USMIA & MIAMI & 20140601 & 083808 & 25 & 4 AEREA & & \begin{tabular}{l|l|}
10 & NUEVO \\
\end{tabular} & 4 & 20544707541 & SISTEMA DE INYECCIËN DIESEL M \& F E.I.R. & US & UNITED STATES \\
\hline $105007-1120$ & USLAX & LOS ANGELES & 20140415 & 175550 & 49 & 1 MARITIMO & & \begin{tabular}{l|l|}
10 & NUEVO \\
\end{tabular} & 4 & 20100084768 & PEVISA AUTO PARTS S.A. & US & UNITED STATES \\
\hline $105007-1120$ & USLAX & LOS ANGELES & 20140329 & 147666 & 99 & 1 MARITIMO & & 10 NUEVO & 4 & 20100084768 & PEVISA AUTO PARTS S.A. & US & UNITED STATES \\
\hline $105007-1120$ & USMIA & MIAMI & 20140330 & 047928 & 25 & 4 AEREA & & 10 NUEVO & 4 & 20544707541 & SISTEMA DE INYECCIËN DIESEL M \& F E.I.R. & US & UNITED STATES \\
\hline $105007-1120$ & USLAX & LOS ANGELES & 20140301 & 086165 & 105 & 1 MARITIMO & & \begin{tabular}{l|l|}
10 & NUEVO \\
\end{tabular} & 4 & 20100084768 & PEVISA AUTO PARTS S.A. & US & UNITED STATES \\
\hline $105007-1120$ & USPEF & PORT EVERGLADES & 520140213 & 065170 & 7 & 1 MARITIMO & & 10 NUEVO & 4 & 20136890329 & REPUESTOS JAPONESES S.A. & US & UNITED STATES \\
\hline $105007-1120$ & USMIA & MIAMI & 20140213 & 022533 & 13 & 4 AEREA & & \begin{tabular}{l|l|}
10 & NUEVO \\
\end{tabular} & 4 & 20544707541 & SISTEMA DE INYECCIËN DIESEL M \& F E.I.R. & US & UNITED STATES \\
\hline $105007-1120$ & USMIA & MIAMI & 20140601 & 083808 & 25 & 4 AEREA & & 10 NUEVO & 4 & 20544707541 & SISTEMA DE INYECCIËN DIESEL M \& F E.I.R. & US & UNITED STATES \\
\hline $105007-1120$ & USLAX & LOS ANGELES & 20140415 & 175550 & 49 & 1 MARITIMO & & 10 NUEVO & 4 & 20100084768 & PEVISA AUTO PARTS S.A. & US & UNITED STATES \\
\hline $105007-1120$ & USLAX & LOS ANGELES & 20140329 & 147666 & 99 & 1 MARITIMO & & 10 NUEVO & 4 & 20100084768 & PEVISA AUTO PARTS S.A. & US & UNITED STATES \\
\hline $105007-1120$ & USMIA & MIAMI & 20140330 & 047928 & 25 & 4 AEREA & & 10 NUEVO & 4 & 20544707541 & SISTEMA DE INYECCIËN DIESEL M \& F E.I.R. & US & UNITED STATES \\
\hline $105007-1120$ & USLAX & LOS ANGELES & 20140301 & 086165 & 105 & 1 MARITIMO & & 10 NUEVO & 4 & 20100084768 & PEVISA AUTO PARTS S.A. & US & UNITED STATES \\
\hline $105007-1120$ & USPEF & PORT EVERGLADES & 520140213 & 065170 & 7 & 1 MARITIMO & & \begin{tabular}{l|l|}
10 & NUEVO \\
\end{tabular} & 4 & 20136890329 & REPUESTOS JAPONESES S.A. & US & UNITED STATES \\
\hline $105007-1120$ & USMIA & MIAMI & 20140213 & 022533 & 13 & 4 AEREA & & 10 NUEVO & 4 & 20544707541 & SISTEMA DE INYECCIËN DIESEL M \& F E.I.R. & US & UNITED STATES \\
\hline $105007-1120$ & USLAX & LOS ANGELES & 20140815 & 322707 & 56 & 1 MARITIMO & & 10 NUEVO & 4 & 20100084768 & PEVISA AUTO PARTS S.A. & US & UNITED STATES \\
\hline $105007-1120$ & USMIA & MIAMI & 20140731 & 116806 & 13 & 4 AEREA & & 10 NUEVO & 4 & 20544707541 & SISTEMA DE INYECCIËN DIESEL M \& F E.I.R. & US & UNITED STATES \\
\hline $105007-1120$ & USLAX & LOS ANGELES & 20140919 & 374702 & 78 & 1 MARITIMO & & 10 NUEVO/B & 14 & 20100084768 & PEVISA AUTO PARTS S.A. & US & UNITED STATES \\
\hline $105007-1120$ & USMIA & MIAMI & 20140929 & 150354 & 16 & 4 AEREA & & 10 NUEVO/B & 44 & 20544707541 & SISTEMA DE INYECCIËN DIESEL M \& F E.I.R. & US & UNITED STATES \\
\hline $105007-1120$ & USMIA & MIAMI & 20141020 & 416086 & 11 & 1 MARITIMO & & 10 NUEVO/B & & 20136890329 & REPUESTOS JAPONESES S.A. & US & UNITED STATES \\
\hline $105007-1120$ & USLAX & LOS ANGELES & 20141206 & 493601 & 81 & 1 MARITIMO & & 10 NUEVO/B & $(4$ & 20100084768 & PEVISA AUTO PARTS S.A. & US & UNITED STATES \\
\hline $105007-1120$ & USMIA & MIAMI & 20141228 & 204044 & 22 & 4 AEREA & & 10 NUEVO/B & 4 & 20544707541 & SISTEMA DE INYECCIËN DIESEL M \& F E.I.R. & US & UNITED STATES \\
\hline $105007-1120$ & USMIA & MIAMI & 20141228 & 203951 & 9 & 4 AEREA & & 10 NUEVO/B & 44 & 20544694112 & SISTEMA DE INYECCION DIESEL D \& RJ E.I.R & US & UNITED STATES \\
\hline $105007-1120$ & USMIA & MIAMI & 20141228 & 203951 & 17 & 4 AEREA & & 10 NUEVO/B & 14 & 20544694112 & SISTEMA DE INYECCION DIESEL D \& RJ E.I.R & US & UNITED STATES \\
\hline
\end{tabular}

Fuente y elaboración: Superintendencia Nacional de Aduanas y de Administración tributaria - SUNAT 


\section{ANEXO 3: Costo para calcular el monto real del salario del trabajador}

\begin{tabular}{|c|c|}
\hline \multicolumn{2}{|c|}{ Costos por trabajador en planilla } \\
\hline Detalle de costo & Factor \\
\hline Remuneración & 1 \\
\hline Essalud & $1 * 0,09$ \\
\hline CTS & $(1 / 12)^{*} 2$ \\
\hline Gratificaciones & $(1 / 12)^{*} 2$ \\
\hline Vacaciones & $1 / 12$ \\
\hline Factor & $\mathbf{1 , 5 0 6 7}$ \\
\hline
\end{tabular}

\begin{tabular}{|c|c|c|c|c|}
\hline \multicolumn{5}{|c|}{ Salario de Colaboradores existentes en la planilla de Senatinos S.A. } \\
\hline Colaboradores & $\begin{array}{c}\text { Salario Bruto } \\
\text { (S/.) }\end{array}$ & $\begin{array}{c}\text { Costo total } \\
\text { (se incluye factor) } \\
\text { (S/.) }\end{array}$ & $\begin{array}{c}\text { Costo por día } \\
\text { (S/.) }\end{array}$ & $\begin{array}{c}\text { Costo por } \\
\text { hora } \\
\text { (S/.) }\end{array}$ \\
\hline Comprador 1 & $1.500,00$ & $2.260,00$ & 94,167 & 11,77 \\
Comprador 2 & $1.500,00$ & $2.260,00$ & 94,167 & 11,77 \\
Jefe de Compras & $2.500,00$ & $3.766,67$ & 156,944 & 19,62 \\
Jefe de logística & $2.500,00$ & $3.766,67$ & 156,944 & 19,62 \\
Jefe de ventas & $2.000,00$ & $3.013,33$ & 125,556 & 15,69 \\
Ejecutivo de ventas & $1.200,00$ & $1.808,00$ & 75,333 & 9,42 \\
\hline Total & $\mathbf{1 1 . 2 0 0 , 0 0}$ & $\mathbf{1 6 . 8 7 4 , 6 7}$ & $\mathbf{7 0 3 , 1 1}$ & $\mathbf{8 7 , 8 9}$ \\
\hline
\end{tabular}

\begin{tabular}{|c|c|c|c|c|}
\hline \multicolumn{5}{|c|}{ Salario de Colaboradores a contratar con implementación de proyecto } \\
\hline Colaboradores & $\begin{array}{c}\text { Salario Bruto } \\
\text { (S/.) }\end{array}$ & $\begin{array}{c}\text { Costo total } \\
\text { (se incluye factor) } \\
(\mathrm{S} / .)\end{array}$ & $\begin{array}{l}\text { Costo por } \\
\text { día } \\
\text { (S/.) }\end{array}$ & $\begin{array}{l}\text { Costo por } \\
\text { hora } \\
\text { (S/.) }\end{array}$ \\
\hline Vendedor de mostrador & $1.200,00$ & $1.808,00$ & 75,333 & 9,42 \\
\hline Vendedor de campo & $1.200,00$ & $1.808,00$ & 75,333 & 9,42 \\
\hline Total & $2.400,00$ & $3.616,00$ & 150,67 & 18,83 \\
\hline
\end{tabular}




\section{ANEXO 4: Costo para capacitaciones en sistema de inyección diesel}

Programa de Capacitación Profesional 2015

Diesel - Electricidad - Nuevas tecnologías

$\checkmark$ Actualización profesional

$\checkmark$ Perfeccionamiento

$\checkmark$ Seminarios

$\checkmark$ Especialización

$\checkmark$ El conocimiento es la principal herramienta para el desenvolvimiento profesional de una empresa, sobretodo en un rubro de constante evolución como el sector automotriz.

$\checkmark$ De nada sirve equipamiento y tecnologías avanzadas sino contamos con técnicos que posean una preparación adecuada.

$\checkmark$ Nuestra misión como Autorex y Bosch es facilitar el acceso al conocimiento disponibilizando informaciones relevantes a través de cursos y entrenamientos a la medida de cada negocio sobre diversos temas de innovación en el campo automotriz.

$\checkmark$ Tecnología es nuestro negocio, entrenamientos y capacitación es nuestra vocación

BOSCH

Programa de Capacitación 2015

autorex

Programa de Capacitación Profesional 2015

Diesel - Electricidad - Nuevas tecnologías

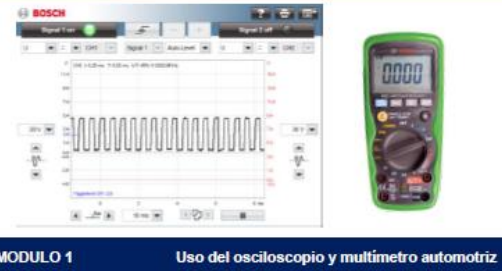

Duración: 16 horas

Fechas: Jueves 09 y viernes 10 de Abri

Objetivo: Los participantes serán capaces de conocer las magnitudes
fisicas relacionadas con las mediciones eléctricas y electrónicas y fisicas relacionadas con las mediciones eléctricasy electronicas

familiarizarse con el manejo del multimetro y osciloscopi.

Contenido:

*Definición de las magnitudes eléctricas básicas y su medición con

multimetro.

* Definición de señales. \$Práctica con multimetro y osciloscopio del KTS.

Inversión: SI. 400 incl. IGV

№ de participantes: Min. 6...Máx. 8. Se iniciará el curso con el número

mínimo de participantes

Fecha límite de inscripción: sábado 04 de abril

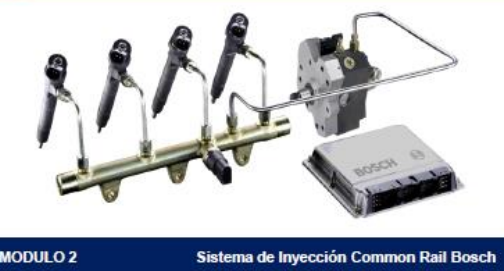

Duración: 8 horas

Fecha: Viernes 22 de Mayo

Horario: $8: 30$ - 17:30 hrs

Objetivo: Capacitar a los participantes en la comprensión y funcionamiento del sistema CRS y aplicar los fundamentos técnicos en la identificación de

los componentes del sistema.

Contenido: Rail: CRI. CRIN. Piezoeléctricos: Funcionamiento * Bombas de alta presión: tipos, funcionamiento * Gestión electrónica Diesel. ESI[tronic] 2.0 Equipo de comprobacion EPS 200 y software.

Inversión: SI. 200 incl. IGV

No de participantes: Mín. 6...Máx. 8. Se iniciará el curso con el número mínimo de participantes.

Fecha límite de inscripción: viernes 15 de mayo

BOSCH

nnovación para tu vida

Programa de Capacitación 2015 


\section{Costo para capacitaciones en sistema de inyección diesel}

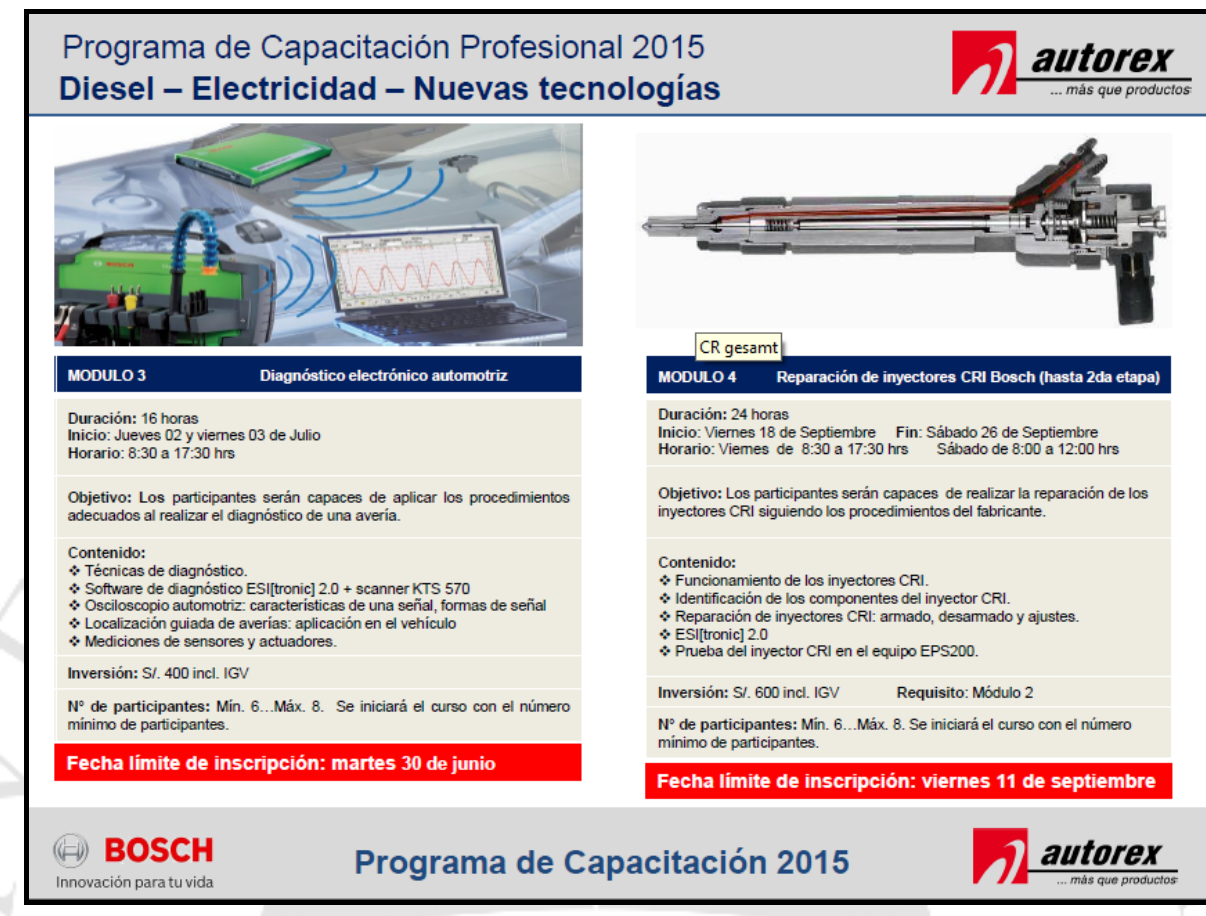

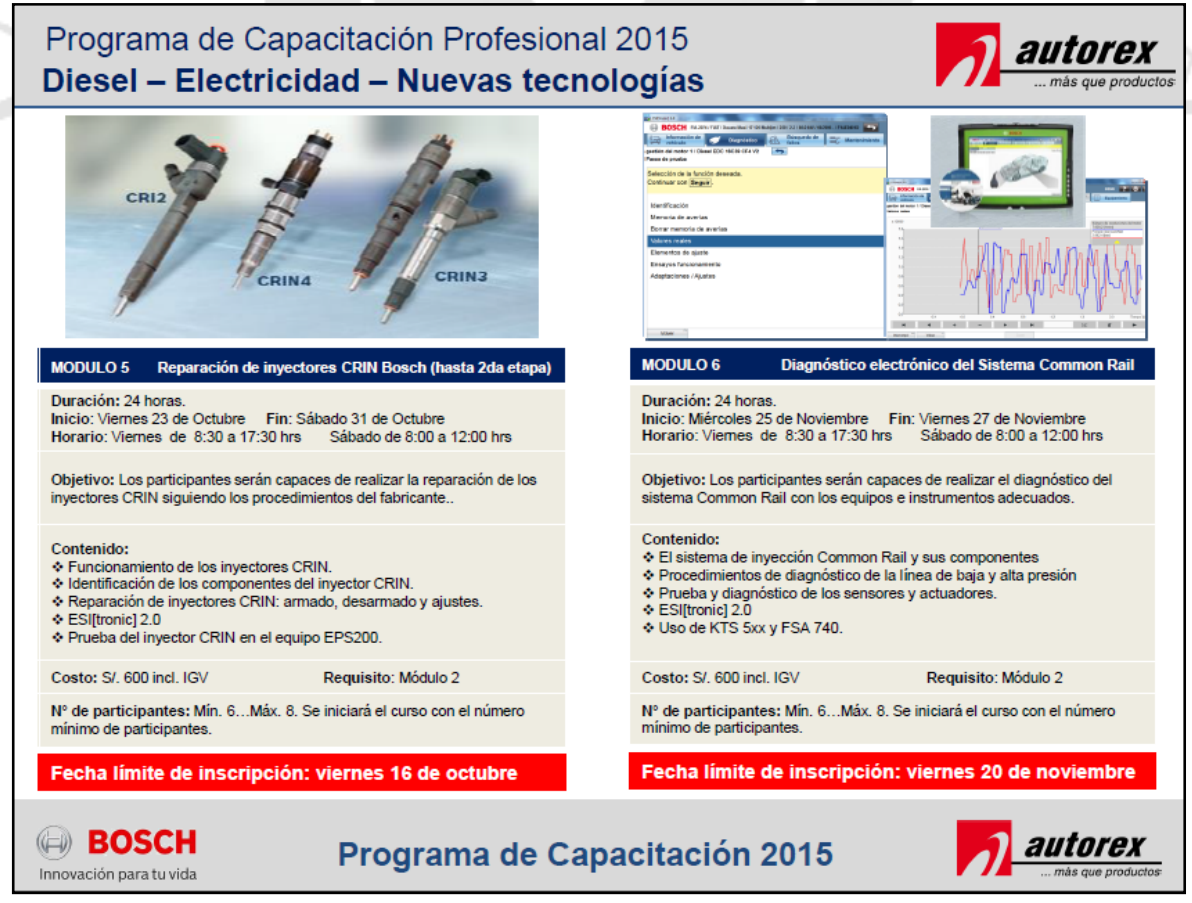

